Portland State University

PDXScholar

$1-1-1984$

\title{
Fringe area growth in Metropolitan Portland: an analysis of space-time variations in residential housing and land conversion, 1970-1980
}

Sheku Gibril Kamara

Portland State University

Follow this and additional works at: https://pdxscholar.library.pdx.edu/open_access_etds Let us know how access to this document benefits you.

\section{Recommended Citation}

Kamara, Sheku Gibril, "Fringe area growth in Metropolitan Portland: an analysis of space-time variations in residential housing and land conversion, 1970-1980" (1984). Dissertations and Theses. Paper 832.

https://doi.org/10.15760/etd.832

This Dissertation is brought to you for free and open access. It has been accepted for inclusion in Dissertations and Theses by an authorized administrator of PDXScholar. Please contact us if we can make this document more accessible: pdxscholar@pdx.edu. 


\title{
FRINGE AREA GROWTH IN METROPOLITAN PORTLAND: AN ANALYSIS OF SPACE-TIME VARIATIONS IN RESIDENTIAL HOUSING AND LAND CONVERSION, 1970-1980
}

by

SHEKU GIBRIL KAMARA

A dissertation submitted in partial fulfillment of the requirements for the degree of

\author{
DOCTOR OF PHILOSOPHY \\ in \\ URBAN STUDIES
}

Portland state University

(C) 1984 Sheku Gibril Kamara 
TO THE OFFICE OF GRADUATE STUDIES AND RESEARCH:

The members of the Committee approve the dissertation of Sheku Gibril Kamara presented December 8, 1983.

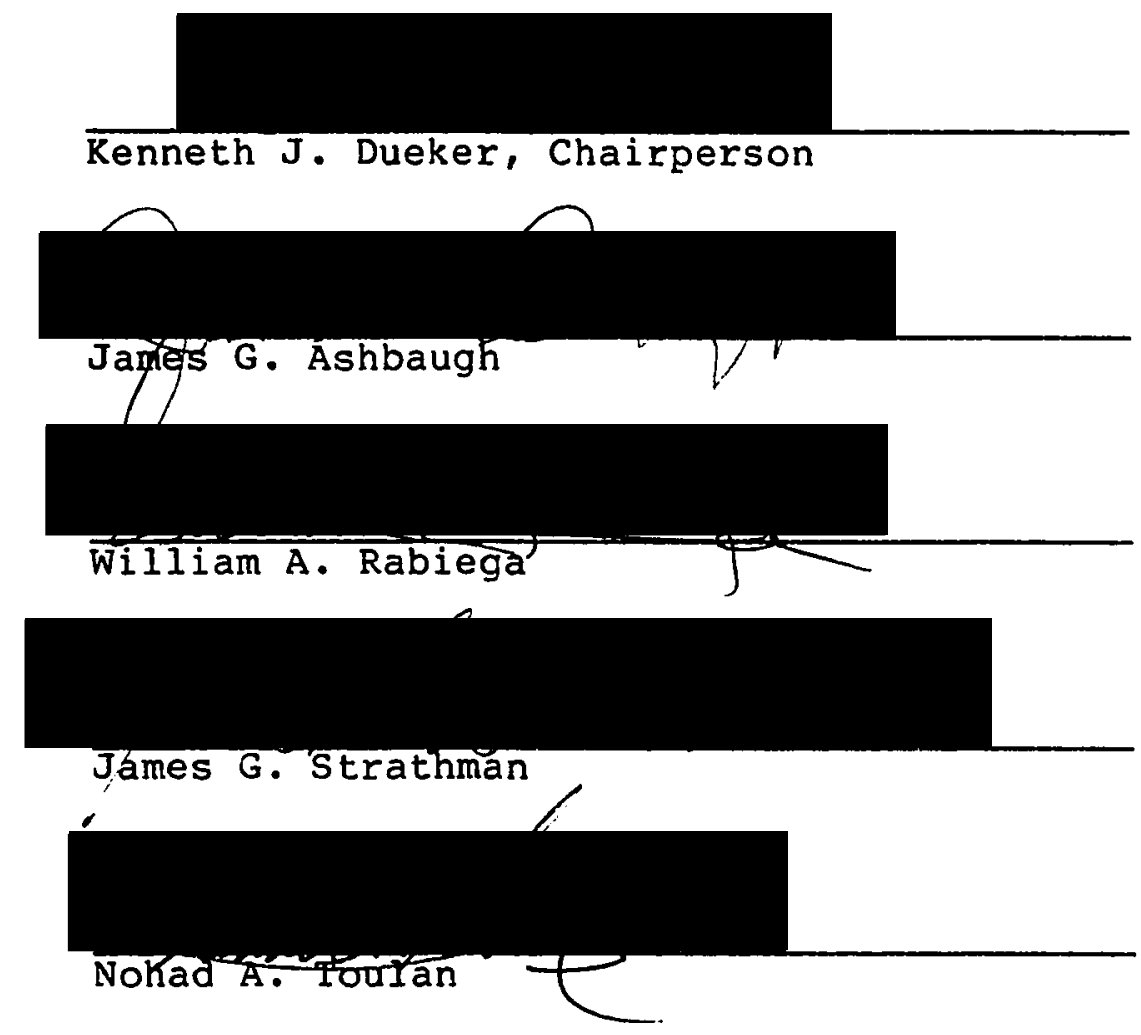

Approved:
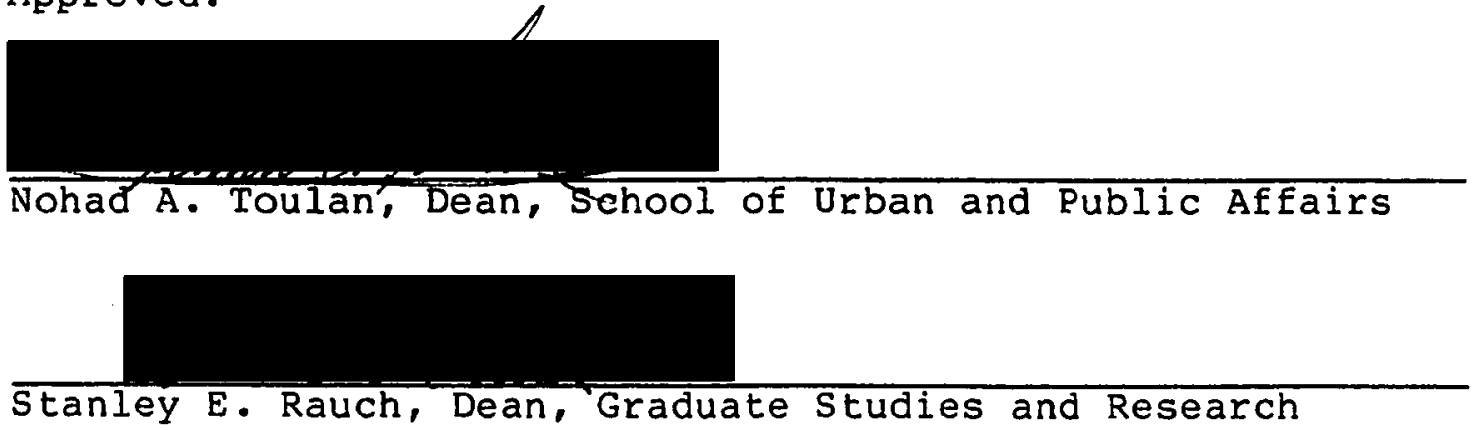
AN ABSTRACT OF THE DISSERTATION OF Sheku Gibril Kamara for the Doctor of Philosophy in Urban Studies presented December 8,1983

Title: Fringe Area Growth in Metropolitan Portland: An Analysis of Space-Time Variations in Residential Housing and Land Conversion, 1970-1980.

APPROVED BY MEMBERS OF THE DISSERTATION COMMITTEE:

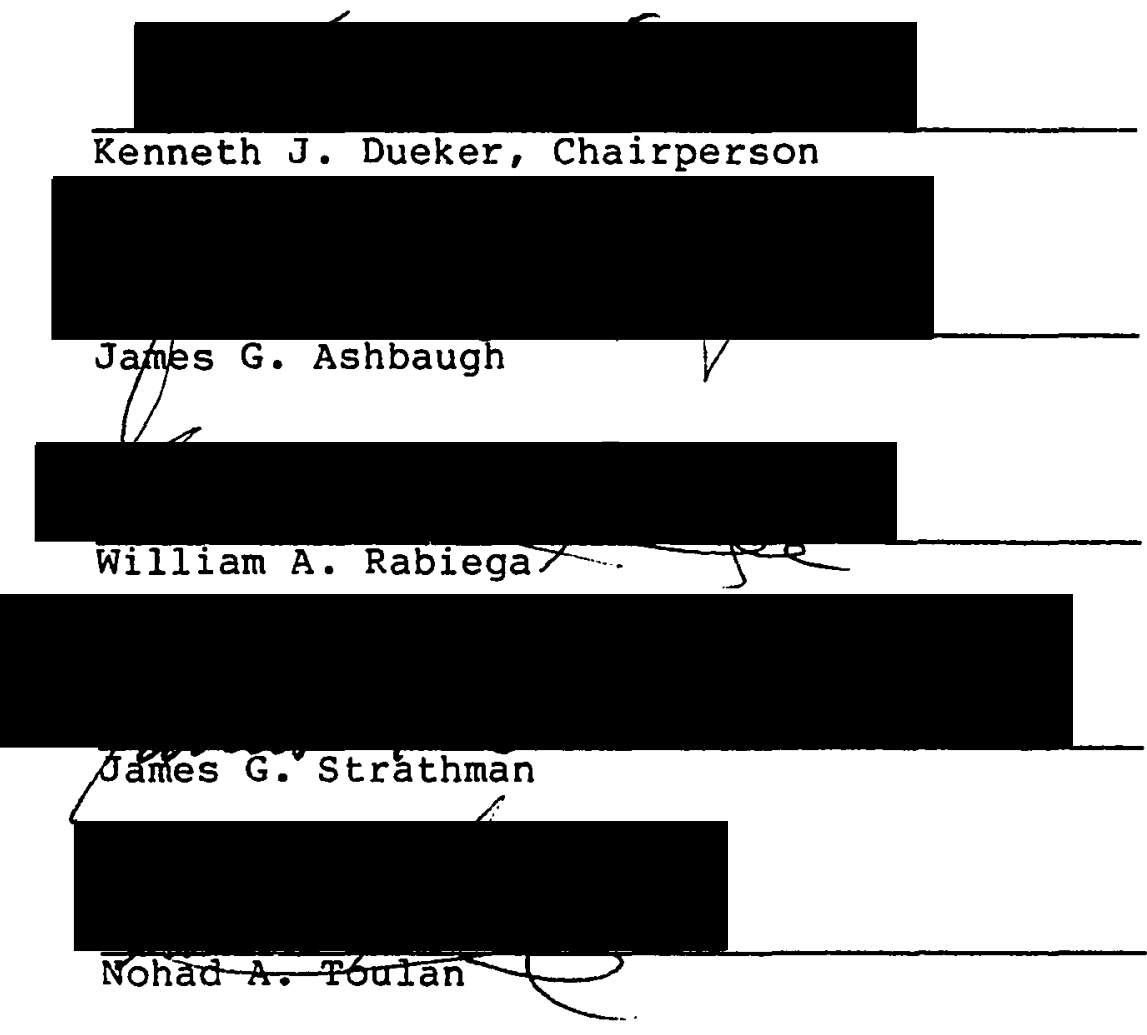

Urban ecological problems have hitherto been addressed using one of two major approaches. The Eirst has a social 
impetus directed at ethnic, economic and family characteristics and their relationships with the spatial distribution of urban residential housing. The second approach emphasizes the influence of the physical environment and the services available to subareas. The sociological method has had much more attention in modeling applications than the physical analytic technique.

This study adopts the physical approach with a focus that is emphatic on infrastructural factors and land attributes, and their influence on the differential rates of fringe area residential growth in the portland metropolitan region.

Data were acquired through direct research supplemented by building permit records, jurisdictional estimates, and information from the 1970 and 1980 U.S. Censuses. Growth functional relationships were operationalized using housing starts and residential land conversion as two dependent variables against which the explanatory factors of infrastructure (water and sewer), land characteristics, road network density, accessibility, and social factors were regressed in recursive models over three subperiods in the decade 1970-1980.

Five models were derived for the SMSA and the four counties for the decade, and three more subperiodic models for each area, for the categories of housing starts and land conversion. 
The derived models were tested against a standard econometric technique (Chow 'cest) to verify the consistency of the coefficients (elasticities) over the different subareas in the four time periods. The results showed extremely high levels of significance of the chow tests, deeming it necessary to examine the behavior of the elasticities in more detail over space and time. The results of the examination verified that the performance of infrastructure variables were highest in Washington county, while accessibility and road network density showed very high performances in Multnomah County. Land attributes were most notable in clark County, while income elasticities were equally high in Multnomah, Washington, and Clark Counties. The lag effects of residential development in the immediate anteceding period were more important in Multnomah and Washington than in other counties. In Clark county, residential development in the early part of the decade was the only significant lag variable in models of the latter part of the decade.

The conducted tests lend adequate support to the postulated hypotheses. In general, there was differential response to the selected attributes in the subareal models. Also, the results and tests confirmed that parameter estimates of attributes varied in different governmental jurisdictions. This implies that the counties placed different emphasis on the tested variables. Where the favorable set 
of variables was emphasized with one major sewer service district (Washington County), fringe area growth was enhanced. The emphasis of congestion-related variables (Multnomah County) without the desired infrastructure resulted in a relatively reasonable decline in fringe area residential housing. 


\section{ACKNOWLEDGEMENT}

Halfway through the masters program in Geography, my former advisor, Professor W. Rhynsburger, encouraged me to consider pursuing a doctorate degree in Urban Studies and Planning. On entering the program, scarcely was I convinced of having made the right decision, especially when I kept imagining the rigours of coursework and the length of time it usually took to complete the dissertation. I now realize what invaluable counsel he provided me, and for this I express my gratitude.

The members of my committee deserve equal gratitude for generously sharing their knowledge and expertise on the subject, and for their responses throughout the research and draft review process. Special thanks to Dr. Kenneth J. Dueker, Chairperson, for expertly coordinating the committee, and to Dr. Nohad A. Toulan, my personal counselor and mentor through the comprehensive examinations. My thanks also go to Dr. William A. Rabiega for making valuable suggestions, especially on the methodological literature coverage, and to Dr. James G. Ashbaugh for tutorial guidance on the local geography of the study area. Dr. James strathman conducted the Urban Studies Graduate Research Seminar during the past two years, and many useful suggestions and criticisms were generated during my quarterly presentations. My 
thanks to the participants of the class, and especially to Dr. Strathman for the additional sessions on quantitative methodology in his office.

I was awarded the Dan Davis Doctoral Fellowship through the School of Urban and Public Affairs during the last year of my research, and a half-time research assistantship with the Center for Urban Studies, both of which provided some pecuniary support effecting a timely completion of the writing. My thanks to the fellowship donor and to the Center for these awards.

My wife, Hawa, endured my long and frequent absences from home when I was doing research, computerizing the data, and writing the text. She also relieved me of many responsibilities which would otherwise have delayed the completion of this dissertation. My thanks to her for her support and understanding.

Finally, my thanks go to Susan Doyle for typing part of the draft and to Darlene Maddox for her skilled word processing. 
In loving memory of my late father... and dedicated to my mother, for her patience and fortitude. 


\section{TABLE OF CONTENTS}

PAGE

ACKNOWLEDGEMENT . . . . . . . . . . . . . . . .

LIST OF TABLES • . . . . . . . . . . . . . . . . $\mathrm{x}$

LIST OF FIGURES • • • • • • • • • • • • • • • • • • • $\mathrm{xV}$

CHAPTER

I INTRODUCTION

SCOPE OF THE RESEARCH PROBLEM • . . . . . . 5

STUDY AREA • . . . . . . . . . . . . 9

THE SUBURBAN AREA • • . . . . . . . . . . 14

II URBAN ECOLOGICAL CONCEPTS . . . . . . . . 18

MAJOR LAND-USE THEORIES • • • . . • . . . 19

SUBURBANIZATION AND URBAN SOCIO-SPATIAL

DIFFERENTIATION . . . • . . . . . • . . . . 24

PHYSICAL FACTORS AND CONCEPTS • . • . . . 35

ECONOMIC CONCEPTS . . . . . . . . . . . 43

PLANNING AND GROWTH FORECASTING MODELS • • . 49

COMMENTARY ON METHODOLOGICAL TECHNIQUES

AND PARAMETER ESTIMATES . . . . . . . . . 55

III METHODOLOGY . . . . . . . . . . . . 57

STUDY DESIGN • • • • • • • • • • • • . 59

HYPOTHESES . . . . . . . . . . . . 60

OPERATIONALIZATION OF THE PROBLEM . . . . . 63

MEASUREMENT OF VARIABLES . . . . . . . . 64 
vii

PAGE

Dependent Variables . . . . . . . . 64

Independent Variables . . . . . . 65

Infrastructure . . . . . . 65

Network Density and
Local Circulation . . . . . . 66

Accessibility . . . . . . . 66

Land Characteristics . . . . . 66

Socio-Economic Conditions . . . 69

ANALYTIC TECHNIQUES • . . . . . . . . . 71

IV A RETROSPECTIVE ANALYSIS OF THE GROWTH

OF PORTLAND AND THE SMSA . . . . . . . . 73

COMPARATIVE GROWTH ANALYSIS . . . . . . . 74

RESIDUAL RESIDENTIAL LAND • . . . . . . . 77

CHANGES IN SERVICES •. . . . . . . . . . 80

NETWORK IMPROVEMENTS AND CONGESTION . . . . 85

CHANGES IN SOCIO-ECONOMIC CONDITIONS . . • . 87

RESIDENTIAL LAND CONVERSION IN SUBURBS . • . 93

V DATA ANALYSIS AND RESULTS • • . • • . . • . 95

GENERAL FORMAT OF EQUATIONS OF THE MODELS • • 96

SCREENING OF THE VARIABLES • • . • • • • . 98

MODEL SPECIEICATION . . . . . . . . . 102

THE REGIONAL MODELS . . . . . . . . . . 104

The Residential Growth Model . . . 108

The Residential Land Conversion

Model .............. . 110

Submodels for Housing Starts and Land

Conversion for the subperiod

$1971-1973$. . . . . . . . . . 111 
viii

PAGE

Recursive Submodels for Housing

Starts and Land Conversion for the

Subperiod 1974-1976 . . . . . . .

112

Recursive Submodels for Housing

Starts and Land Conversion for the

Subperiod 1977-1979 . . . . . . .

MULTNOMAH COUNTY SUBMOdELS • • • • • • . 117

WASHINGTON COUNTY SUBMODELS . . . . . . . . 124

Clackamas COUNTy SUbModels . . . . . . . 131

CLARK COUNTY SUBMODELS . . . . . . . . . 136

RELATIVE STRENGTHS OF THE MODELS . • . • . 141

SPATIAL AND TEMPORAL DIFFERENCES IN SUBURBAN

RESIDENTIAL HOUSING AND LAND-CONVERSION

TRENDS

143

The Chow Test... . . . . . . 143

BEHAVIOR OF ELASTICITIES OVER SPACE AND

TIME . . . . . . . . . . . . . . 147

Land Attributes . . . . . . . . 147

Infrastructure Conditions . . . . . 149

Socio-Economic Conditions . . . . . 151

Accessibility . . . . . . . . . 153

Network Density . . . . . . . . . 154

Lag Effect of Previous Development . . 155

Summary of Spatial and Temporal Differences in the Performance of Models . . 158

VI

CONCLUSION . . . . . . . . . . . . . . 160

SUMMARY . . . . . . . . . . . . 160

CONCLUSION •. . . . . . . . . . . . 162

DISCUSSION . . . . . . . . . . . . 164 
LIMITATIONS OF THE RESEARCH . . . . . . . 168

UTILITY AND IMPLICATIONS OF THE RESEARCH • • 169

SUGGESTIONS FOR FUTURE RESEARCH . • . • . • 170

REFERENCES ..................... 174

APPENDIX . . . . . . . . . . . . . . . 188 


\section{LIST OF TABLES}

TABLE

PAGE

I Shifts in U.S. Population, 1970-1980 . . . . 2

II Population Shifts in the Portland SMSA, $1970-1980$. . . . . . . . . . 6

II Ratings of Selected soil Classifications

for Suitability for Residential

Development . . . . . . . . 68

IV Growth Trend of the City of Portland . . . . 76

V Growth of the Portland-Vancouver Metro-

politan Area Since 1960 . . . . . . 77

VI Population and Land Area of Study Area

and SMSA by County . . . . . . . 78

VII Land Converted to Residential Use and Number

of Units Constructed Between 1970 and 1980 . 81

VII Changes in Water and Sewer Coverages Between

1970 and 1980 . . . . . . . . 82

IX Estimated Land Values in Suburbs in 1970 . . 84

$X$ Suburban Road Network Density and Relative

Degrees of Congestion . . . . . . 85

XI Proportion of Households and Families Resi-

ding in Study Area in 1970 and 1980 . . 88

XII Median Income of Families and Households in Dollars by County . . . . . . . . 89 
XIII A Comparison Between Study Area and County Area Mean Family and Household Incomes. in 1970 and 1980 ......... 90

XIV Percentage Distribution of Families in Study and County Areas by Income Level in 1970 and 1980 .......... 92

$\mathrm{XV}$ Variables Used in Regression Analysis and their Basic Parameters . . . . . 105

XVI Regression Equations for Housing Starts and Land Conversion in All Suburbs for the Period 1970-1980 ......... 107

XVII Regression Equations for Housing Starts and Land Conversion in All Suburbs for the Period 1971-1973 .........113

XVIII Recursive Models of Housing Starts and Land Conversion in All Suburbs for the Time Period 1974-1976 ........ 114

XIX Recursive Models of Housing Starts and Land Conversion in All Suburbs for the Time Period 1977-1979 . . . . . . 116 Xx Multnomah County Submodels of Suburban Residential Development and Land Conversion for the Decade 1970-1980 . . . . . 118 
XXI Multnomah County Submodels of Suburban Residential Growth and Land Conversion for the Subperiod 1971-1973 . . . . . 120

XXII Recursive Submodels for Multnomah County

Suburbs for the Subperiod 1974-1976 • . 121

XXIII Recursive Submodels for Multnomah County

Suburbs for the Subperiod 1977-1979 • 123

XXIV Washington County Submodels of Suburban Residential Development and Land Conversion for the Decade 1970-1980 . . . . . 125

XXV Washington County Submodels of Suburban Residential Growth and Land Conversion for the subperiod 1971-1973 . . . . . . 127

XXVI Recursive Submodels for Washington County

Suburbs for the Subperiod 1974-1976 • 128

XXVII Recursive Submodels for Washington County

Suburbs for the subperiod 1977-1979 • . 130

XXVIII Clackamas County Submodel for Residential

Land Conversion During the Decade

$1970-1980$. . . . . . . . . . 132

XXIX Clackamas County Submodels of Residential

Growth and Land Conversion for the Subperiod 1971-1973 . . . . . . . 134 
xiii

PAGE

XXX Recursive Submodels for Clackanas County Suburbs for the Subperiod 1974-1976 . . 135

XXXI Recursive Submodels for Clackamas County Suburbs for the subperiod 1977-1979 • 136

XXXII Clark County Submodels of Residential

Growth and Land Conversion for the Decade 1970-1980 . . . . . . . . 137

XYXIII Clark County Submodels of Residential Development and Land Conversion for the Subperiod 1971-1973 . . . . . . 139

XXXIV Recursive Submodels for Clark County Suburbs for the subperiod 1974-1976 . . . 140

XXXV Recursive Submodels for Clark County Suburbs for the Subperiod 1977-1979 . . . 141

XXXVI Results of Chow Tests for Spatial and Temporal Differences in Stability of Coefficients . ......... 146

XXXVII Behavior of Elasticities of Variables Measuring Land Attributes . . . . 148

XXXVIII Behavior of Elasticities of Infrastructure variables ........... . 150

XXXIX Behavior of Elasticities of Social Factors . 152

XL Behavior of Coefficients of Accessibility Variables .............. . 153 
xiv

PAGE

XLI Behavior of the Coefficients of Variables

Measuring Network Density . . . . 156

XLII Behavior of Elasticities of Variables Mea-

suring Effects of Previous Residential

Development in Recursive Models . . . 157 


\section{LIST OF FIGURES}

1. The Portland-Vancouver Standard Metropolitan

Statistical Area Showing Incorporated

Cities and County Boundaries . . . . . .

2. The Portland-Vancouver Standard Metropolitan

Statistical Area Showing the Study Area . • 17

3. Areas Covered by Water and sewer Services in 1979 . . . . . . . . . . . 


\section{CHAPTER I}

\section{INTRODUCTION}

In June 1969, the U.S. Congress recognized the concern for urban growth and appointed an ad hoc committee to look into the "...problems of the tremendous growth... in the next 30 years, and where the growth will take place; whether in the core city, the suburban ring, or the rural areas" (U.S. Government, 1969). This concern grew as a result of the new trend in metropolitan population dynamics during the period since 1960. The decade of the $1960^{\prime}$ 's had the lowest metropolitan growth, yet it had the highest rate of suburbanization since 1930 (Schnore and Klaff, 1972). ${ }^{1}$ Recent analyses indicate that since 1960, more people have been moving to the suburbs of metropolitan areas than hitherto. The census figures of 1970 confirmed that trend, showing that for the first time the suburbs had more people in 1970 than either the central cities or rural areas. According to Muller (1976), suburban residents numbered 75.6 million as against 68.3 million living in central cities, whereas 63.8 million people resided in rural areas (Table I).

${ }^{1}$ Bogue (1953) and Hawley (1956) jointly agree that prior to 1920, there was centralization of urban population and activities to the city center, and since 1920 there has been gradual decentralization. 
TABLE I

SHIFTS IN U.S. POPULATION, $1970-1980$

\begin{tabular}{|c|c|c|c|c|c|c|}
\hline \multirow{2}{*}{$\begin{array}{c}\text { Ecological } \\
\text { Area }\end{array}$} & \multicolumn{2}{|l|}{1970} & \multicolumn{2}{|l|}{1980} & \multicolumn{2}{|c|}{$\begin{array}{l}\text { Increase } \\
\text { Over } 1970\end{array}$} \\
\hline & $\begin{array}{l}\text { Pop. In } \\
\text { Militions }\end{array}$ & $s$ & $\begin{array}{l}\text { Pop. In } \\
\text { Militions }\end{array}$ & s & $\begin{array}{l}\text { Pop. In } \\
\text { Militions }\end{array}$ & $s$ \\
\hline Central Cities & 63.8 & 31.4 & 67.9 & 30.0 & 4.1 & 6.4 \\
\hline $\begin{array}{l}\text { Outside Cen- } \\
\text { tral Cities }\end{array}$ & 75.6 & 37.2 & 101.5 & 44.8 & 25.9 & 34.3 \\
\hline Outside SMSA's & 63.8 & 31.4 & 57.1 & 25.2 & $-7.6-$ & -10.5 \\
\hline Total & 203.21 & 100.0 & 226.51 & 100.0 & 23.3 & 11.5 \\
\hline
\end{tabular}

Source of data: Bureau of Census, U.S. Census of Population, 1980: Number of Inhabitants. (Supplementary Reports, PC80-51-5.)

As an area of domicile, the suburbs in 1970 also had for the first time a higher residential holding (dwelling units) than either the central cities or nonmetropolitan areas; the respective figures being 24 million, 22.6 million, and 22.4 million dwelling units. In addition, nearly half the total metropolitan area jobs and 60 percent of the retail sales occured in the suburban ring (Sly and Tayman, 1980), resulting in the clustering of especially middle income groups and a mismatch of skills and jobs, as weil as disparities in the delivery of educational and other services (Neiman, 1980). 
Since 1970, the suburbanization process appears to have continued at a comparable rate with that of the 1960's. Although estimates of the late 1970's were skeptical (Chalmers and Greenwood, 1980), the census results showed that approximately 101.5 million of the 169.4 million SMSA residents lived outside of central cities (Table I). This represents 35.3 percent increase in SMSA fringe area population over that of 1970 , as compared to 37.7 percent increase in the preceding decade. In absolute terms, however, these represent increases of 25.9 million (1970-1980) and 20.7 million (1960-1970).

With respect to the suburban space, inner suburbs have lost population since 1970 (Long and DeAre, 1983), but the outer suburbs have grown at an even faster rate that more than compensates for the inner suburban loss, resulting in larger and less dense urban areas. However, in some metropolitan areas, population dynamics at the fringe area continue to raise interesting questions about the urban land market theory. For example, it has been shown (Dueker, et al., 1983) that fringe area households show an increasing tendancy for praference of rural residential location to the suburb or the city center. Aside from the fact that ruralization (increase of rural portion of SMSA population) occured in 18 states since 1970, the suburbs of metropolitan areas have continued to account for the growth of especially the "supercities" (Long and DeAre, 1983). 
The possible causes of the increasing rate of suburbanization have been ascribed to numerous reasons. Some of the major ones are larger space for housing which suburbs provide closer to new shopping attractions and amenities, the flexible use of the private automobile, decentralization of employment, mass transit commuter ridership, and easy access to freeways and arterials. The large land subdivisions allow for reasonably spaced single-family residences enhancing the privacy of the family (Dolce, 1976). At the same time, expansion of the suburbs poses additional problems to municipal governments in providing basic infrastructure (water, sewer, etc.), regardless of the fact that they also contribute to a larger tax base (Berry and Kasarda, 1977 ).

In large Standard Metropolitan Statistical Areas (SMSA's), a number of outlying satellite cities may compete with one another as well as with some unincorporated areas to attract residential as well as nonresidential developments that are moving away from the inner city. Some of the attractions, such as basic infrastructure and their reliability and efficiency levels, may vary among different jurisdictions, especially where special service districts may be empowered to provide them locally in some areas and public agencies in others. Within the Portland SMSA for example, there are a number of water, sewer, fire, and other types of service districts. Some of these are large (e.g., 
Unified Sewerage Agency - USA), while others (such as Mossy Brae, Alto Park, Barwell Park, Raleigh, and Darlington Water Districts) hardly approach the size of a typical suburban census tract. In many of these districts, fragmentation of services is perceived to result in low levels of efficiency as well as higher costs to the consumer. Thus, a larger, more efficient, and stable service district may have a tremendous influence on the attraction of high density development with a significantly high tax base which would otherwise locate in other areas within the same metropolis.

\section{SCOPE OF THE RESEARCH PROBLEM}

The intent of this rsearch is to study the process of suburbanization as it has occured in the last decade in the Portland Metropolitan Area covering Multnomah, Clackamas, and Washington counties in the state of Oregon, and clark County in the state of Washington. To achieve this purpose, the research examines the effects of salient physical, structural, and social factors on residential development and land conversion in the fringe area within the decade 1970-1980. Through detailed statistical and computer analyses, models are estimated to explain residential development in the Portland metropolitan fringe for the decade as a whole, as well as for shorter, periodic durations of time.

The suburbs of the Portland SMSA appear to have 
experienced accelerated growth between 1970 and 1980 with a growth rate that is approximately 9 percent more than the national average (Table II). This growth seems to have been unevenly shared by the four component counties. Certain parts of the region have grown at faster rates, while others at slower or even declining rates. Many new commercial centers and industrial parks sprang up in the suburbs during the decade in selective county areas, indicative of a response to disparities in the conditions within the component counties, resulting in the possible loss of potential development by some counties to others that previously had slower

TABLE II

POPULATION SHIFTS IN THE

PORTLAND SMSA,

$1970-1980$

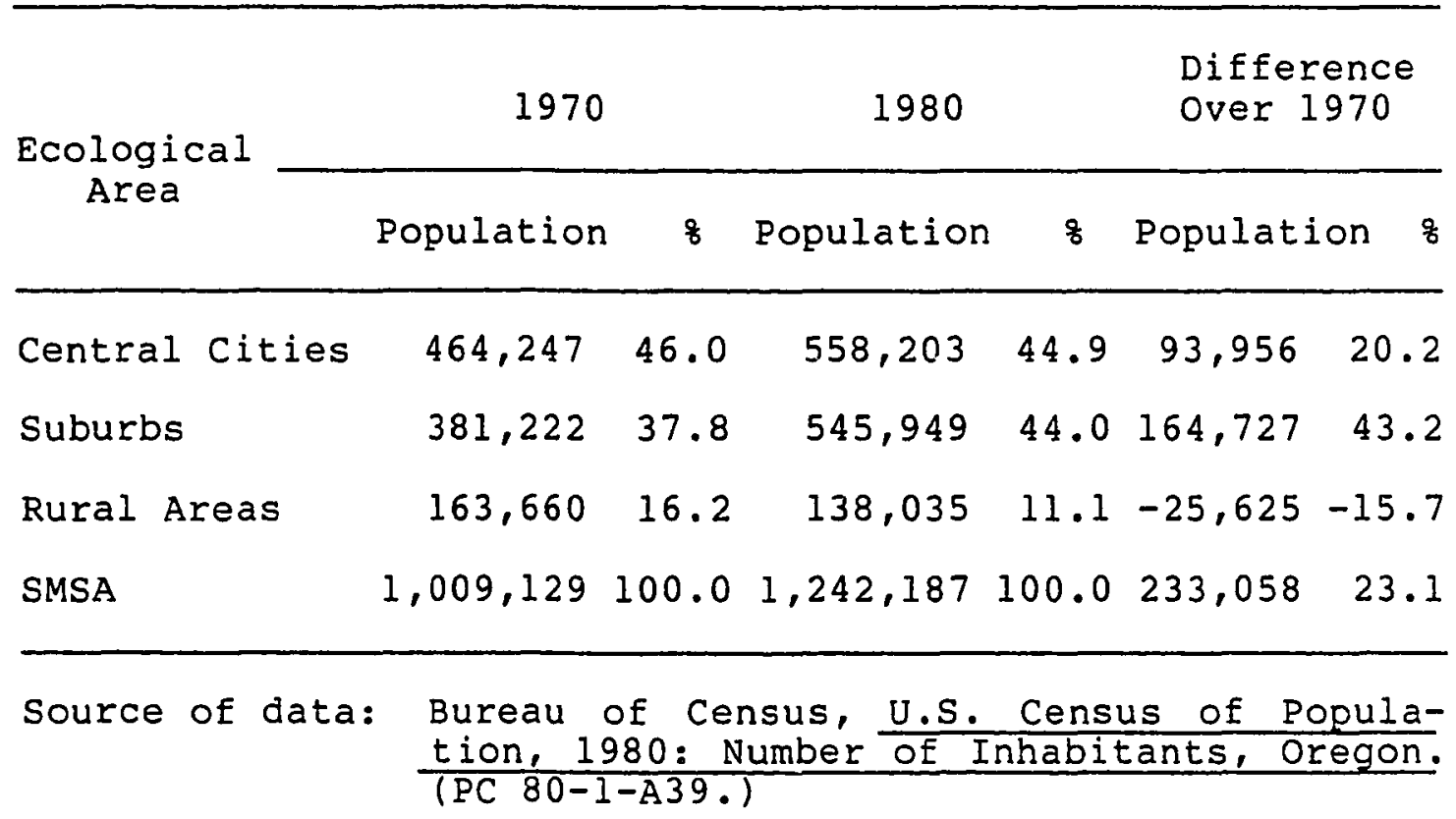


paces of growth. In this regard, the research will look at infrastructure available to each subarea, relative accessibility of the different areas, differences in the land characteristics and soil conditions, densities of the local network, and major socio-economic differences such as changes in income and cost per unit area of land. From these major factors, variables will be operationalized and used in a series of regression analyses to identify the major contributors to the differential nature of residential growth in the counties. In specific terms, the study will determine:

1. The major variables that significantly account for suburbanization and fringe area land conversion in the SMSA, and their relative importance in terms of absolute and relative elasticities for the decade under study;

2. The variables accounting for the different rates of land conversion in 3-year subperiods of the decade; and

3. The differences among constituent counties in the suburbanization of residential activity in the decade as a whole and in different subperiods (i.e., spatial by time variation).

As demonstrated later in the theoretical review section, most of the planning and land-use forecasting models designate infrastructure as having a major thrust on residential development. Chapin and Kaiser (1979) advise that variables selected for inclusion in a land-use study 
should comprise "relevant reality" based on (1) spatial characteristics (physical, locational, institutional, etc.), and (2) characteristics of the land-use activity in question. Physical characteristics refer to land and soil conditions, while institutional attributes refer to mechanisms for the provision of public facilities and infrastructure. These variables have been labeled as growth constraints which heavily influence the direction of growth of metropolitan residential housing (Burrows, 1978). Although the importance of these constraints in the Portland situation emerged in the late 1960's, Burrows argues that the programming of these services should be congruent with planning techniques designed to accommodate growth in any metropolitan area, if problems due to mismatch of projections with actual growth rates should be averted. As a result, the growth constraining variables will form a central focus of the research. The technique of measurement will be designed to be sensitive enough to reflect small variations in the levels of these services. In the case of water and sewer services, a single measure will be created in which the absence of sewer service alone will be reflected by a low score in the measurement index.

The final major concern of this study is that the bulk of the literature on planning methodology assumes constant parameters for variables across the SMSA. Although in some cases separate attributes have been assigned to traffic 
zones, it may be argued that these are usually comprised of groups of census tracts which are in turn subdivisions of governmental jurisdictions. Further, distance forms a major criterion in the assignment of attributes to traffic zones. As a result, differences in subareal attributes of jurisdictions are neglected. This issue will be addressed in order to determine whether, in similar planning studies encompassing a number of jurisdictions, variables should be evaluated in terms of as many parameters as there are jurisdictions in the study area, with different policies regarding land development.

In this study counties are used to test whether variables and parameters vary across governmental jurisdictions.

\section{STUDY AREA}

The fourteenth goal of the state land-use monitoring agency, the Oregon Land Conservation and Development Commission ( $L C D C$ ), addresses urbanization issues with the intent of providing "...an orderly and efficient transition (conversion) from rural to urban land use" (LCDC, 1974), based on the "...demonstrated need to accommodate long-range urban growth requirements consistent with LCDC goals...." The growth requirements include planning for the accommodation of the housing needs of the urban center, systematic provision of economically affordable services and public 
facilities, and adequate land supply to meet projected needs. for different uses. Infill should be encouraged in areas of low density development before new land is converted, and fringe area land should be judiciously parcelled to ensure maximum utility. As a result, every city and jurisdiction was required to demarcate and administer an "Urban Growth Boundary" (UGB) which will accommodate projected growth of urban centers to year-2000 without undue expansion into rural areas.

For the Portland Metropolitan Area, the Metropolitan Service District (METRO) was primarily responsible for coordination of the demarcation of the UBG, and for researching the ancillary population and housing forecasting data in support of the proposed boundary limits. The process was finally concluded when the METRo council approved the boundary in November 1979, and the LCDC in January 1980 .

Within the four counties, there are a number of incorporated cities (Figure 1). Among them the cities of Portland, Beaverton, Vancouver, Gresham and oregon City currently form the urban nucleus with a number of suburban cities and communities in the immediate vicinity. Within the three oregon counties, LCDC ruled that the cities of Canby, Estacada, Molalla, Gaston, Banks, North Plains, and the Mt. Hood Corridor were no longer under the jurisdiction of METRO (METRO, 1979). On the washington side of the 


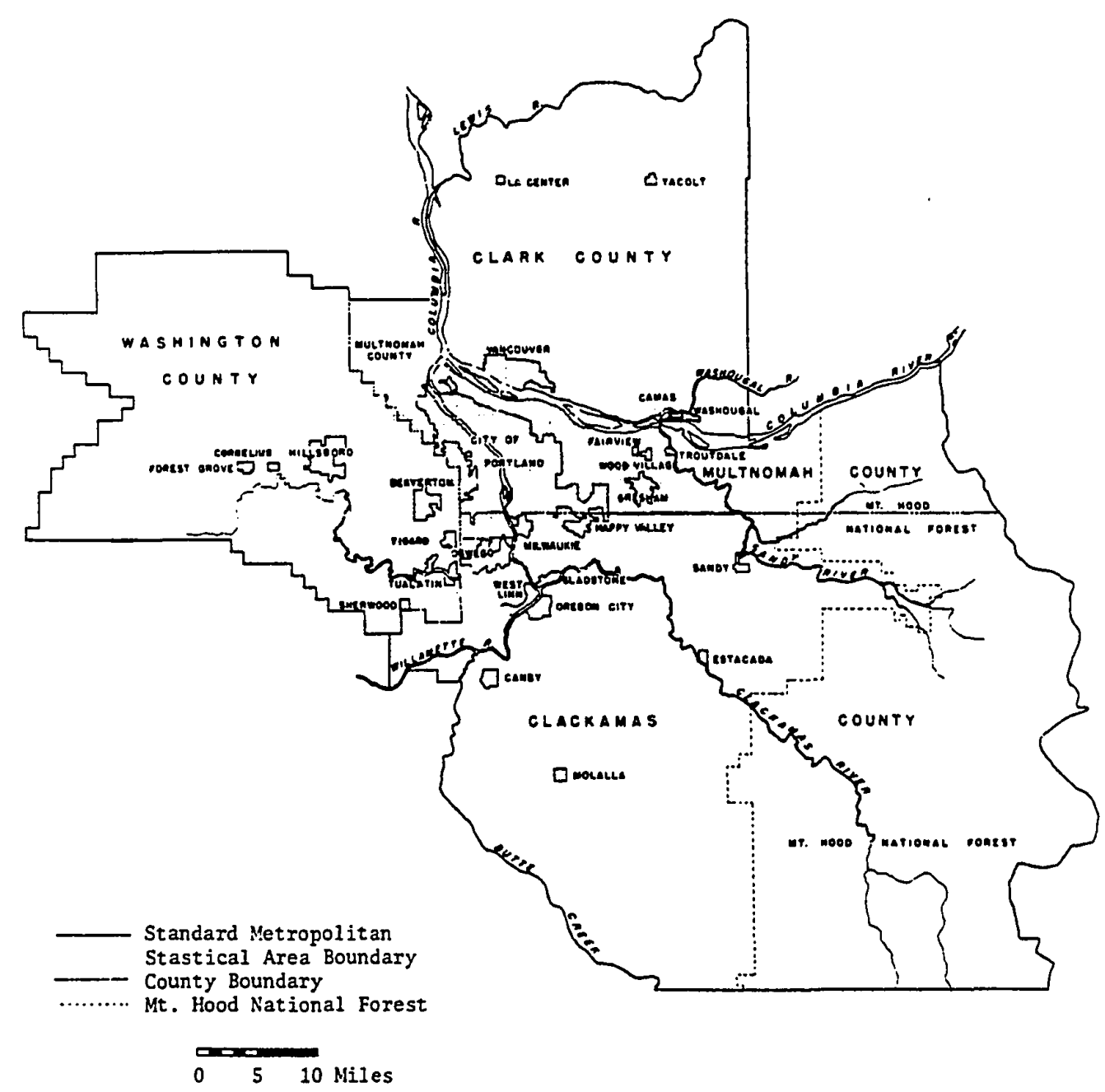

Figure 1. The Portland-Vancouver Standard Metropolitan Statistical Area showing incorporated cities and county boundaries. 
Columbia River, Clark County undertook its own boundary delimitations separately.

Multnomah County contains a significant proportion of the built-up area, with much of it occupied by the city of Portland. The eastern part of Multnomah County contains the cities of Gresham, Troutdale, Fairview, and wood Village, and a relatively low-density unincorporated area, the development of which is constrained by the lack of sewer service. In much of this area, sewerage is provided by individualized septic tanks and cesspools. In the cities, however, channeled services are provided for sewer and water by service districts and by the city of Portland. The city of Portland Water Bureau is the largest provider of water service in the region.

Clackamas County has a number of separately functioning water and sewer districts covering the urban portion of the county. Urban growth in this county has been concentrated in the northwest partly because of historical reasons, and partly because of the existence of the city of Portland to the north. The county portion closer to Portland (e.g., Lake Oswego area) constitutes some of the highest income residential property in the region. In other respects, however, the county is characterized as having a relatively large proportion of low income residents.

Like Clackamas County, Washington County is large and contains a good proportion of the region's high density 
development. The county has a number of water districts, but it is almost totally sewer-serviced by the Unified Sewerage Agency. The road conditions in the county have been alleged to be a serious deterrent to development. Nonetheless, the bulk of the high technological development, such as computer and electronics industries, has been agglomerating in this county. The probable reasons for this concentration relate to the fact that decisions affecting the location of these industries depend only to a minimal extent on differences in transportation conditions, especially when those differences (such as between the counties) are not great. Thus, the land factor plays a heavier role, and Washington County has large expanses of suburban tracts within the UGB and appropriately zoned for industrial development. A reasonable amount of land of proximate distance to the urban nucleus is also zoned for commercial and industrial uses.

Clark County in the state of Washington has reasonably dense development to the south in the cities of Vancouver, Camas, and Washougal. Immediately abutting and surrounding the city of Vancouver is a large urban, unincorporated portion which is serviced by the county. Clark County has had considerable growth in the last decade in industry and commerce.

The development of the SMSA has been characterized by mutual interdependency and cooperation among the counties 
since the 1960's when the Columbia Region Association of Governments (CRAG) was formed. CRAG was entrusted with the responsibility of studying problems of mutual concern, especially those relating to land use and comprehensive planning issues. CRAG made many regionwide research publications, among which the biennial reports on building permits and land-use data are the most relevant to this research. The continuity of these publications has been maintained by METRO (Data Resources Center) which succeeded both CRAG and the old Metropolitan Service District (MSD). A comprehensive tally of residential structures constructed between 1970 and 1980 was obtained from these sources as well as from the Housing Division of the state Department of Commerce. Along with other sources such as the Bureau of Census, these form the prime sources of data for studying the development of the Portland Metropolitan Area fringe.

\section{THE SUBURBAN AREA}

The definition of what constitutes the suburban area of an SMSA has been a controversial issue in urban research. Downs (1973) presented a rather generalized definition of suburban area to mean "...all parts of all metropolitan areas outside the central cities." Berry and Kasarda (1977) defined as suburban, all areas outside of the central city (or largest central city) but within the rest of the SMSA. The broad nature of these definitions has provoked criticism 
from other scholars (Muller, 1976). While agreeing that either definition will apply with minimum inaccuracy in heavily populated SMSA's (e.g., the New York City-New Jersey SMSA in the "Bos-Wash" megalopolis), critics argue that the norm is that many metropolitan centers are surrounded predominantly by rural landscape. In such cases (as the Portland SMSA), essentially rural populations will be included in the suburban category. Thus, depending on what the researcher is looking for, his definition of a suburb is likely to vary from that of another who is studying different phenomena or interrelationships.

CRAG's Building Permit Statistics by Census Tract (CRAG, 1972), designated the 1970 urban area as closely approximating the limits of the major cities (Portland, Beaverton, Milwaukie, Oregon City, Gresham, Vancouver) and parts of the immediate surroundings (Figure 1). For this study, this area will be considered as the urban area of the SMSA in 1970 with the exception that the area east of the I-205 freeway and west of the Sandy River will be considered suburban.

Residential land development is the key element of interest in this study. As a result, the definition of the suburbs to be studied will be limited to those census tracts outside of central cities that have experienced some change in residential development in the decade under study. The limits of the study area will then be defined by all census 
tracts abutting the limits of central cities of the SMSA in 1970, outwards to include all tracts either bordering on or partially included in METRO's year-2000 JGB for the oregon portion of the SMSA (Figure 2). In the washington state portion, census tracts around the city limits of Vancouver, Camas, and washougal but within the urban services extension area (similar to UGB) designated by the clark county Regional Planning Commission (RPC), will be included in the study. In general, a band of census tracts (one to three wide for the most part), describe the suburban ring of this study. In eastern Multnomah County, however, census tracts are really small, recessitating the inclusion of additional tracts in the ring in some cases. In general, however, one tract of the band will lie within the 1970 urban nucleus. In some previous studies (Czamanski, 1963), whole sections (i.e., 640 acres) along the fringe area have been used as units of analysis. But in contemporary research, this delimitation technique poses problems. The U.S. Census Bureau publishes information at tract or census-block level, either of which does not coincide with sections or quartersections. Also, a section is much larger than an optimum populated census tract in a SMSA, and smaller than many fringe area tracts. Thus, more reliable analysis can be attained using census tracts instead of sections or other subdivisions. 


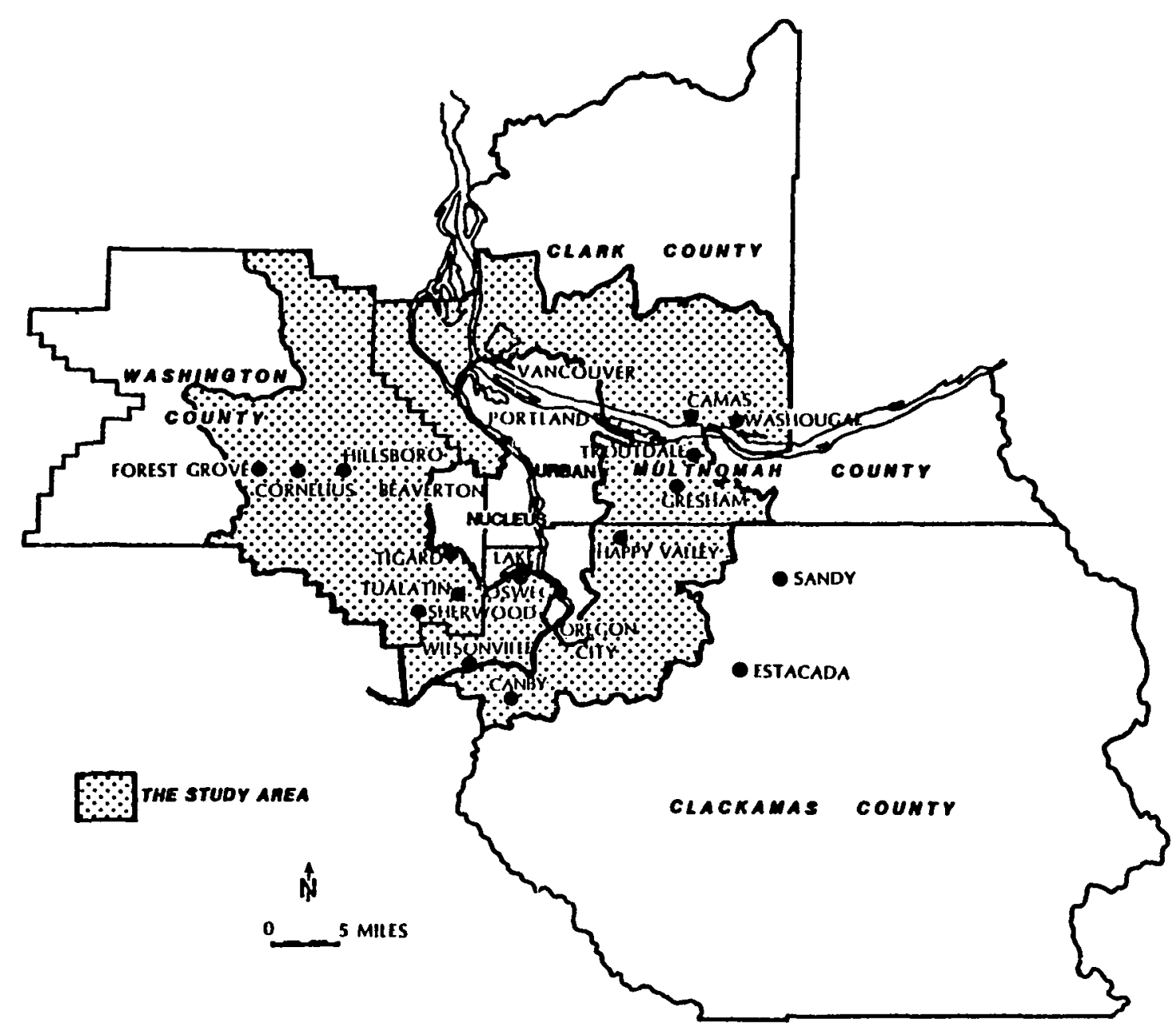

Figure 2. The Portland-Vancouver Standard Metropolitan statistical Area showing the study area. 
CHAPTER II

URBAN ECOLOGICAL CONCEPTS

Urban ecological studies have presented two major approaches to the explanation of growth and suburbanization. The first of these is the sociological view which relates growth and spatial differentiation of the urban region to the social conditions of its residents. The second view places greater emphasis on the structure of the physical environment such as land utilization factors and public facilities. The planning profession has had its quota of criticisms for leaning heavily on the latter. ${ }^{2}$ part of the reason for this bias is that questions posed by developers often have a physical impetus which could hardly be satisfactorily addressed by social factors. Thus the social aspects have been left almost exclusively as the prerogative of social planners and workers. This dissertation will take the traditional planning approach, but with due consideration given to pertinent social factors that the literature suggests are useful contributors to the process of suburbanization.

This chapter will discuss the major concepts of urban

2 Erber, E. (1970), pp. xi-xx. Erber defends this bias of planners as a natural response to the processes that led to urban sprawl. 
ecological growth and suburbanization within the context of the major land-use theories. Then the major contentions of the two apparently divergent schools of thought, social and physical, will be reviewed. The final section of the literature review will provide an insight into the contributions of land economists.

\section{MAJOR LAND-USE THEORIES}

Land-use studies have formed a major component of the research conducted in planning schools across the country. Part of the reason for this was the developmental problems of urban growth in the post-war era. Varying processes of growth led to undesirable patterns of development such as leapfrog development, cluster development, irregular sprawl, or what has been generally referred to as "formless spread" (Johnson, 1967). The concern for solutions to these problems has resulted in the postulation of numerous theories. Three major theories of urban growth had emerged prior to 1945 based on pre-World War II experiences. These were: (1) the concentric zone theory (Park, Burgess, and Mckenzie, 1925), (2) the sector theory (Hoyt, 1939a), and the multiple nuclei theory (Harris and Ullman, 1945). The adequacy of these theories in explaining general patterns of growth in the urban ecology met with little questioning in times when suburban development was minimal, when the term "suburb" carried a more rural connotation than it currently does. 
However, post-war freeway development has led to increased suburbanization, resulting in a consideration of the suburb as an integral part of the urban complex, rather than as "sub to the urb," (Muller, 1976).. Thus, the classical theories have limited applicability in the contemporary setting (Harris, 1943). Yet it is necessary to review their salient features as the bolstering of the succeecing generation of theories occurred by building upon or modifying the earlier ones.

In Burgess's concentric zone theory (first proposed in 1924 but more widely publicized in 1925), the proponent intended a continuous land-use arrangement of commercial, industrial, residential, and commuter uses around the central business district (CBD) disrupted only by major intervening physical conditions or "opposing factors" (Johnson, 1967). Nonetheless, he was heedlessly criticized on those bases as well as on others such as the nonuniformity of city center access from the peripheral areas. The sector theory (Hoyt, 1939a), was one of many that followed the criticism of Burgess's model. Hoyt noted that different land-use types (such as a retail area alongside a manufacturing or industrial area) could occur close to the center of a city. Thus, differentiation would continue in a sectoral way because of transportation axes, which were more likely to effect a radial development rather than a concentric pattern. Hoyt's theory also had limitations in the empirical 
setting. For example, only high income residential areas have been observed to respond to this pattern with any appreciable measure of consistency.

As transportation conditions improved, smaller nodes in the urban field became more accessible growth points for particular land-use types. Harris and Ullman (1945) explained that similar activity types were observed to cluster around the same growth point. The result was a series of smaller centers, each associated with a different land-use type, in addition to the regular CBD. The multiple nuclei theory was thus postulated and received relatively more acclamation among geographers, planners, and sociologists than did the previous theories.

Quantitatively, urban growth has been explained in various forms collectively referred to as "gradient analysis" (Shaw, et al., 1929; Clark, 1951, 1967). This connotes the existence of generally declining densities of activities and uses from center to periphery. Testing the technique, however, presupposes the applicability $O \vec{F}$ one of the classical theories, and thus not only compounds the problems of the referent theory, but becomes plagued by new changes brought about by suburbanization of various land-use and economic activities.

Recent patterns of metropolitan development have shown the existence of different types of urban growth depending on whether a clearly dominant city or a set of "suburban" centers form the metropolis. With respect to the latter, 
Burton (1959) and Philbrick (196l) advanced the dispersed city concept based on separate studies in Illinois and Michigan. Briefly stated, the concept implies the existence of a number of small-sized communities functioning as an urban unit with no clearly defined downtown (CBD) and no hierarchical structure as tested against christaller's central place theory and the zipf rank-size rule. Writers like stafford (1962) have raised criticisms against the concept especially in regards to Philbrick's (1961) use of the term "dispersed city" to mean no significant difference from the process of urban sprawl.

In his global synthesis of a theory of urban form, Lynch (1961) described the dispersed sheet city development pattern as one of five major component patterns of urban development. Lynch's dispersed sheet was hardly different from the dispersed city, except that the sheet characterized spreading metropolitan areas that have attained a high degree of activity decentralization and dispersal into the suburban ring. No nodal points claim predominance over the others, and no major terminals or arterials occur. Access to the rural areas would not be necessary because recreational facilities and amenities (usually located in the fringe areal would be close at hand. The other city forms reviewed by Lynch were the galaxy of settlements, the core city, the urban star, and the ringed city. The galaxy represented a group of individual settlements separated by 
rural land where intersettlement access is useful. The core city represented the high-rise, city-center form, often crowded and characterized by congestion. The star-shaped city reflects the influence of major arterials on a corecity type of development, which, according to Leven (1978) characterizes old, large SMSA's. The ringed city contained reasonably high development toward the periphery with relatively low density core area and criss-crossing arterials. In addition to the five forms, Lynch presented the alternative of the multicentered city, which is very similar to the multiple-nuclei theory of Harris and Ullman, with three basic differences: (1) a triangular-grid transportation network, (2) open space preservation, and (3) imageability.

The Iand-use theories relate to the development process and differentiation of major urban centers in general. In fact, many of them were based on observations made on the city of Chicago at various points in time. For example, the concentric ring and sector theories were derived from such studies before World War II, and Harris and Ullman's postulations basically reflected modifications on Chicago during the war years. Nonetheless, the historical and theoretical knowledge they provide is a useful guide for a study like this one which is focused on a small part of the urban area. 


\author{
SUBURBANIZATION AND URBAN \\ SOCIO-SPATIAL DIFFERENTIATION
}

One of the more recent synoptic reviews of suburban development theory has been presented by Muller (1976). Muller views the suburb as an integral part and logical extension of the city. Numerous subcentral areas progressively emerge and attract middle-class populations who feel increasingly oblivious of any continued dependence on the existing central city. The growth of minor centers may be influenced initially by transportation axes, but consequentIy depend on the varying degrees of many factors, some of which are local determinants. Muller described three patterns of growth that have emerged in three distinct periods in the urban evolutionary process. His first period was the pre-World war II era in which the traditional city was characterized by a high central focus, limited suburban growth, and a correspondingly small field of influence as a reflection of the influences of the modes of walking, the horse car, and the electric car. The secund pattern, the post-war city, maintained the single high-density center but with a growing suburban area as a result of arterial street expansion due to the additional influence of the automobile. The contemporary, the third pattern, has had the freeway influence and CBD decentralization which have led to the growth of a number of smaller centers in the suburbs as well as the field. 
While Muller's synopsis is based for the most part on physical conditions, variations in social conditions and their influence on the differentiation of the urban space have been documented in earlier works generally referenced as social area analysis or factorial ecology.

Social area analysis is the technique of measuring and analyzing social differentiation. The technique comprises of factor analysis of socio-economic data. By factoring variables, the technique distinguishes social areas and derives a typology of urban forms. The derived social area would have particular measurable social characteristics which are in some way distinct from those of other areas that are similarly designated.

The first proponents of social area analysis were Shevky and Williams (1949), who examined three major categories of factors which in their postulation represented the key elements accounting for social differentiation in the city of Los Angeles. These factors were social rank (family status), urbanization (economic status), and segregation (ethnic status). Using 1940 census information for Los Angeles County, three variables were selected to measure each of social rank and urbanization, and one for segregation. The measurements of social rank comprised of occupation, education and income. Occupation was defined as the percentage of the total employment that is comprised of craftsmen, operatives and laborers. The ratio of the number 
of people who completed grade school or less to the number of people aged 25 or older constituted the measurement of the education variable. Income was defined as rent per capita (i.e., total monthly rent in each census tract divided by the total population of the tract). The mean of the three scores was used to indicate social rank. A low score implied a low social rank, while a high score indicated a higher family status.

The urbanization factor was measured by fertility (number of children aged less than 5 years in relation to women aged 15-44), women in labor force (working women aged 14 years or older), and the percentage of total dwelling units that are singie family and detached. The mean value of these scores denoted the urbanization score. A high score meant low fertility, many employed women, and few single-family units.

Segregation was measured by the number of persons in highly isolated population groups in relation to the total population. A ratio of 1.0 denotes a random distribution. Groups are highly isolated if their average proportions in the populations of the neighborhoods where they live are equal to three or more times their respective proportions in the population of the county.

The above three indices presented the three dimensions of the analytic technique reulting in a typology of social areas for Los Angeles. To determine the types, the regres- 
sion line of urbanization was estimated in relation to social rank. Using those two as axes, social rank (X-axis) was divided into three equal intervals of low, middle, and high. For urbanization ( $Y$-axis), the area between \pm 1 standard deviation about the regression mean was used to denote random, the areas above and below it as high and low urbanization respectively. The third dimension, segregation, was dj.vided into high and low forms. The result of the typology was nine possible social areas. Generally, areas of high urbanization had a low social rank and vice versa, with over half of the population distributed around the middle social rank category.

Bell (1955), was the first to seek to establish the extent to which the three dimensions of the Shevky/Williams typology are necessary and adequate to account for social differentiation in urban populations. In addition, Bell wanted to determine how well the measures of the variables in each of the social rank and urbanization dimensions possessed a measure of unidimensional index of the respective two dimensions. In other words, do occupation, education, and rent produce a unidimensional index of social rank? Similarly, do the variables of fertility, feminine labor force participation and neighborhood physical character produce a unidimensional index of urbanization? Or, do any of these variables measure something else? Bell used the exact seven variables used by Shevky and williams with 
similar indexing. The only modification he made was to the ethnic variable, where he used the number of minorities (blacks and foreign-born) per 1000 population. Bell found that the variables defining economic status (education, occupation and rent), showed low definitive association, while the other variables showed respectively high family and ethnic status. Further, factor analysis verified education, occupation, and rent as loading one factor (economic status) in a basic continuum. The second factor, family status, was also heavily loaded by the hypothesized variables of fertility, iabor force participation by women, and single-family detached housing units, in a continuum. The third factor was similarly heavily loaded by the ethnic variable.

To ascertain the useability of the three dimensions to establish the typology, Bell tested the three factors against each other in a factor correlation. Economic status was negatively correlated to family and ethnic status, meaning that in 1940, areas of Los Angeles County with high economic status had low family status (i.e., few children under age five, many women in labor force and predominantly multifamily residential units), and low ethnic status (i.e., a high concentration of minorities of Blacks, Orientals, Mexicans, Italians and Russians).

Bell repeated the same logical steps and technique for the San Francisco Bay Area using 1940 census data and found 
the same results. He concluded that the three dimensions account for social differentiation in urban populations. The Shevky/williams and Bell studies were specific to the two cities of Los Angeles and San Francisco. To test the generality of the scheme, Van Arsdol, Camilleri, and Schmid (1958) used six variables (education, occupation, fertility, women in labor force, single-family dwelling units, and Black population) in ten selected U.S. cities: Akron, Atlanta, Birmingham, Kansas City, Louisville, Minneapolis, Portland (Oregon), Providence, Rochester, and Seattle. From the results, the authors concluded that there was a high degree of generality.

In a later study, Anderson and Bean (1961) expressed doubts about the adequacy of the three factors postulated by Skevky/Bell. Their study focused on Toledo, a northern city not likely to be affected by the fertility problem. In addition, Toledo was about the same size as those cities studied by shevky and Bell. To the variables (except for rent), the authors added seven more: (1) residential stability defined as the percentage of people residing in the same place in 1949 and 1950 , (2) percent of people aged 15+ and married, (3) median family income, (4) ratio of families to unrelated individuals, (5) owner-occupancy (percent), (6) percent of married couples living without their own households, and (7) crowding or percent of all dwelling units with 1.01 or more persons per room. 
Where social rank and family status appeared in previous studies as the same factor, in the Anderson/Bean study, they appeared as separate factors, so that they ended up with four factors. The fourth factor, segregation, was loaded by the variables of crowding and double occupancy in addition to the minority variable.

A confirmation of the social rank and urbarization axes of the Shevky/Bell typology was made by Udry (1964) in a longitudinal study for the period 1850-1960 using seven variables. The results were that the segregation index failed to appear as an independent axis affecting the differentiation but only as a general factor of differentiation, indicating that the segregation index may be measuring something else.

Perhaps the most important study outside the American scene on social area analysis was done by Herbert (1967) in New Castle-Under-Lyme in Britain. Excluding the segregation variable by assuming uniform segreation in New Castle-UnderLyme, Herbert used four variables, two each for the dimensions of social rank and urbanization. For social rank he used the variables of occupation and education while for urbanization he used fertility and women in labor force. Using these indices, Herbert compared New Castle-Under-Lyme to Rome and ten American cities (Van Arsdol, et al., 1958) where the technique had been previously applied. He found correlations between the two indices and between either of 
them and the others in all the studies. In conclusion Herbert noted that social area analysis was a comparatively useful tool. The resulting diagrams provided valuable frames of reference for sample studies in the future.

A general criticism levied against social area analysis is that no variables measuring characteristics of 10cation directly are included. Anderson and Bean (1961) referred to this situation as "unfortunate" because the homogeneity of a census tract is argued only in respect of its location. There has also been criticism that the Shevky/Bell system places much more emphasis on social rather than territorial areas. For example, "urbanization" refers to human values or patterns of social interaction--a term which refers to the whole community rather than to segments or groups. "family status" also refers to the family group, while segregation is probably the only exception.

It has been further noted that variables that correlate normally (with high colinearity), come out to load different factors in the analysis, e.g., socio-economic variables of education and occupation versus median income. Thus, people with higher incomes are only partially drawn to areas with high average occupational/educational levels. In this regard, Anderson and Bean suggest that the social rank factor should be a measure of prestige value instead of socio-economic status. 
Hawley and Duncan (1957) are perhaps the severest critics of social area analysis. They describe as confusing the shevky/Bell notation that "...the social area is not limited only to the geographic frame of reference of the census tract, but that certain other populations selected as units of analysis may also be used" (Hawley and Duncan, 1957). They also argue that the proponents of the technique used geographic units to make a classification whose categories they called "social" while maintaining that the categories have no areal reference. Further, they state that census data have only basic factors of urban differentiation and stratification and are insufficient to describe the whole spectrum of urban differentiation. Finally, they claim that the technique lacks a formulated theoretical basis and has failed to answer the question why residential areas within cities should differ from one another. This argument suggests the relevance of nonsocial factors such as locational characteristics and physical conditions to the study of spatial differentiation as well as the social ones. Polk (1967) observed that some social area studies Eailed to establish any relationship between economic characterics of urban areas and ecological distribution of delinquency due to the lack of appropriate methods and theoretical precision.

Earlier students of urban studies such as Park, et al. (1925) were concerned with ecclogical space. Social area 
analysis, on the other hand, focused on social differentiation. This apparent discrepancy is examined by orleans (1966), noting that the shevky/Bell typology neglects ecological space and is based on "...an attribute space representing a conceptual typology of positional differences which are denoted by measures of a series of characteristics of population aggregates". In conclusion, Orleans argues that there is now the need to logically bridge the gap between social space and associational ecological space. Researchers in disciplines other than sociology viewed social area analysis more favorably than some sociologists. Tiebout (1958) incidated that many of the criticisms levied on the technique emanate from problems of interpretation. In his Staffordshire study, Herbert (1967) noted that the selection of New Castle-Under-Lyme to demonstrate the technique of social area analysis was because there have been many previous studies done on that city so that its sociology is well documented, and that problems emanating from the suitability of the technigue were easy to discern. However, the map resulting from the study was meaningful, and the tool (technique) was comparatively useful.

Murdie (1969) combined cross-sectional with longitudinal investigation of the change taking place in the urban ecology of Toronto. His emphasis was on patterns (structure) rather than process of urban ecological change. He used the same three variables of economic status, family 
status, and ethnic status and their associations with a whole range of social and demographic factors such as income, occupation, education, fertility, type of dwelling unit, female labor participation, and general tendencies of groupings of people in the urban space. He used factor analysis and other multivariate techniques to determine social areas, and concluded with a model of the factorial ecology of Toronto.

Schnore (1973) summarized the social factors leading to the city-suburb population differentiation into color or ethnicity, socio-economic class, and type of family, with median family income being the most important indicator of socio-economic class. Admitting that this conclusion was based on preliminary observations of the 1960-1970 trend, Schnore makes the concluding remarks that a more detailed analysis of census data would augur this assertion.

In the summary of a study in the Portland Metropolitan Area (Lycan, et al., 1978) in which respondents were interviewed, housing conditions, neighborhood environment, and quality of infrastructure were cited as important considerations in residential mobility in the metropolitan area.

The foregoing discussions shed some light on the extent to which social factors have been treated in studying the growth and differentiation of subareas of the urban space. Physical factors have not been studied as well, and the gap between the two sets of factors remains to be 
bridged. In particular, the relationship between the two sets of factors in determining spatial differentiation (whether simultaneous, synergistic, or perhaps mildly antagonistic, etc.), needs to be addressed. Some of the important variables in studies like the shevky-Bell typology, such as the family and urbanization factors are partially included in this study to lend some support in the gapbuilding effort between the two schools of thought.

\section{PHYSICAL FACTORS AND CONCEPTS}

Perhaps the most important contribution by a single writer on the effect of the physical structure of the environment on the spatial distribution of urban population and economic activity has come from Hawley (1950, 1956, 1971, 1975). Hawley has maintained that "the distribution of the elements of that (physical) structure form a pattern of land uses which is expressive of the interdependencies among the various activities comprised by the city" (Hawley, 1950). Thus, much of the subareal differences influencing the centrifugal drift of the urban population can be accounted for by the physical structure guided by a reasonable knowledge of the social variations such as Schnore's (1973) factors of differentiation. Along those lines Berry and Kasarda (1977) have asked a reciprocal question: What is the effect of suburbanization on the provision of public facilities and infrastructure by central cities? Using the 
168 SMSA's existent in 1950, the authors looked at trade (using sales taxes) and the expenditures of city government for noneducational activities for the years 1948, 1958, and 1967, and the census figures for 1950, 1960, and 1970. They found that trade and services showed little relationship with central city size, but exhibited a significant positive relationship with suburban population size. Even more relevant was the finding that the suburban population posited a larger effiect than that of the central city. A similar effect was also observed in the Richmond region (Muller, et al., 1978).

A relevant research to the Pacific Northwest is that of Morrill's (1965) use of probability and simulation modeling technique to study the process of expansion of the urban fringe in Seattle; Washington. Morrill used accessibility to major arterials, site quality, and nearness to amenities as key variables in a model to predict the probability of fringe area development. Although the overall results of the simulation were not identical with the actual situation, the author noted that the effects of the key variables in the simulation compared well with the actual situation.

Using Erankling County, Ohio, Habig (1972) adapted the gravity model in a series of simultaneous regression equations relating different types of activities (residential, commercial, employment, income categories, etc.), to the 
independent variables of attraction (shopping, industry), access, sewer service, and the residual holding capacity of land for residential use. One interesting result was that sewer service was useful in predictions of commercial developments and particular income group residents, but insignificant in the prediction of residential development. The most useful predictors of residential development were commercial employment and accessibility.

Bourne (1974) used a number of variables on access, employment, and subareal attributes to determine a typology of land use in metropolitan Toronto. Using factor analysis with varimax rotation, he concluded that the availability of open space, institutions, shopping malls, and industrial complexes remote from the CBD, were important conditions for suburbanization. Corsi's (1974) study of land around interchanges in the Ohio Turnpike also attributed the high rate of conversion to the availability of public facilities, proximity to centers, and rates of growth of jurisdictions around those interchanges, in addition to other variables that are influenced by location conditions.

In testing exponential, opportunity and gravity models to predict population changes in the city of Milwaukie, Wisconsin, Ottensman (1974) used data for variables measured in 1924, 1945 and 1963, and data from the U.S. decinnial censuses (1920-1970). His study arrived at the conclusion that the power of the models in predicting the differential 
nature of urban population distribution remained high over time. Accessibility to work place was found to have a relatively declining importance over the years. And between the years 1940 and 1970 the sector pattern of areal differentiation held much less significantly in comparison to the concentric zone pattern--a finding which was supported by further study using the technique of factor analysis.

Famisa (1977) was concerned with the effect of leapfrog development on the rate of land conversion in the corridor between the metropolitan areas of Tucson and Phoenix, Arizona. Between 1940 and 1975, Famisa found that leapfrog development was immediately followed by accelerated low density, nonagricultural land uses in unplanned scattersites along the corridor between the two cities. Unfortunately, this study did not address the issue of containment of leapfrog development or how the relationship between leapfrog development and land conversion might be affected by the imposition of a growth ceiling such as an urban growth boundary.

Recent urban planning strategies have incorporated the use of "Planned Unit Developments", such as King City in the Portland Metropolitan Area as possible means by which a small community could be made to maximize the utilization of available services. Counter to azonic sprawl and leapfrog developments, PUD's were expected to provide answers to planning querries regarding efficient land utilization, 
energy contingencies, transportation problems, as well as other social issues relating to the use of public services. These expectations have been questioned on the condition that there is no difference (especially with respect to travel characteristics) between residents of conventional residential areas and those of PUD's (weyland, 1977).

At a more local environment and in a historically oriented approach, Malarkey (1978) traced the development of the city of Wilsonville since the 1950's. The study concluded that although the study area was too microcosmic to allow for generalizations for the whole of the metropolitan area, urban development was observed to be a slow, accretive, and irreversible process, with land potential playing a dominant role even before land-use changes have been effected through jurisdictional or zoning regulations.

zoning by itself may be related to a number of problems. Permissive zoning may lead to land depletion and congestion as a result of the inclusion of people of low socio-economic status (Reed, 1982). According to a study in Springfield, Massachusetts, no evidence of racial segregation was determined either in an extreme case of intentional exclusion of the poor, or a moderate situation involving intentional inclusion of the economically well-to-do.

The influence of public facilities on the conversion of agricultural land to urban uses was investigated in Urbandale, Iowa (Lee, 1977), with the result that for the 
period 1950-1974, public Eacilities in interaction with accessibility and land-suitability conditions, represented the most important single variable in the conversien process. Areas of poor access and flood plain conditions showed a diminishing importance of public faclities to the conversion process. More specifically, Fagerlund (1979), compared the costs of providing sewer service in singlefamily and apartment structures. The costs evaluated included construction costs, on-site costs for septic tanks), as well as maintenance and administration costs. Fagerlund arrived at the general conclusion that cost savings would depend on the density, location, and time period of the development of the subarea or zone. For instance, according to his model, more cost savings were realized if a neighborhood was settled all in one year (which in reality is hardly ever the case) than if it took a longer time period.

The efficiency of water supply systems was evaluated in a study by Bruggink (1979). He questioned whether a water supply system provided by a private firm was more efficient than if provided by a city, jurisdiction or service district. A good deal of argument on this subject has centered on the issue that in a monopoly system, there are no cost-minimization incentives, thereby leading to higher costs to the consumer. Bruggink's analysis used regression techniques to explain operating and capital costs 
of water service. The results showed that publically controlled utilities were more efficient than private-owned ones, with significantly lower capital and operation costs. The incidence of urban fire hazards and the structural, social, and morphological conditions leading to their frequency was studied by Donnell (1980) in the city of Syracuse, New York. High incidence of fire was correlated with poverty, renter-occupancy, low median educational attainment of neighborhoods, mixed land-use areas and deteriorating structures, all of which characterized innercity neighborhoods. Fringe areas and suburban areas had insignificant fire problems because of the lower density of development and lower congestion conditions.

The adequacy of water supply in meeting the needs of growing populations of metropolitan areas was assessed by Greenberg (1969) in the New York Metropolitan Area. Particular attention was paid to the different needs of residential, commercial, industrial, and public land-use types. Greenberg addressed the issue of the growing needs of the sprawling metropolis with specific focus on the urbanizing fringe area, following a preview of the water requirement analysis of two contrasting small cities in the same region --Newark, New Jersey (typifying an industrial city), and Yonkers, New York (an overwhelmingly residential area). Major findings of the research suggested that changes in the water distribution in New York reflected the outward move- 
ment of people and some high-density land-use activity to peripheral areas that were formerly sparsely developed.

Industrial location factors emphasize the need for large tracts of land, in addition to accessibility, and adequate facilities. The location of rental housing on the other hand, depends on where the developer thinks he is most likely to attain maximum profit, which in part is also related to services. With regard to different jurisdictions, variations in fiscal conditions may also strongly influence residential location [Tiebout's (1956) hypothesis]. Thus, there are considerable differences in locational requirements for different uses, and attempts to include all of them in a single model have either floundered or lacked adept treatment. One early attempt at such an operational model was presented by Czamanski (1963), who made the contention that economic base and other functional approaches to the explanation of urban growth had many pitfalls, and the derivative models lacked practical applicability in real world planning situations. In addition to utilizing industrial location theory, Czamanski considered as additional inputs to his model the effects of new job sites as well a other productive locations. Four statistical techniques were employed. These were correlational analysis and chi-square $\left(x^{2}\right)$ tests to establish the validity of his hypotheses, analysis of variance technique to establish similarities and differences among cities and size- 
classes of cities, and regression analysis to establish the relations in a linear model. It has been twenty years since this research was conducted, and since then the effects of industrial location as an explanation of urban growth have diminished. Further, Czamanski's study was taxonomically concerned with classifying cities based on their general growth patterns.

\section{ECONOMIC CONCEPTS}

Alonso $(1960,1964,1968)$ extended the urban rent theory in the form of the bid-rent function as a new concept, reconciling the concentric zone theory with the behavior of households in maximizing utility. A household's bid-rent function in this context is defined as "the set of land rents the household would be willing to pay at various distances from the $C B D$ in order to maintain the same level of satisfaction, i.e., the same level of utility everywhere which makes the household indifferent between locations," (Richardson, 1977). In the suburban context, this means that pecuniary variables such as travel costs, land values, etc., would have to substitute for each other, and perhaps even for nonpecuniary variables such as scenery. In this regard, Wingo (1961) made an assumption on the expenditure of households that the costs of rent and commuting sum up to a constant. For these assumed relationships, wingo developed a land market model based on transportation and its 
complementarity with rent, which set the stage for the derivation of an even larger model by Mills (1967). Mills' product was a general equilibrium model for the city in which he investigated the roles of the sectors of production, housing, and transportation in determining the household location decision. The macro-nature of this model has generated criticism. Richardson (1977) has described it as ambitious, but nevertheless, it contains useful attributes; it addressed the question of locational equilibrium, it noted the effects of congestion and the importance of the allocation of land for transportation, and it gives an insight into what thetermines the urban boundary.

Muth (1969) presented a different approach from the other theorists by being less theoretical. He considered such factors as building age, racial segregation, and slum development, as well as transport costs and distance in the locational process. Muth's analysis (based on the city of Chicagol derived that distance relates to the nature of housing production functions and the proportion of residentially zoned land within the locality. He also considered the influence of secondary centers of employment, shopping centers, and rapid transit routes on population distribution patterns. On the segregation issue, Muth concluded that blacks pay more for housing than whites because of their faster growth of demand for housing, rather than for racial reasons. 
The suburban labor market and its future role in suburban growth were analyzed by Stanback and Knight (1976). They attempted to answer the question: will the suburb increasingly diversify its job market until the inner-city becomes a "burnt-out", drained core? The authors think that the suburban job market will continue to diversify, but it is unlikely that it will become an entity independent of the core city [contrary to Muller's (1976) view by definition]. It will continue to serve a dormitory capacity, with its labor force dependent to some extent on core-city jobs. Further, Stanback and knight contend that as population continues to move out of the core city, manufacturing is likely to move in. In addition, although more sophisticated services such as hospitals, junior colleges, theaters, museums, etc., will continue to move to the suburbs, other advanced services such as law, architecture, and banking will stay in the CBD.

Tiebout (1956) assessed local jurisdictional expenditures on public facilities and how they influence tax levels. He noted that if a local resident moves, he will move to a suburb where his consumer preference patterns (taxes, cost for services, etc.) are best satisfied, and within the limits of optimum mobility costs. Thus governments of local jurisdictions constantly strive to lower their service costs as each is in constant competition with the others, very much like firm entrepreneurs, to keep costs 
(taxes) at a minimum. The mobility constraint Tiebout refers to is also emphasized by Richardson (1977) and Wingo (1961). Richardson argues that the distance from the $C B D$ (or travel cost) is a very important locational determinant which, according to wingo can be traded-off with land values.

Tiebout's hypothesis has been criticized by recent researchers. While agreeing that it holds true for population movements, Moses and Williamson (1967), and Schmenner (1975) reached conclusions that with respect to industrial location, there is no statistically significant evidence in support of the influence of economic factors such as taxes on the suburbanization of industry. However, as Wheaton (1979) notes, the establishment of statistically significant links between location and economic factors had methodological flaws. Wheaton argues that in both cases the authors used poor quality zonal data, and relative rather than absolute zonal attributes. Regardless of the controversy, the Tiebout hypothesis has import to this study, especially as the movement of population to the suburbs is highly colinear with the dependent variables that this study seeks to explain.

With respect to the price of suburban land, Hushak (1975) stated that suburban land prices related to distance to both the central city and the nearest smaller settlement 
or center. He also found that zoning, and road and rail access were important influences.

Gleeson (1979) looked at how the values of both farmland and vacant urban land in the fringe area might be affected by the imposition of growth management systems such as a UGB. Reiterating that accessibility in terms of minutes of travel time, site characteristics (suitability for development), availability of services and amenities, are all positively correlated to land values and development, Gleeson states that the bulk of the difference in values between farm and urban land is attributable to the growth management system in the Twin Cities Metropolitan Area in Minnesota. Further, the importance of local factors is noteworthy in addition to those mentioned above, as indicated by a study (Diamond, 1980) which concluded that holding local conditions constant, it was cheaper to live farther away from the city (in terms of land values) for the same level of amenities. The level of amenities may also be related to the zoning conditions and the uniformity of land use (Jud, 1980). Jud states that where the zoning is rather uniform, residential properties cost a little higher than where mixed uses occur, such as a residential area close to commercial or other use.

Reasonable documentation exists on the evaluation of the impacts of land development, technical considerations in measuring land conversion, and the effects of major trans- 
portation construction activities on the naturai environment as well as on residential and commercial uses. Much of this is comprised of papers published by the Urban Institute. Among the relevant are Keyes' (1976) assessment of land suitability vis-a-vis the natural environment. Keyes assesses the deleterious effects of impervious surfaces (e.g., concrete, asphalt, or compacted soill on surface runoff, the potential cause of diseases by flooding, destruction of vegetation cover, and underground leakages from septic tank leach fields. Keyes' work concluded with suggestive measures of flooding among which are change variables on property damage, people affected by flooding, flood frequency and severity.

The analysis of fiscal and other impacts have also been documented by Muller (1975), schaenman (1976), and Schaenman and Muller (1974). Muller (1975) described a cost-revenue method of testing cross-sectional and timeseries data to determine the pecuniary costs and benefits to the household, the community and the local region. Muller discusses spillover and spill-in effects of new industrial or commercial projects in suburbs, which explains why certain communities prefer attracting new industries to new residential developments. Schaenman (1976) outlines numerous variables (public services, accessibility, aesthetics, etc.) and the way they can be measured for localized or areawide studies. Some variables, he suggests, may be 
measured by the proportion of households satisfied with their service efficiency. Problems with these kinds of measures include the definition of satisfaction and the relative differences in satisfaction levels.

PLANNING AND GROWTH FORECASTING MODELS

The economic principles of urban land use present.a conceptual framework within which relationships are expected to occur, all things being equal. But as conditions vary in different metropolitan areas, the quest for standard procedures of operationalization and the desire to derive appropriate techniques of empirical testing have necessitated the development of many different land-use planning and growth forecasting models. These models vary from simple techniques of projecting specific land-use activities to sophisticated relationships involving elaborate quantifications. Mohan (1979) notes that these multifarious kinds of models may be categorized into two broad groups: (1) analytic or explanatory models; and (2) operational or policy-oriented models. ${ }^{3}$

Analytic models present general systematic explanatory

3 It is worth noting that Harris (1968) made a more detailed classification of urban land-use models into six dichotomous categories: (1) descriptive versus analytic; (2) holistic versus partial; (3) macro versus micro; (4) static versus dynamic; (5) deterministic versus probalistic; and $(6)$ simultaneous versus sequential. Essentially, these categories are by no means mutually exclusive; for example, a macro model may have a holistic focus utilizing a series of simultaneous regression equations. 
paradigms such as locational determinants of urban activities, economies of scale, and the effects of agglomeration (Miron, 1974). Among these are Alonso's (1964) land rent theory, and Muth's (1969) household utility function concept. Thus, the thrust of analytic models is primarily based on economic theory, with other variables being of secondary concern.

Operational models, on the other hand, characterize many practical land-use forecasting techniques. The Lowry Model (Lowry, 1964), is one of the first major examples used in forecasting subareal employment and household locations. The model identifies site characteristics (including site quality and available infrastructure), locational attributes, and legal considerations as important variables and constraints of land-use forecasting. It then uses an iterative procedure with nine structural equations and allocation techniques to generate the forecast data for different zones.

Similar to the Lowry technique is the EMPIRIC Model (Hill, 1965) developed originally for application in the forecasting of development in the Greater Boston Region, using a set of simultaneous equations rather than the sequential set used in the Lowry approach. The basis of the EMPIRIC forecast is the assumption that an equilibrium tendency exists whereby change in the condition of one variable in a particular subregion could be expressed as a 
function of changes in the levels of such other variables as accessibility, land supply, infrastructure, and their lag conditions. In the Boston situation, accessibility and lag variables were most important in deriving the forecasts. Like the Lowry Model, the EMPIRIC has been described as generally too large and refers to too many sections of the city at once (Chapin and Kaiser, 1979). Thus, applications of both models seem to have been restricted to regional forecasting situations utilizing zonal estimates and undertaken by regional governments and planning agencies which can afford the expensive data collection procedures and duration of time required to calibrate them and generate the forecasts.

A series of smaller planning models structured after the Lowry technique are currently applied in many metropolitan areas. Lathrop and Hamburg developed the AccessibilityOpportunity Model after Schneider's (1968) intervening opportunities model of trip distribution (Lathrop, 1965). As the name implies, accessibility is a major input of the model along with the residual land suitable for development and policy considerations. Residential and nonresidential activities are then assessed from the respective trip ends generated by those activities. This model bears import to this study in that the competitive effects of minor activity centers is a major constituent of the opportunities component of the model. Thus, the resultant density of a parti- 
cular activity would depend on the number of associated subcenters. Important variables utilized by the model are base-year population, employment, trip generation, and travel time. The model is calibrated after every few years for use in subsequent predictions.

The Lowry and Accessibility-Opportunity Models Eormed the basis of formulation of Goldner's (1968) Predictive Land Use Model (PLUM). PLUM utilizes allocation algorithms to project future zonal population, employment, and residential land-use distributions. The technique identifies general employment and site-specific or local area employment, and associates the projection of households with these variables. Although it was developed initially to provide the input necessary for the planning activities of the Bay Area Transportation study Commission (BATSC), the model has been successfully calibrated and applied in many other metropolitan areas.

The Urban systems Model (USM) is one of the more recent planning strategies also developed after the Lowry scheme but structurally similar to the EMPIRIC (Voorhees and Associates, 1974). It is comprised of a series of submodels using modified forms of variables of the Gravity Model. These are transport costs between zones, zonal attraction, and the total holding capacity of each zone. Structurally, it approximates PLUM with the exception that additional transport cost parameters for home, workplace, and shopping 
site are used to calibrate it. Its utility has included the forecasting of small area population and employment, market potentials, and accessibility levels of activity centers.

One model that is both analytic and operational is the Urban Performance Model (UPM) which is based on assumptions that are very similar to the equilibrium concepts of the EMPIRIC and the Accessibility-Opportunity Model (Brown and Kirby, 1971). This model assumes that subareal opportunities vary, and the development potential of a site depends on the quality of the immediate surrounding. Thus, growth forecasting is based on the relative differences in these conditions. The opportunity component of the model is measured by the relative accessibility of subareas to regional attractions or subcenters, and the derived indexes are similar to those of the EMPIRIC and the Accessibilityopportunity Models. The quality of the surrounding is measured by the resident population stratified by income level. Relative and marginal utilities of location and land value constitute the major constructs of the allocation process. Utilities of location basically refer to changes in land-use activity while utilities of value refer to differentials in land value when a tract is utilized for nonresidential purposes as opposed to residential housing. Thus, in addition to income characteristics, employment, transportation, and land-use data form major inputs of this 
model. It is calibrated at approximately 2-year intervals for re-application.

In general, the nature and focus of the land-use planning models discussed above present a few concerns with respect to their relevance to and possible utility in this study. Lycan and Weiss (1979) note that their complexity and high cost of implementation and calibration pose numerous impediments, making it difficult to adopt them wholly in certain planning studies. For their purpose: they designed an integrated model to project changes in the age structure of metropolitan area populations using the three oregon counties of the current study area. This technique was comprised of regression analysis with four submodels estimating changes in demographic characteristics (i.e., total population and 5-year cohort projections), housing inventory, census tract population and age composition, respectively. The regression equation for the housing inventory estimation was noted as the most successful. The authors contend that this submodel could be used in isolation for similar predictions.

With reference to their structure and content, it is difficult to adopt any of the above models in dissertation research without encountering problems of data collection and time constraints. Also, with the exception of income differentials, social factors are only marginally considered by these models. Like most planning techniques, however, 
they emphasize the importance of physical facilities such as infrastructure, accessibility, and land characteristics. Within the Portland situation, these predictive components have not been adequately appraised and tested. Thus, reasonable explanations for subareal differences in fringe area residential growth would be expected to be arrived at when these variables are adopted and applied in a modified technique.

\section{COMMENTARY ON METHODOIOGICAL TECHNITUES}

AND PARAMETER ESTIMATES

From the foregoing review, a few issues seem clear. First, both the socio-spatial and physical-infrastructural approaches may be equally effective in assessing fringe area growth and spatial differentiation of residential housing. It would, however, be erroneous to regard either of these apparently divergent techniques as more appropriate than the other. Rather, one should complement the other. Second, the assumption of constant parameters for attributes across the SMSA in traditional planning methodology may be criticized as neglectful of jurisdictional distinctions which may heavily influence growth patterns. Whereas both traffic zones and census tracts are subdivisions of the jurisdictions (counties) used in the study, the assignment of attributes to especially traffic zones is based on proximity to CBD or other area of focus rather than on characteristic distinctions of the jurisdictional subdivisions. Thus, 
zones at approximately equal distance from the center of focus tend to be assigned uniform attributes with the assumption that county distinctions are either nonexistent or negligible. The research will address this issue by considering county differences in infrastructure levels, land attributes, network densities, accessibility conditions, and income characteristics. Parameters will be estimated for the SMSA and the respective counties accordingly. The sets of parameter estimates will be compared to test the possible existence of as many estimates as there are councy distinctions in the SMSA. Finally, the relative influences of the attributes on the differential rates of fringe area residential development and land conversion will be estimated. 


\section{CHAPTER III}

\section{METHODOLOGY}

A major point made in the previous chapter is that the current trend in urban growth is basically a dichotomous situation of a deconcentrating center and growing suburbs. Sternlieb's (1971) description of this dichotomy is that the central city has now become a sandbox (dumping ground) for the disadvantaged poor, minorities and elderly, and also an elitist service center for higher order activities (such as administration, banking, law and justice, etc.) that cannot easily deconcentrate. Muller (1976) also notes that the city used to be "...the economic center, a romanticized fantasy, the font of civility and graciousness, (and a) heart-warming center for social critics", but it is no longer the only economic center, and in addition, it is now the dreaded reality of decay. As a result the suburbs have become the fastest growing areas. But their growth is also being checked through the demarcation of different forms of growth ceilings [e.g., exclusionary zoning (Reed, 1982), urban growth boundaries, etc.].

In the past the major instruments of growth containment in the Portland SMSA have been zoning regulations. More recently, a UGB for year -2000 was proposed by METRO and 
approved by the cities and jurisdictions through LCDC. Clark County also has a similar growth boundary and throughout the SMSA, zoning regulations are enforced as growth subcontrols. But as mentioned previously, zoning laws may be a deterrent in some areas whereas in cthers they may lead to overcrowding. Where the laws are exclusionary (i.e., exclusive of particular economic classes of people such as the poor, the elderly, and minorities), the necessity of a growth ceiling has been found to be reduced, but the very purpose for which one is formed would have been defeated. On the contrary, however, less exclusionary (more permissive) zoning may lead not only to land depletion for some uses, but also to a number of congestion-related problems.

Thus, regarding the fact that the process of suburbanization is a relatively recent phenomenon, many questions relating to the interrelationships between the different types of controls and the physical attributes available to subareas are yet to be answered. In this regard, the methodological approach adopted in this dissertation focuses on the provision of some answers to the causes of the massive centrifugal movemert of population and residential housing to the fringe. The intent of this approach is to assess the physical subareal attributes which promote fringe area development, so as to provide decision-making bodies and planners with information for use in short- and longrange allocations and forecasts. 
STUDY DESIGN

The study area covers 83 census tracts in the Portland-Vancouver SMSA as designated in the 1970 decinnial census. These have a comparability of 106 census tracts in the 1980 census due to the subdivision of some tracts as a result of increased populations. These tracts represent approximately one-third of the total number of tracts contained in the SMSA, and their areal extent is approximately 35 percent of the SMSA total. Within the study area, sewer, water, fire, and other service districts are also included. In addition, all developable lands within the UGB's are covered by the study area.

In Multnomah County 35 census tracts are selected, 14 from Clackamas, 20 from Washington, and 24 from Clark County to make up the area of study. The 1980 equivalents are 37 , 19,27 , and 23 , respectively.

The housing data were acquired from building permit records collated by the assessors' offices of the constituent counties, and then cross-checked with the records from the State Housing Department as well as with the 1970 and 1980 census records. Additional land-use data were acquired from METRO, as well as the 32 cities involved in the study. Using the respective mean densities by census tract for single-family residences and apartment complexes, the total residential construction activity was computed and converted to acres of land converted to residential use. 
Thus, the total number of units and the total acres converted were used as measures of land conversion, i.e., the dependent variables in the study.

\section{HYPOTHESES}

The primary concern in using regression analysis is to establish beyond reasonable doubts whether a linear relationship exists between the predicted variable and the predictors. Stated in the null form, one makes the postulation that there is no Iinear association in incremental changes between these two categories of variables, i.e.:

$$
B_{1}=B_{2}=B_{3}=\ldots=B_{n-1}=B_{n}=0
$$

where $B_{1}, B_{2} \ldots B_{n}$ represent changes in the respective dependent variables for a corresponding unit change in the predictor variables holding the others constant or controlling for their effects. To verify the existence of these slopes and the statistically significant levels (or chance) of their occurence, either the $F$ - or $T$-tests may be applied along with other tests. 4 Thus, this general concern forms the major hypothetical postulation of this study.

In a more detailed form, however, specific directional relationships between the dependent variables and major pre-

4 The F-value is basically the square of the $T$-value at $(1+K)$ and $K$ degrees of freedom, respectively (Norusis, $1982)$. 
dictors need be expounded. In this regard, the dependent variable (change in residential land conversion), is evaluated against five major categories of independent variables. These are infrastructure, local circulation conditions, accessibility, land characteristics and what has been called socio-economic factors. The research uses public facilities of water and sewer as representative measures of infrastructure with the expectation that these would have a positive influence on residential growth, both with respect to their absolute coverages at the start of the decade and their relative changes in the duration of the study period. Circulation conditions, operationalized in terms of arterial road density, are also treated similarly with the exception that an additional level will be included, i.e., relative changes expected in the near future that create speculation effects in the minds of developers.

The accessibility variables may have either positive or negative correlation with land development depending on how they are measured. In classical land economics (Wingo, 1961; Richardson, 1977), accessibility maintains a positive slope from center to periphery but a negative correlation with absolute land development using the total urban space. However, in a study area (defined by a semiconcentric band around the high-density nucleus) where incremental land development is used with an increasing rate of conversion from the area near the center outwards to the periphery, 
measuring accessibility in relation to the CBD would result not only in a positive slope but also to a positive association with the dependent variable. Thus, the distance function would of necessity be expected to maintain a positive correlation with land development in this case. An additional rationale is that the CBD tracts are excluded from the stuây, and only relative attributes (increase in residential land consumption) rather than the absolute total residential development that has taken place in the tracts are used to symbolize the growth.

With respect to the land characterictics, places with better scenic condition are expected to attract more development, just as well as the fact that the availability of suitable land is a necessary precondition for the gravitation of residential development to a particular locality. However, even where it is available, a high cost per unit area of land may be an inhibiting factor to growth.

Finally, changes in the social and economic conditions of families and households in the suburbs are viewed as important predictors of the growth of the suburbs especially since the suburban population is characterized more by the social condition of family households that are stable and have home ownership interests than the center city, renteroriented population comprising mostly of "unrelated individuals" living together. 
OPERATIONALIZATION OF THE PROBLEM

The conceptual framework of the research is based on the following general functional relationship:

$$
D=E(I, N, A, L, S)
$$

The right side of tinis relationship is represented by the independent variables at time periods $t-1$ (1970), st (19701980), and $t+1$ (1980-1990). The measurements for the last two periods are expected tc be acquired for those variables which do not present extremely difficult problems of measurement. The letters $I, N, A, L$, and $S$ represent infrastructure, local network and circulation, accessibility, land characteristics, and socio-economic conditions, respectively, while D stands for starts or conversion. Infrastructure, network and some socio-economic variables can be reasonably measured for the periods $s t$ and $t+1$. The first two of these will be measured for the period 1970-1980 (i.e., the change conditions) in addition to the 1970 values, while the third will be measured for all three periods. In addition, in order to capture the concept of local circulation, network measures are done for a group of tracts each time and the values assigned to the surrounded tract. Thus, with these few modifications, for a particular area $i$, the conceptual equation becomes: 


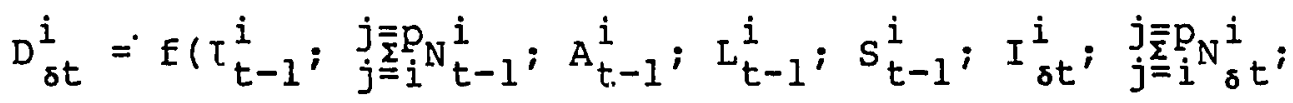

$$
\begin{aligned}
& \left.s_{\delta t}^{i} ; j_{j=i}^{j}=\mathrm{p}_{t+1}^{i}\right) \text {. }
\end{aligned}
$$

where $i$ represents tracts or other subunits, $j$ represents the subset of tracts abutting tract $i$ and including $i$ itself, with $p$ representing the maximum number of tracts in the subset.

This general equation will be used in the regression analysis for the whole suburban region in the composite model. Further, a modified form of it will be employed for subperiods of about 3-year durations to derive submodels. The assumption here is that development could be influenced by the lag conditions of some variables, and that influence becomes patent only after some period of time.

The final postulation is that of the differences between counties. In that regard, separate submodels will also be attempted for each county for each time period. Thus, in addition to the major model for the SMSA suburbs for the entire decade, a total of twelve submodels will be derived in regression equations.

\section{MEASUREMENT OF VARIABLES}

\section{Dependent Variables}

Development will be quantified by assessing the total number of residential units constructed for the entire 
decade from January 1, 1970, through December 31, 1979. The number of units constructed for the specific subperiods will also be tallied. As the density of construction would differ among the four counties (or even among census tracts of the same county), mean densities of single-family residences and apartment complexes will be used separately to derive the total acreages converted for the specific time periods in specific counties. Thus, both number of units and acres of land onverted will be used as dependent variables, respectively. However, there is every likelihood that a very high correlation might exist between the two.

Independent Variables

Five categories of factors are identified for which independent variables (or regressors) are measured:

Infrastructure. The primary public facilities of water and sewer services are measured to represent infrastructure. Mere areal coverage of these services is deemed as an inadequate approximator of their relative influences on subareal differences in residential growth. Therefore, for these channeled services, the total holding capacity of the census tract for residential housing is included in computing four variables, two for each service. These were: (1) the area serviced at the initial time of the study (1970 for the decade model, and 1971, 1974, and 1977, respective1y, for the 3-year periodic submodels) expressed as a percentage of the total amount of land within the census tract 
that is suitable for conversion to residential uses including built-up area; and (2) the percentage change in the area serviced $(1970-1980,1970-1973,1974-1976$, and 19771979, respectively) over each initial period.

Network Density and Local Circulation. This was operationalized by multiplying the number of major arterials by the number of lanes per arterial and summing up these values for each tract and all others contiguous to that tract. Three distinct measures (1970, 1970-1980, 1980-1990) are computed and used as three variables. The second measure is intended to capture variations as a result of streetwidening projects as well as the construction of new ones during the decade, such as parts of the I-205 freeway. The future network variable is computed from regional transportation plan designations for future widenings, extensions, and new constructions.

Accessibility. Since the automobile has been the most influential mode on suburbanization, auto access is used as the key element of accessibility to both the CBD and other minor employment centers in the suburb. In this regard, the variables used for accessibility are distance in road miles from the center of the tract to the CBD, travel time in minutes, and travel time from the center of the tract to the major employment center nearest the tract.

Land Characteristics. Land characteristics are represented by the soil condition (soil physical characteris- 
tics), the residual and unconstrained land, and the aesthetic condition of the census tract. From inferences made in earlier studies, variations in soil characteristics appear to have been one of the determinants of differences in the rate of land conversion, especially between areas on the east and west sides of the willamette River, at least in the 1960 's. But the difficulty of measuring soil conditions is manifested by the fact that soil characteristics exhibit a considerable degree of variation both at the intracounty and intercounty levels. Aside from the classificatory differences, the soils have been surveyed in the past within separate time periods, and in one case (clark county), the most recent data available was a survey conducted in the 1960's. Nevertheless, a soil condition variable is constructed using classifications of soil characteristics for dwellings obtained from the soil survey manuals of the four counties. 5 Basically three characteristics are identified: wetness, slope, and shear strength. Wetness describes the permeability of the soil, percolation, and soil moisture retention capasity. Slope refers to the general inclination of the tract of land in question. The general tolerance level in the Portland SMSA is approximately 25-30 percent

${ }^{5}$ United States Department of Agriculture, Soil Conservation Service, (1) Soil Survey of Clark County, Washington, 1972 , (2) Soil Survey of Washington County, Oregon, 1982; (3) Soil Survey of Clackamas County, Oregon, (in print), and (4) Soil Survey of Multnomah County, Oregon, (in print). 
(around 25 degrees). Shear strength measures the compressibility and shrink-swell potential of the soil. 6

since there are also possible combinations of the above three conditions, this variable is measured using a scale of one to seven as defined on Table III.

The limitations of these soil conditions to the construction of residential housing are expected to vary with

TABLE III

RATINGS OF SELECTED SOIL CLASSIFICATIONS FOR SUITABILITY FOR RESIDENTIAL

DEVELOPMENT

\begin{tabular}{lccc}
\hline & Slight & Moderate & Severe \\
\hline Wetness only & 1 & 8 & 15 \\
Wet, slopy & 2 & 9 & 16 \\
Wet, weak strength & 3 & 10 & 17 \\
Slope only & 4 & 11 & 18 \\
Slope, weak strength & 5 & 12 & 19 \\
Weak strength only & 6 & 13 & 20 \\
Wet, slopy, weak strength & 7 & 14 & 21 \\
\hline
\end{tabular}

Sources of data: Soil Survey Manuals (see footnote no. 5).

6 Additional conditions are presented in the survey manuals. The above three are chosen because of their frequency and general representativeness in the study area. For instance, a considerable amount of land, especially in Multnomah County, is described simply as urban, because the top 60 inches (top soil) used for soil analysis has been disturbed through prior construction activities. 
the intensity of the particular condition in question, i.e., a slight, natural limitation may be posed by a tract that is wet, slopy and weak, whereas a slopy tract may pose severe limitations which can only be overcome through the adoption of design and planning measures that will require additional financial investment in construction costs. As a result, three levels of the measurement scale are derived, with 1 to 7 representing slight occurrence of these limitations, 8 to 14 representing moderate limitations, and 15 to 21 representing severe limitations, resulting in 21 different ordinal measures of soil characteristics used in the analysis.

Residual and unconstrained land is defined as vacant land (acres) that is within 25 percent $(22.5$ degrees) of slope with no imminent risk of flooding hazards, i.e., outside the 100-year probability flood zone.

The scenic or aesthetic condition is operationalized in terms of the height (feet above sea level) of the maximum point of elevation within the tract.

Socio-Economic Conditions. Under this category are the variables of household size, mean land values per acre, median family income, change in household income, and employment. Household size (H) was computed from the formula:

$$
\mathrm{H}=\frac{\mathrm{P}_{\mathrm{t}}-\mathrm{P}_{\mathrm{g}}}{\mathrm{UR}}
$$


where $\mathrm{P}_{t}=$ the population of the census tract, $\mathrm{P}_{\mathrm{g}}=$ group population in the census tract, $U=$ the total number of dwelling units in the tract, and $R=$ the mean occupancy rate in the tract. The rationale underlying this method of computation of household size is the consideration to isolate the effects of group population (defined as institutionalized people in prisons, hospitals, old peoples' homes, etc.). In addition, the cushion effects of vacancy rates would also have been accounted for.

Land values in thousands of dollars obtained for 1970 are used in the study. The median income of families is expressed as a percentage of the metropolitan median, while for household income, the change from 1970 to 1980 is expressed as a percentage of the 1970 value.

Employment is measured a little differently. Since the sizes of the tracts vary in terms of population and area, it becomes necessary to relate employment to the resident population within the tracts. Thus, the number of jobs in the tract in 1970 per 1,000 people resident in the tract is used as the measure of employment.

On the whole, a total of eighteen independent variables are included for preliminary screening from which the significant and noncolinear ones will be selected for statistical analysis. 


\section{ANALYTIC TECHNIQUES}

The analysis section of the research consists of two parts. The first part (Chapter IV) is a qualitative analysis that sets the stage for the statistical analysis and model building. A detailed look at population growth in the city of Portland since 1900, and the SMSA since 1960 is taken. The growth trends are studied in order to discern some inferences on suburban development in this SMSA, isolated in a predominantly rural landscape. The preliminary analysis focuses especially on the period 1920-1970, which has been described in current literature as one of moderate suburbanization. The rest of Chapter IV is dedicated to the provision of background information on the disparities in the physical and socio-economic conditions in the county portions comprising of the study area. It is expected that from this evaluation a general set of characteristics typifying the suburban population will be derived. Although that derivation will not form the crux of the test of the postulations, it will provide useful insight in evaluating the relationships estimated in the model.

The second part of the analysis (undertaken in Chapter V) consists of detailed regression modeling of the data. The stepwise option is adopted because, as the literature review attests, the different techniques applied elsewhere found many variables to be relevant. It is, therefore, difficult to isolate any of them for rejection. As a 
cautious approach, the data is allowed to speak for itself through the stepwise alternative in order to systematically eliminate the relatively less signficant variables, based on statistical criteria.

After the derivation of the general format of the decade model, the same format is adopted in the county models as well as the recursive submodels. Tests are conducted to establish differences that abound between models of the counties and time periods. The chapter concludes with a general resume of the major results of the analysis and a commentary on the results. 


\section{CHAPTER IV}

\section{A RETROSPECTIVE ANALYSIS OF THE GROWTH OF PORTLAND AND THE SMSA}

As the central city of the Portland-Vancouver SMSA, Portland is the largest city in the state of oregon. It is surrounded by a number of smaller cities, some of which have fused into the urban nucleus, e.g., the cities of Beaverton [Population: $30,582(1980$ Census)], Oregon City $(14,673)$, and Vancouver $(42,834)$. The suburban area is comprised of the communities of Gresham $(33,005)$, Fairview $(1,749)$, Troutdale $(5,908)$, and Wood Village $(2,253)$ in east Multnomah County; Lake Oswego $(22,868)$, West Linn $(12,956)$, Gladstone $(9,500)$, and Happy Valley $(1,599)$ in Clackamas County; Tigard $(14,286)$, Sherwood $(2,386)$, Tualatin $(7,348)$, Hillsboro $(27,664)$, Forest Grove $(11,499)$, and Cornelius $(4,462)$ in Washington County; Camas $(5,861)$ and Washougal $(3,833)$ in clark County. Unincorporated areas in the fringe area also account for a considerable amount of population. For example, the eastern portion of Multnomah County between the I-205 freeway and the city of Gresham contains approximately 170,000 people. Upon incorporation (a possibility that is indicated by the preliminary hearings currently in pro- 
gress), this area would become the second largest city in the state.

\section{COMPARATIVE GROWTH ANALYSIS}

The growth of the city of Portland has been directly influenced by its location at the confluence of the willamette and Columbia Rivers as well as by the abrupt rise of the West Hills (Iycan, et al., 1978). The urbanized area of Portland including the suburban cities and some of the immediate surrounding unincorporated areas has also grown fairly rapidly, ranking portland as the twenty-eighth of twenty-nine supercities in the U.S. according to the 1980 Census, with a mean density of 4,688 people per square mile and a spatial coverage of 230 square miles (Long and DeAre, 1983). The growth of the SMSA on the other hand, has been dictated by that of the central city. In order to acquire a thorough understanding of the growth process of the suburbs and the SMSA, it is necessary to review the population changes along with the census classifications that have taken place as noted in past census enumerations and compare them over time.

The term "incorporated places" appeared first in census literature during the 12 th census in 1900 . The city of Portland had then doubled its population since the last census to 90,426 people, out of a state total of 672,765 . In 1910, two new concepts were acknowledged and introduced 
in the census enumeration procedure. The first was that it was acknowledged for the first time that city boundaries merely approximated the total number of people forming the respective city complex, so that many other people in the neighboring "suburbs" needed to be included in the population of big cities. Secondly, for the first time, 25 "metropolitan districts" were identified on the basis of the attainment of a population of 200,000 or more people in 1910. Portland was the twenty-fifth of these with 215,048 people, of which 7,834 were classified as resident outside the city proper (suburban). Further, an additional 52,531 people were accounted to reside within the adjacent territory defined as areas within a radius of ten miles of the city of Portland.

In 1950, the terms "urbanized area" and "urban fringe" appeared in the census dictionary. "Urbanized area" was used to mean "...an area with at least one city with 50,000 or more people in 1940...(in addition to) the surrounding closely settled incorporated places and unincorporated areas...." "Urban Eringe" meant the area immediately abutting the demarcated urbanized area.

This sequence of historical events based on urban settlement patterns has led to the unofficial recognition of 1920 as an important benchmark for suburban growth studies. Since 1920, centril cities have grown only moderately as compared to the preceding 30-year period. Between 1900 and 
1920 Portland's population almost tripled, whereas since 1920, the population increase has fluctuated between 40 and 50 percent (Table IV).

TABLE IV

GROWTH TREND OF THE

CITY OE PORTLAND

\begin{tabular}{ccc}
\hline Year & $\begin{array}{l}\text { City of } \\
\text { Portland }\end{array}$ & $\begin{array}{c}\text { \& Growth } \\
1920=100\end{array}$ \\
\hline 1920 & 258,288 & 100.0 \\
1930 & 301,815 & 116.9 \\
1940 & 305,394 & 118.2 \\
1950 & 373,628 & 144.7 \\
1960 & 372,676 & 144.3 \\
1970 & 382,619 & 148.1 \\
1980 & 366,383 & 141.9 \\
\hline
\end{tabular}

Source of data: Census Bureau.

The current size of portland had been largely attained by 1950. Between 1950 and 1960, there was a marginal loss in population of approximately 0.5 percent of 1920 equivalent. This loss was probably indicative of a national trend of an intensifying centrifugal movement of urban populations, concomitant with the elaborate freeway construction, in response to center city congestion pressure. Congestion, 
an earlier cause of freeway construction, has also been recently proving to be an effect of the last condition.

The decade 1960-1970 represented a period in which Portland gained a record increase in population over the 1950 level. But the ensuing decade, 1970-1980, has seen another significant dip below the 1950 level. In contrast, the metropolitan region has realized a sizeable increase, growing by 51 percent since 1960 (Table V).

\section{RESIDUAL RESIDENTIAL LAND}

The continued growth of the portland SMSA can be attributed to the change conditions in the suburbs. The suburbs have been attracting rural populations as well as central city dwellers. Table VI relates the relative distributions of the population by county along with the

TABLE V

GROWTH OF THE PORTLAND-VANCOUVER

METROPOLITAN AREA SINCE 1960

\begin{tabular}{lrc}
\hline Year & $\begin{array}{c}\text { Portland- } \\
\text { Vancouver }\end{array}$ & $\begin{array}{c}\text { of Over } \\
1960\end{array}$ \\
\hline 1960 & 822,000 & -22.8 \\
1970 & $1,009,129$ & 51.2 \\
\hline
\end{tabular}

Source of data: Census Bureau. 
TABLE VI

POPULATION AND LAND AREA OF

STUDY AREA AND SMSA

BY COUNTY

\begin{tabular}{|c|c|c|c|c|c|c|c|c|}
\hline \multirow{3}{*}{ County } & \multirow{3}{*}{$\begin{array}{l}\text { Land Area } \\
\text { County }\end{array}$} & \multirow{3}{*}{$\frac{(\text { Acres ) * }}{\text { S.A. }}$} & \multicolumn{6}{|c|}{ P O P U L A T I O N ${ }^{+}$} \\
\hline & & & \multicolumn{2}{|c|}{1970} & \multicolumn{2}{|c|}{1980} & \multicolumn{2}{|c|}{ \& Increase } \\
\hline & & & County & S.A. & County & S.A. & County & S.A. \\
\hline Clack. & $1,209,160$ & 148,251 & 166,088 & 57,060 & 241,919 & 96,827 & 45.7 & 69.0 \\
\hline Mult. & 249,900 & 61,560 & 556,667 & 140,984 & 562,640 & 153,797 & 1.1 & 9.1 \\
\hline Wash. & 459,590 & 214,539 & 157,920 & 86,152 & 245,808 & 147,850 & 55.7 & 71.6 \\
\hline Clark & 425,905 & 149,255 & 128,454 & 71,311 & 912,227 & 120,373 & 49.7 & 68.8 \\
\hline SMSA & $2,344,555$ & 573,605 & $1,009,129$ & 355,507 & $1,242,594$ & 518,846 & 23.1 & 46.0 \\
\hline
\end{tabular}

S.A. represents "study area".

Sources of Data: * Metropolitan Service District (METRO).

Census Bureau. 
respective land areas. Multnomah County has the largest population (over half a inillion people), while clackamas county has the largest land area (over 1.2 million acres). In the last decade, the growth rate of Multnomah is recorded to be less than the cumulative percentage natural increase for the decade. Clackamas and clark Counties, on the other hand, had half as many more people in 1980 as they did in 1970. Washington county has been the fastest growing with approximately 56 percent more people added to the 1970 population within the decade.

The growth rate of the study area population has generally been higher than that of the individual counties (Table VI). Washington, Clackamas, and Clark County suburbs had pouplation increases of between 69 and 72 percent. Even though Multnomah County as a whole grew by only 1.1 percent, the suburban portion grew by 9.1 percent. In absolute terms, this results in an increase of approximately 6,000 people more than the total county increase, implying a greater loss of population from the central city component. In contrast, about 52 percent of the population increase in Clackamas County and over 70 percent in each of Washington and Clark Counties occured in the suburbs. The result is that the urban nucleus (including the central city) and the rural areas of the SMSA accommodated a meager 30 percent of the total population growth. With the central city and the 
metropolitan county dwindling in size, the suburbs thus had a tremendous growth in the last ten years.

From estimates made by CRAG (1971) and the constituent jurisdictions, approximately 113,000 acres of land were vacant and zoned for residential use in 1970 (Table VII). This compares with METRO's (1979) estimate of approximately 63,147 acres of unconstrained land within the UGB (1978) in the three oregon courities. Of this, Washington County's share was approximately 46 percent, Clackamas, 25 percent, and Multnomah, 31 percent. A relatively high proportion of vacant land is attributed to Multnomah County. This is due to the fact that being the urban county, all vacant parcels are included, except for the portion that lies east of the Sandy River and in census tract 71 including Sauvie Island and the Burlington area. Clackamas County, on the other hand, is the largest county in the SMSA. It is larger than the rest of the counties combined (Table VI). The bulk of its land reserve, however, is dedicated to rural and public uses (Mount Hood National Forest). Thus, only a small proportion of the county is represented in the UGB, while Washington county has a reasonable amount of vacant land within the UGB.

\section{CHANGES IN SERVICES}

In Clackamas and Washington Counties, the additional land area approximated to be sewer-serviced since 1970 was 
TABLE VII

LAND CONVERTED TO RESIDENTIAL USE AND NUMBER OF UNITS CONSTRUCTED BETWEEN 1970 AND 1980

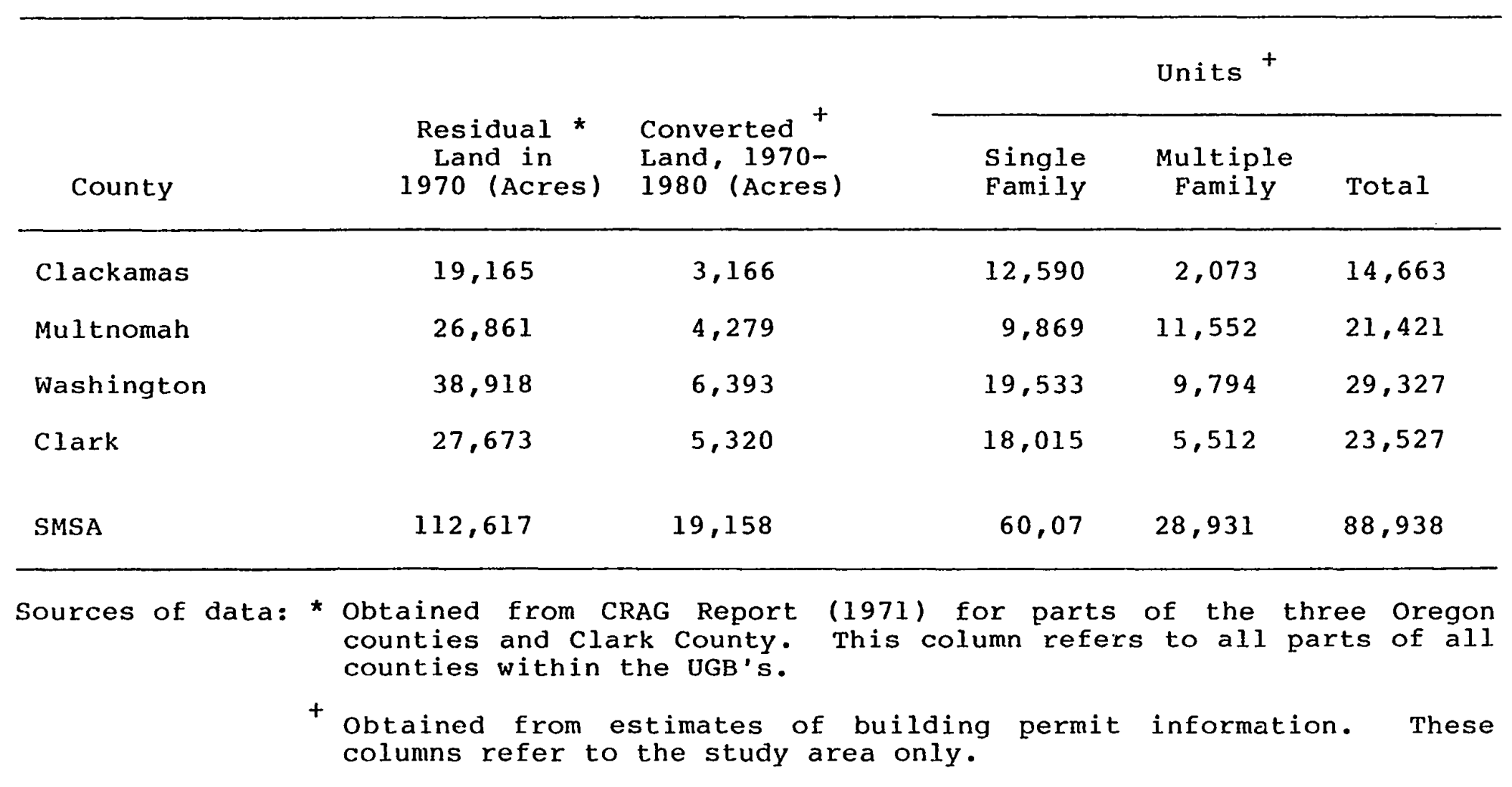


larger than the additional area serviced by water (Table VIII). Some explanations for this apparent discrepancy are that a number of areas that had water in 1970 had only septic tanks and cesspools. When sewers became available and more easily affordable, the septic tanks and cesspools were eventually dismantled and replaced by the sewers. Aside from that, more new land was serviced by both water and sewer in the Washington County suburbs during the decade than in those of any other county. Clark county had the second largest water-serviced area, while clackamas county service districts combined to provide the second largest sewered area (Figure 3 ).

TABLE VIII

CHANGES IN WATER AND SEWER COVERAGES

BETWEEN 1970 AND 1980

\begin{tabular}{ccc}
\hline County & $\begin{array}{c}\text { Water } \\
\text { (Acres) }\end{array}$ & $\begin{array}{c}\text { sewer } \\
\text { (Acres) }\end{array}$ \\
\hline Clackamas & 3,014 & 4,882 \\
Multnomah & 3,240 & 2,629 \\
Washington & 5,881 & 8,513 \\
Clark & 4,726 & 3,416 \\
\hline
\end{tabular}

Source of data: Computed from maps and records of public facilities at METRO. 


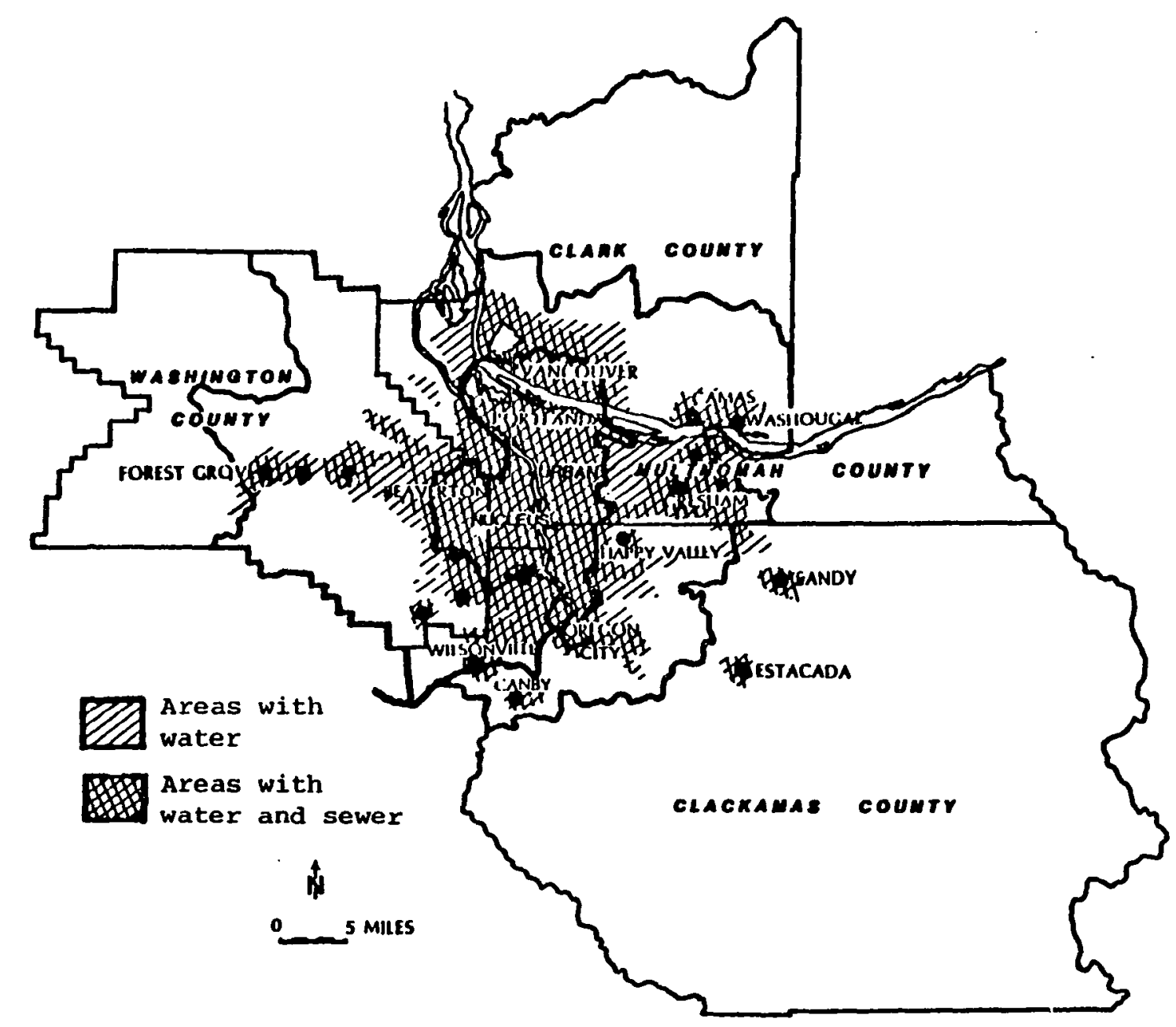

Figure 3. Areas covered by water and sewer services in 1979. Note that areas with only water also have septic tanks and/or cess-pools. 
Table IX shows estimated land values in 1970. Land in the near-east Multnomah County area (i.e., east of I-205 but west of the sandy River) was approximately three times as expensive as in the Washington and Clackamas County suburbs, and over four times more expensive than in the suburbs across the Columbia River in Clark County.

TABLE IX

ESTIMATED LAND VALUES IN

SUBURBS IN 1970

\begin{tabular}{lc}
\hline County & $\begin{array}{c}\text { Land Value Per } \\
\text { Acre (Dollars) }\end{array}$ \\
\hline Clackamas & 2,730 \\
Multnomah & 8,980 \\
Washington & 2,930 \\
Clark & 1,570 \\
\hline
\end{tabular}

Source of data: Computed from selected samples of plots for each census tract identified from assessors' jackets.

A few points are noteworthy; first, these differences are based on assessors' estimates, and as such, errors are bound to be introduced and may be magnified as well. Second, the rates of increase in land values have not been proportionately additive over the 10-year period. Nevertheless, estimates do favor Clark as the county with by far the cheapest residential land in the entire metropolitan area. 
NETWORK IMPROVEMENT AND CONGESTION

During the early part of the decade, suburban Multnomah County had a population density of 2.29 persons per acre while the remainder of the counties each had less than 0.50 (Table $\mathrm{X}$ ). But the density increases in these other coun-

TABLE X

SUBURBAN ROAD NETWORK DENSITY AND

RELATIVE DEGREES OF

CONGESTION

\begin{tabular}{|c|c|c|c|c|c|}
\hline Period & Condition & Clack. & Mult. & Wash. & Clark \\
\hline \multirow[t]{4}{*}{1970} & Population Density & 0.38 & 2.29 & 0.40 & 0.48 \\
\hline & Network Density (R) & 41.60 & 54.10 & 48.10 & 26.60 \\
\hline & Network Density (A) & 16.00 & 123.80 & 19.30 & 12.70 \\
\hline & L.P.A. $\left(x 10^{-6}\right)$ & 0.28 & 0.88 & 0.22 & 0.22 \\
\hline \multirow{4}{*}{$\begin{array}{l}\text { Change } \\
(1970- \\
1980)\end{array}$} & Population Density & 0.27 & 0.21 & 0.29 & 0.33 \\
\hline & Network Density (R) & 3.50 & 237.40 & 26.00 & 25.60 \\
\hline & Network Density (A) & 9.50 & 49.40 & 7.50 & 8.40 \\
\hline & L.P.A. $\left(x 10^{-6}\right)$ & 0.24 & 3.86 & 0.12 & 0.17 \\
\hline \multirow[t]{4}{*}{1980} & Population Density & 0.65 & 2.51 & 0.69 & 0.81 \\
\hline & Network Density $(R)$ & 39.10 & 69.30 & 38.90 & 26.10 \\
\hline & Network Density (A) & 25.50 & 173.20 & 26.80 & $21 \cdot 10$ \\
\hline & $L \cdot P \cdot A \cdot\left(x 10^{-6}\right)$ & 0.26 & 1.13 & 0.18 & 0.18 \\
\hline
\end{tabular}

(R) represents lane-miles per 1,000 residents and (A) lanemiles per 1,000 acres. L.P.A. means lane-miles per person per acre. 
ties during the intercensal period have been greater than Multnomah's. Clark County (with the highest increase) has a current density of 0.81 , while Washington and Clackamas have 0.69 and 0.65 , respectively. Multnomah still maintains the highest at about 2.51 people per acre.

With regard to the density of street arterials (computed in lane-miles), Multnomah county indexes (in terms of network density per resident person per acre of suburban territory) have consistently been greater than the sum of all the other counties. The current densities in Multnomah County are significantly higher than 1970 levels, whereas in each of the other counties, the current density per resident is even lower than in 1970, due to the fact that their populations have outgrown the road development schemes (especially in washington County). Thus, in terms of congestion (i.e., lane-miles per person per acre), only clark and Multnomah Counties have better current conditions than in 1970, due to relatively high road improvements in clark County and population loss in Multnomah County, respective1y. Washington and Clackamas Counties currently measure up slightly worse than 1970 congestion levels, with more population increases than the corresponding developments.

Assuming that traffic in the suburbs of the constituent counties flows at comparative levels, the index of lane-miles per person per acre reflects the relative levels of accessibility in these subareas. Thus, the high indices 
of Multnomah County may be expected to figure prominently in the modeling process as important contributing factors to the explanation of residential development (or lack thereof) in the Multnomah County suburbs.

\section{CHANGES IN SOCIO-ECONOMIC CONDITIONS}

At the beginning of the decade, approximately 35 percent of all metropolitan families and 31 percent of the houesholds resided in the suburbs. By the end of the decade, the corresponding figures had risen to 45.6 percent and 44.4 percent, respectively. All other factors being equal (such as increase in population), this indicates a significant shift of population to the suburbs. Washington and Clark Counties figure as the major recipients, which in 1970 had only slightly more than half of their populations residing in the suburbs. In 1980, the corresponding figures were both higher than 60 percent (Table XI). To the contrary, Multnomah County had only 25 percent of its 1970 residents and 33 percent of the 1980 population in the suburbs. Clackamas County had the comparative figures of 33 and 40 percent, respectively.

Multnomah County families had lower income increases than the SMSA average over that of 1970. In addition to the fact that all counties doubled their 1970 median levels, Washington and Clackamas counties had the most dramatic increases. 
TABLE XI

PROPORTION OF HOUSEHOLDS AND FAMILIES RESIDING IN STUDY AREA

IN 1970 AND 1980

\begin{tabular}{|c|c|c|c|c|c|c|c|}
\hline Year & Area & Group* & Clack. & Mult. & Wash. & Clärk & SMSA \\
\hline \multirow[t]{3}{*}{1970} & county & $\begin{array}{l}\text { HH } \\
\text { FM }\end{array}$ & $\begin{array}{l}54,145 \\
43,484\end{array}$ & $\begin{array}{l}219,619 \\
142,910\end{array}$ & $\begin{array}{l}52,530 \\
41,470\end{array}$ & $\begin{array}{l}42,426 \\
33,689\end{array}$ & $\begin{array}{l}368,710 \\
261,553\end{array}$ \\
\hline & Study Area & $\begin{array}{l}\mathrm{HH} \\
\mathrm{FM}\end{array}$ & $\begin{array}{l}17,742 \\
14,633\end{array}$ & $\begin{array}{l}43,974 \\
36,089\end{array}$ & $\begin{array}{l}28,201 \\
22,218\end{array}$ & $\begin{array}{l}22,810 \\
18,769\end{array}$ & $\begin{array}{r}112,727 \\
91,709\end{array}$ \\
\hline & 8 of county & $\begin{array}{l}\text { HH } \\
\text { FM }\end{array}$ & $\begin{array}{l}32.7 \\
33.7\end{array}$ & $\begin{array}{l}20 \cdot 0 \\
25 \cdot 3\end{array}$ & $\begin{array}{l}53.7 \\
53.6\end{array}$ & $\begin{array}{l}53.8 \\
55.7\end{array}$ & $\begin{array}{l}30.6 \\
35.1\end{array}$ \\
\hline \multirow[t]{3}{*}{1980} & County & $\begin{array}{l}\mathrm{HH} \\
\mathrm{FM}\end{array}$ & $\begin{array}{l}84,698 \\
65,880\end{array}$ & $\begin{array}{l}233,135 \\
141,719\end{array}$ & $\begin{array}{l}90,930 \\
65,568\end{array}$ & $\begin{array}{l}68,750 \\
51,390\end{array}$ & $\begin{array}{l}477,513 \\
324,557\end{array}$ \\
\hline & Study Area & $\begin{array}{l}\mathrm{HH} \\
\mathrm{FM}\end{array}$ & $\begin{array}{l}32,285 \\
26,671\end{array}$ & $\begin{array}{l}63,835 \\
46,138\end{array}$ & $\begin{array}{l}55,654 \\
42,641\end{array}$ & $\begin{array}{l}40,926 \\
32,694\end{array}$ & $\begin{array}{l}192,700 \\
148,144\end{array}$ \\
\hline & $z$ of County & $\begin{array}{l}\mathrm{HH} \\
\mathrm{FM}\end{array}$ & $\begin{array}{l}38.1 \\
40.5\end{array}$ & $\begin{array}{l}27.7 \\
32.6\end{array}$ & $\begin{array}{l}61.2 \\
64.8\end{array}$ & $\begin{array}{l}59.5 \\
63.6\end{array}$ & $\begin{array}{l}40.0 \\
45.6\end{array}$ \\
\hline
\end{tabular}

* HH represents households and FM families.

Sources of data: METRO and Center for Population Research and Census. 
Median household income also doubled in all counties with Clackamas and Washington Counties exhibiting 19 and 16 percent, respectively, above the average increase of the SMSA median (Table XII).

In addition to the median incomes, the mean incomes for families and households also portray a reasonable basis for comparing improvements in the economic conditions of the individual counties as well as comparing the suburbs with the rest of the SMSA. In 1970, with the exception of

TABLE XII

MEDIAN INCOME OF FAMILIES AND HOUSEHOLDS

IN DOLLARS BY COUNTY

\begin{tabular}{lrrrrrr} 
& \multicolumn{3}{c}{ Families } & \multicolumn{3}{c}{ Households * } \\
\cline { 2 - 7 } County & 1970 & 1980 & $8^{+}$ & 1970 & 1980 & q $^{+}$ \\
\hline Clack. & 10,680 & 23,572 & 123.2 & 9,409 & 21,177 & 140.2 \\
Mult. & 10,138 & 20,464 & 98.7 & 7,527 & 16,082 & 102.1 \\
Wash. & 11,476 & 24,820 & 127.5 & 10,083 & 21,575 & 137.2 \\
Clark & 10,195 & 21,484 & 107.9 & 8,947 & 18,959 & 119.5 \\
SMSA & 10,463 & 22,102 & 111.2 & 8,378 & 18,540 & 121.3 \\
\hline
\end{tabular}

* Defined as families and unrelated individuals.

+ Represents the percentage increase over the 1970 SMSA median.

Sources of Data: METRO and Center for Population Research and Census, P.S.U. 
Washington County, all the suburban areas of the other counties had higher average family and household incomes than their corresponding county averages (Table XIII).

The mean family and household incomes of the suburbs of Washington and, to a less extent, clackamas were much lower than expected. It could be reasonably argued that the

TABLE XIII

A COMPARISON BETWEEN STUDY AREA AND COUNTY AREA MEAN FAMILY AND HOUSEHOLD INCOMES IN 1970 AND 1980

\begin{tabular}{|c|c|c|c|c|c|}
\hline \multirow[b]{2}{*}{ county } & \multirow[b]{2}{*}{ Group } & \multicolumn{2}{|c|}{1970} & \multicolumn{2}{|c|}{1980} \\
\hline & & county & $\begin{array}{l}\text { Study } \\
\text { Area }\end{array}$ & county & $\begin{array}{l}\text { Study } \\
\text { Area }\end{array}$ \\
\hline \multirow[t]{2}{*}{ Clackamas } & $\mathrm{HH}$ & 10,459 & 11,184 & 23,644 & 26,845 \\
\hline & EM & 11,964 & 12,675 & 27,030 & 22,871 \\
\hline \multirow[t]{2}{*}{ Multnomah } & $\mathrm{HH}$ & 8,948 & 10,501 & 19,335 & 21,781 \\
\hline & FM & 11,582 & 11,788 & 23,308 & 23,416 \\
\hline \multirow[t]{2}{*}{ Washington } & $\mathrm{HH}$ & 11,183 & 10,243 & 24,041 & 24,654 \\
\hline & FM & 12,939 & 11,953 & 27,965 & 20,692 \\
\hline \multirow[t]{2}{*}{ Clark } & $\mathrm{HH}$ & 9,725 & 10,680 & 20,998 & 23,306 \\
\hline & FM & 11,136 & 11,541 & 23,406 & 26,369 \\
\hline \multirow[t]{2}{*}{ SMSA } & $\mathrm{HH}$ & 9,578 & 10,580 & 21,235 & 23,783 \\
\hline & EM & 11,803 & 11,913 & 25,257 & 23,186 \\
\hline
\end{tabular}

Sources of data: METRO and Center for Population Research and Census. 
exclusion of a great deal of areas such as part of the city of Lake Oswego on the north side of the lake, and the cedar Mills, Cedar Hills, and Hillsdale areas in Washington County, may have contributed to the lowering of the mean incomes of the suburan areas of the two counties in question. These excluded areas are reputed to be among the highest income areas of the SMSA. In addition, they exhibit suburban characteristics akin to those found elsewhere in the region.

The income relationships outlined on Table XIII do not take into consideration the effects of inflation, and thereby the real value of the 1980 figures may be exaggerated. Table XIV presents similar information on family incomes adjusted to 1967 dollars to control for the effects of inflation. Further, the information is broken down into income groups in order to discern which groups cluster at the fringe. The results show that metropolitan area earning families became poorer in the last decade. Only the highest income earners $(\$ 25,000$ and over) were better off, increasing slightly in proportion during the decade. In general, there was a significant shift of especially middle income earners to the low income groups.

With respect to the Eringe area, the proportion of families earning less than $\$ 7,000$ in both 1970 and 1980 was lower than the metropolitan average. High income earners were proportionally fewer in the fringe area in 1970 but 
TABLE XIV

PERCENTAGE DISTRIBUTION OF FAMILIES IN STUDY AND COUNTY AREAS BY INCOME LEVEL IN 1970 AND $1980^{*}$

\begin{tabular}{|c|c|c|c|c|c|c|c|c|c|c|c|c|c|}
\hline \multirow[b]{2}{*}{ County } & \multirow[b]{2}{*}{ Area } & \multicolumn{2}{|c|}{$\begin{array}{l}\text { Less than } \\
\$ 7,000\end{array}$} & \multicolumn{2}{|c|}{$\begin{array}{l}\$ 7,000- \\
\$ 9,999\end{array}$} & \multicolumn{2}{|c|}{$\begin{array}{l}\$ 10,000- \\
\$ 14,999\end{array}$} & \multicolumn{2}{|c|}{$\begin{array}{l}\$ 15,000- \\
\$ 24,999\end{array}$} & \multicolumn{2}{|c|}{$\begin{array}{c}\$ 25,000 \\
\text { And Above }\end{array}$} & \multicolumn{2}{|c|}{ TOTAL } \\
\hline & & 1970 & 1980 & 1970 & 1980 & 1970 & 1980 & 1970 & 1980 & 1970 & 1980 & 1970 & 1980 \\
\hline clack. & $\begin{array}{l}\text { Total } \\
\text { S.A. }\end{array}$ & $\begin{array}{l}3.9 \\
2.9\end{array}$ & $\begin{array}{l}5.5 \\
3.5\end{array}$ & $\begin{array}{l}3.6 \\
2.7\end{array}$ & $\begin{array}{l}4.5 \\
3.7\end{array}$ & $\begin{array}{l}5.3 \\
6.2\end{array}$ & $\begin{array}{l}6.3 \\
6.0\end{array}$ & $\begin{array}{l}3.1 \\
2.6\end{array}$ & $\begin{array}{l}3.0 \\
3.1\end{array}$ & $\begin{array}{l}0.9 \\
1.5\end{array}$ & $\begin{array}{l}1.5 \\
1.6\end{array}$ & $\begin{array}{l}16.8 \\
15.9\end{array}$ & $\begin{array}{l}20.9 \\
17.9\end{array}$ \\
\hline Mult. & $\begin{array}{l}\text { Total } \\
\text { S.A. }\end{array}$ & $\begin{array}{r}15.1 \\
8.5\end{array}$ & $\begin{array}{r}12.7 \\
8.5\end{array}$ & $\begin{array}{r}11.6 \\
8.5\end{array}$ & $\begin{array}{r}10.5 \\
7.4\end{array}$ & $\begin{array}{l}16.4 \\
12.4\end{array}$ & $\begin{array}{r}11.9 \\
9.7\end{array}$ & $\begin{array}{l}8.9 \\
8.9\end{array}$ & $\begin{array}{l}4.6 \\
3.6\end{array}$ & $\begin{array}{l}3.1 \\
1.5\end{array}$ & $\begin{array}{l}2.3 \\
1.7\end{array}$ & $\begin{array}{l}55.1 \\
39.8\end{array}$ & $\begin{array}{l}42.0 \\
30.0\end{array}$ \\
\hline Wash. & $\begin{array}{l}\text { Total } \\
\text { S.A. }\end{array}$ & $\begin{array}{l}3.0 \\
5.3\end{array}$ & $\begin{array}{l}5.0 \\
6.2\end{array}$ & $\begin{array}{l}3.0 \\
5.2\end{array}$ & $\begin{array}{l}4.3 \\
6.2\end{array}$ & $\begin{array}{l}4.8 \\
8.5\end{array}$ & $\begin{array}{l}6.6 \\
9.5\end{array}$ & $\begin{array}{l}3.2 \\
4.1\end{array}$ & $\begin{array}{l}3.2 \\
4.4\end{array}$ & $\begin{array}{l}0.8 \\
1.0\end{array}$ & $\begin{array}{l}1.7 \\
2.1\end{array}$ & $\begin{array}{l}14.8 \\
24.1\end{array}$ & $\begin{array}{l}20.8 \\
28.4\end{array}$ \\
\hline Clark & $\begin{array}{l}\text { Total } \\
\text { S.A. }\end{array}$ & $\begin{array}{l}3 \cdot 3 \\
4.0\end{array}$ & $\begin{array}{l}5.1 \\
5.7\end{array}$ & $\begin{array}{l}3.0 \\
4.3\end{array}$ & $\begin{array}{l}3.9 \\
5.8\end{array}$ & $\begin{array}{l}4.2 \\
7.0\end{array}$ & $\begin{array}{l}4.8 \\
7.6\end{array}$ & $\begin{array}{l}2.1 \\
3.8\end{array}$ & $\begin{array}{l}2.8 \\
2.8\end{array}$ & $\begin{array}{l}0.7 \\
1.1\end{array}$ & $\begin{array}{l}0.7 \\
0.9\end{array}$ & $\begin{array}{l}13 \cdot 3 \\
20.2\end{array}$ & $\begin{array}{l}16.3 \\
22.8\end{array}$ \\
\hline SMSA & $\begin{array}{l}\text { Total } \\
\text { S.A. }\end{array}$ & $\begin{array}{l}25.3 \\
20.7\end{array}$ & $\begin{array}{l}28.3 \\
23.9\end{array}$ & $\begin{array}{l}21 \cdot 2 \\
20.7\end{array}$ & $\begin{array}{l}23.2 \\
23.1\end{array}$ & $\begin{array}{l}30.7 \\
34.1\end{array}$ & $\begin{array}{l}29.6 \\
32.8\end{array}$ & $\begin{array}{l}17.3 \\
19.4\end{array}$ & $\begin{array}{l}12.6 \\
13.9\end{array}$ & $\begin{array}{l}5.5 \\
5.1\end{array}$ & $\begin{array}{l}6.2 \\
6.3\end{array}$ & $\begin{array}{l}100.0 \\
100.0\end{array}$ & $\begin{array}{l}100.0 \\
100.0\end{array}$ \\
\hline
\end{tabular}

* All values deflated to 1967 dollars. S.A. represents study area.

Sources of data: METRO and Center for Population Research and Census. 
increased over the decade to slightly more than the SMSA proportion. The middle income groups (between $\$ 10,000$ and $\$ 25,000)$ were proportionally higher in the fringe area in both periods. Considering the reduction in the total middle income earners in the region, this represents a clustering of this group at the fringe (Neiman, 1980).

In general, in terms of socio-economic conditions, the fringe area has had improvements during the decade. With respect to the counties, Washington County has seemingly had the most attractive changes followed by Clark and Clackamas Counties. Multnomah County has more or less consistently exhibited a losing trend in many respects in the intercensal period.

\section{RESIDENTIAL LAND CONVERSION IN SUBURBS}

As referenced earlier (Table VI) Multnomah County population increased by 1.1 percent, Clackamas by 45.7 percent, Clark by 49.7 percent, and Washington by 55.7 percent, respectively. The SMSA as a whole had an increase of 23.1 percent.

Within the study area, approximately 19,000 acres of land were converted to residential use during the decade 1970 to 1980 . An estimate of 88,938 residential units were constructed on that acreage with over two-thirds $(60,007$ units) being single family and detached (including relatively few mobile homes). The remainder, 28,931 units, was 
comprised of a variety of duplexes, triplexes, and mostly higher order multiple-unit apartment complexes. Washington County alone accounted for 30 percent of the total construction as well as acreage converted. Twothirds of that proportion were single-family residences constructed at an average annual race of approximately 2,000 units. Clark County, which had previously maintained a relatively less dramatic increase in residential construction activity, accounted for 25 percent of the total metropolitan construction, mostly in single-family units. In contrast, 20 percent of the construction occured in Multnomah county, and two-thirds of that figure comprised of multiple-family units, whereas in clackamas county, singlefamily construction amounted to four-fifths of the county total. 


\section{CHAPTER V}

DATA ANALYSIS AND RESULTS

The discourse of the last chapter centered on the argument that from a retrospective analysis the suburbs of Washington and Clark Counties provided more congenial attributes of growth attraction during the decade of the 1970's than their counterparts. Consequently, their populations grew more than the other counties, with an equally greater share of the residential development. Clackamas County grew only moderately while Multnomah County showed a declining tendency.

The current chapter explores the argument further by subjecting the data to detailed statistical analysis utilizing regression modeling techniques to assess the significance of the relative influences of the regressors on the regional pattern of residential growth and land conversion in the suburbs. The analysis involves a series of models and submodels that are area (county level) and time specific. The latter approach adapts the equations to 3-year intervals in a recursive manner, based on the premise that current rate of development depends, to some degree, on the trend of events in the anteceding period. In addition, models are derived for the entire decade for the region and 
for each of the subareas. Further, statistical tests are subsequently applied to the derived models and submodels to ascertain their consistency or variation over the jurisdictions.

\section{GENERAL FORMAT OF EQUATIONS OF THE MODELS}

At the regional level (SMSA), the following four regression equations are employed:

$$
\begin{aligned}
R_{d}= & a_{d 0}+b_{d 1} x_{d 1}+b_{d 2} x_{d 2}+\ldots \ldots+b_{d n} x_{d n}{ }^{7}+E_{d} \\
R_{1}= & a_{10}+b_{11} x_{11}+b_{12} x_{12}+\ldots \ldots+b_{1 n} x_{1 n}+E_{1} \\
R_{2}= & a_{20}+b_{r 1} R_{1}+\left(b_{21} x_{11}+b_{22} x_{12}+\ldots \ldots\right. \\
& \left.+b_{2 n} x_{1 n}\right)+E_{2} \\
R_{3}= & a_{30}+b_{r 2} R_{1}+b_{r 3} R_{2}+\left(b_{31} x_{21}+b_{32} x_{22}+\right. \\
& \left.\ldots \ldots+b_{3 n} x_{2 n}\right)+E_{3}
\end{aligned}
$$

where $R_{d}, R_{1}, R_{2}$, and $R_{3}$

are the dependent variables for the decade model (d) and the three respective recursive submodels for 1971-1973, 1974-1976, and $1977-1979$.

$$
a_{d 0}, a_{10}, a_{20} \text {, and } a_{30} \begin{aligned}
& \text { are the respective } \\
& \text { intercepts for the four } \\
& \text { models. }
\end{aligned}
$$

$b_{d 1}, b_{d 2}, \ldots b_{d n}$ are the respective coefficients of the independent variables specifying the decade model.

${ }^{7}$ Note that although the $X$ 's are numbered consecutively from 1 to $n$, their representations include variables measured for the time periods $t-1, \delta t$, and $t+1$ as previously discussed. 


$$
\begin{aligned}
& b_{11}, b_{12}, \ldots b_{1 n} \\
& b_{r 1}, b_{21}, \ldots b_{2 n} \\
& b_{r 2}, b_{r 3}, b_{31}, \ldots b_{3 n}
\end{aligned}
$$$$
x_{d 1}, x_{d 2}, \ldots x_{d n}
$$$$
x_{11}, x_{12}, \ldots x_{1 n}
$$$$
x_{21}, x_{22}, \ldots x_{2 n}
$$$$
E_{d}, E_{1}, E_{2} \text {, and } E_{3}
$$

are the coefficients of the independent variables of the first subperiodic model.

are the coefficients of the independent variables of the second recursive subperiodic model.

are the coefficients of the independent variables of the final recursive subperiodic model.

are the specified independent variables for the decade model.

\begin{abstract}
are the independent variables measured for the first time period but also used as lag variables in the ensuing period.

are the independent variables measured in the second period and used as lag variables in the final period.
\end{abstract}

are the terms for the measurement errors associated with each model.

The first equation represents the primary model for the decade and for all the counties pooled together. Equations 2, 3, and 4 are also regional in scope and recursive for the time periods 1971-1973, 1974-1976, and 1977-1979. The equations are lagged such that equation 4 includes the dependent variables of equations 2 and 3 in addition to the independent variables measured for the second time period. Similarly equation 3 includes the dependent variable of 
equation 2 and the independent variables in equation 2 as independent variables. A modified form of these equations is used for each county separately to capture the spatial differences.

Depending on the results of the screening procedure, either residential units or acres of land converted to residential use will represent the dependent variable. If the association between these variables is such as many warrant the use of both of them as separate dependent variables, then that procedure will be adopted in the analysis in order not to lose pertinent explanatory information. In that regard, two separate equations will represent each of the four equations above. Further, the submodels for each of the counties will also be regressed against these two separate dependent variables.

\section{SCREENING OF THE VARIABLES}

The number of units constructed in each tract and the corresponding residential acreage showed over 80 percent association. However, there were marked differences with regard to their relationships with some of the important predictors. Thus, it appears that the use of either as the sole dependent variable may not obviate the utility of the other. As a result both variables were utilized.

The screening of the independent variables involved a number of transformations and combinations. The variables 
representing water and sewer services (and their separate transformations) showed associations of 0.9 or better in a consistent manner at the regional level. For the pooled (SMSA) equations, therefore, it was necessary to either drop the weaker of the two, or derive an appropriate combination of them into a composite variable. The latter option was pursued by multiplying the respective proportions of the total suitable residential land in the tract (including built-up land) that are covered by these services. The change conditions of these variables were computed in like manner. Thus, where the services overlap, their combined effect was approximated by two times the index of measurement. This implies that the interpretation of the coefficient is that half its value represents one unit effect on development.

The variables used to denote accessibility to the CBD showed high negative correlations with land values. In agreement with Wingo's (1961) postulations, there appears to be a reasonable measure of substitutive association between these two groups of predictors. Distance to the CBD and its squared function are expected to capture the effects of CBD access. But as land values also change with distance to subcenters (Corsi, 1974), there is need to capture the effects of subcentral access separately. However, in the screening process, this variable by itself and its interaction with $C B D$ access were consistently insignificant in 
terms of predictive power. The ratio of the two variables showed moderate significance, and so it was used to capture the effects of access to subcenters. The rationale is that since distance to $C B D$ and its square are both utilized, the effects of CBD access would have been accounted for as much as possible, and whatever explanatory influence accessibility ratio might exhibit would be attributed to variations in subcentral access. The ratio thus implies that for the same distance from the CBD, as distance to a subcenter increases, the index becomes smaller and vice versa. In terms of interpreting the coefficient, a positive value denotes increased development closer to subcenters and a negative value signifies increased construction activity away from subcenters. Since variation in this index is a function of county location, the outcome of this variable is expected to have more noticeable effects in the county submodels than the regional models.

The soil characteristics variable was ineffective by itself, when transformed, or when combined with others such as suitable land. The original measures were, however, included with a few nonlinear transformations but they all dropped out of the step-wise analysis.

The residual and suitable land originally accounted for high ( 34 percent) variability in the dependent variables. This large proportion of explanatory power of land supply may be within expected limits. However, it was 
deemed equaliy necessary to isolate the effects of less powerful explanatory variables, especially if there is little variation in the influence of land supply on the differential rates of conversion among the counties or subperiods. The squared values and the natural logarithms were even less useful in solving the problem, changing the $\mathrm{R}^{2}$ by 3 and -2 percent, respectively, without any corresponding improvement in the relative proportions of the contributions of the other independent variables. In other words, it appears that a strong linear relationship is being weakened through the transformation process.

Two more independent variables were added in order to capture the effects of (1) areas with water and no channeled sewer services but with septic tanks and cesspools at the initial time of the study period, and (2) changes in those areas through the respective time intervals. The rationale here is that users of septic tanks would construct homes as long as water is available (even from a well source) albeit at lower densities. In addition, there might be a buffer effect created by the watered but unsewered area and the change therein on residential land conversion.

The original definition of "family income" was modified (from median family income of the tract as a percentage of the metropolitan median) to the absolute value of the tract median. In addition, household income was dropped because of the high association between the two. The rest 
of the variabies (distance, land value, local network, and household size) were used in the analysis as originally defined.

MODEL SPECIFICATION

The initial analytical task in the model building process is the determination of an appropriate and more uniform scale applicable to most of the variables with minimum bias exhibited in their effects. To achieve this, six combinations of scaled data for both the dependent and independent variables were tried. These were the absolute and logarithmic values of the dependent variables against the absolute, logarithmic, and mixed (some logged, others not) values of the regressors. The pooled data for all the counties over the entire decade were used as the basis for selecting the best scale based on:

1. The strength of the $R^{2}$;

2. The sensitivity of the coefficients in terms of the direction of the signs;

3. The non-existence of counter-intuitiveness; and

4. The statistical significance of the variables as well as that of the regression as a whole.

In the linear model (absolute values), comparison of $b$ coefficients is precluded by the fact that variables are measured in different units (scale effect). This is one reason why some researchers favor change in $\mathrm{R}^{2}$ in assessing 
the effects of the independent variables. In the logarithmic model, however, the transformation process provides a consistent measure across the variables. Thus, the elasticities can be directly compared and evaluated in terms cf their relative importance.

From the results of the transformations, the logarithmic values of both categories of variables emerged as the best combination. These were then adopted in all subsequent analyses. The general format of the equations then became:

$$
\begin{aligned}
& \log R_{i j}=\log a_{i j}+b_{1 i j} \log x_{1 i j}+b_{2 i j} \log x_{2 i j}+ \\
& \ldots \ldots+b_{n i j} \log _{n i j}+E_{i j} \\
& \text { where } R_{i j} \\
& \text { represents eicher of the de- } \\
& \text { pendent variables for location } \\
& i \text { and time period } j \text {. } \\
& a_{i j} \text { is the Y-intercept of the } \\
& E_{i j} \quad \text { is the error term for the }
\end{aligned}
$$$$
x_{l i j} \ldots x_{n i j} \text { are the specified independent }
$$$$
\text { time } j \text {. }
$$

The exception to the rule of logarithmic transformations are the distance variable (which is regressed in the linear form) and its squared function. The coefficients of 
the logarithms included denote elasticity effects of the variables on the predicted growth pattern. The elasticity of each independent variable depicts the magnitude of change in the dependent variable given a 1 percent change in that independent variable. For example, if the LAND variable has $a$ b coefficient of 0.22 , it means that for every 1 percent increase in the available suitable land, 0.22 percent increase in residential development is estimated.

The final list of the screened variables and their basic statistics for the decade measurements for all suburbs of the SMSA are shown on Table XV. The distributions of the majority of the variables appear to satisfy the condition of bivariate normality, i.e., the distribution of the $x_{i j}$ 's around the $Y_{i j}$ 's tend to be normal, and vice versa. The variables of family income, household size, and network, show a much tighter distribution around the mean than the rest, implying a tendency towards a leptokurtic distribution.

THE REGIONAL MODELS

The regional housing starts (U) model and the corresponding land development (A) model for the decade are each associated with a larger number of explanatory variables than all their corresponding periodic or areal submodels, except for those of the first subperiod. A total of nine variables define the conversion model, seven of which also 
TABLE XV

VARIABLES USED IN REGRESSION ANALYSIS AND THEIR BASIC PARAMETERS

\begin{tabular}{|c|c|c|c|}
\hline Variable & Definition & $\begin{array}{l}\text { Mean of } \\
\text { Logarithm }\end{array}$ & $\begin{array}{l}\text { Standard } \\
\text { Deviation }\end{array}$ \\
\hline $\mathrm{U}$ & $\begin{array}{l}\text { Number of new residental } \\
\text { units constructed }\end{array}$ & 2.72 & 0.69 \\
\hline A & $\begin{array}{l}\text { Number of equivalent acres } \\
\text { of land converted }\end{array}$ & 1.95 & 0.71 \\
\hline LAND & $\begin{array}{l}\text { Residual suitable and vacant } \\
\text { land in acres }\end{array}$ & 2.53 & 0.94 \\
\hline FINC & Median family income & 4.07 & 0.09 \\
\hline NET & $\begin{array}{l}\text { Number of lane-miles of } \\
\text { arterial street network }\end{array}$ & 2.24 & 0.21 \\
\hline CNET & Change in arterial network & 1.89 & 0.24 \\
\hline FNET & Planned arterial network & 1.25 & 0.29 \\
\hline ACSR & Accessibility ratio & 1.61 & 0.23 \\
\hline PINF & $\begin{array}{l}\text { Percentage of land with } \\
\text { infrastructure (water and } \\
\text { sewer) initially }\end{array}$ & 1.28 & 1.33 \\
\hline PCIN & $\begin{array}{l}\text { Percentage change in infra- } \\
\text { structure }\end{array}$ & 1.29 & 1.31 \\
\hline WNS & Area with water and no sewer & 2.28 & 0.75 \\
\hline CWNS & $\begin{array}{l}\text { Change in area with water and } \\
\text { no sewer }\end{array}$ & 0.11 & 0.43 \\
\hline LVL & Land value in dollars per acre & 3.55 & 0.49 \\
\hline HHS & Household size & 0.48 & 0.04 \\
\hline DIST * & Distance from $C B D$ in miles & 14.77 & 5.04 \\
\hline DIST2 * & Distance squared & 243.34 & 162.93 \\
\hline
\end{tabular}

* Absolute values. 
constitute the starts model. The rest of the submodels are comprised of combinations of fewer selections from the regional decade and first subperiodic models. In general, however, change in infrastructure, land value, change in network, family income, and the availability of suitable land supply appear to be the most important variables explaining the regional trend (Table XVI).

The signs of the coefficients are generally as expected. With the exception of planned network (FNET) and land value (LVL), all other variables have positive gradients. The. negative coefficient of the land value variable is consistent with theory, while that of FNET is perhaps due to the alignment of planned arterials alongside courses which avoid dense residential areas. Also, planned projects involving the widening and extension of existing arterials may be associated more with areas that have a predominantly nonresidential development than with residential areas.

The linear distance function shows positive correlation with residential development, unlike the case in general land-use theory. Land development theory, however, relates distance to total rather than incremental residential development. In the suburban ring, incremental development progresses from high to low density areas. There is, therefore, an equilibrating tendency whereby incremental development increases with distance from the built-up core to the outer suburbs, before tapering down asymtotically at 
TABLE XVI

REGRESSION EQUATIONS FOR HOUSING STARTS AND LAND CONVERSION IN ALL SUBURBS FOR THE PERIOD 1970-1980

\begin{tabular}{|c|c|c|c|c|c|c|c|c|c|c|c|c|}
\hline \multirow[b]{2}{*}{ Variables } & \multicolumn{2}{|c|}{$\bar{B}$} & \multicolumn{2}{|c|}{ Beta } & \multirow{2}{*}{$\begin{array}{cc}\mathrm{R} 2 & \mathrm{Cl} \\
\mathrm{U} & \end{array}$} & \multirow{2}{*}{$\frac{\text { hange }}{\mathrm{A}}$} & \multicolumn{2}{|c|}{ T-Value } & \multicolumn{2}{|c|}{ Sig. Level } & \multicolumn{2}{|c|}{ Step } \\
\hline & $\mathrm{U}^{\star}$ & $A^{*}$ & $\mathrm{U}$ & $\mathrm{A}$ & & & $\mathrm{U}$ & $\mathrm{A}$ & {$[\mathrm{]}$} & $\mathrm{A}$ & $\mathrm{U}$ & $\mathrm{A}$ \\
\hline PCIN & 0.16 & 0.10 & 0.30 & 0.18 & 0.27 & 0.05 & 3.94 & 2.59 & 0.00 & 0.01 & 1 & 4 \\
\hline CNET & 1.23 & 0.78 & 0.43 & 0.26 & 0.16 & 0.12 & 5.13 & 3.21 & 0.00 & 0.00 & 2 & 2 \\
\hline LAND & 0.24 & 0.20 & 0.32 & 0.27 & 0.10 & 0.06 & 4.20 & 3.42 & 0.00 & 0.00 & 3 & 6 \\
\hline FNET & -0.39 & -0.42 & -0.16 & -0.17 & 0.04 & 0.01 & -1.72 & -1.94 & 0.09 & 0.06 & 4 & 9 \\
\hline EINC & 1.95 & 2.71 & 0.26 & 0.35 & 0.03 & 0.08 & 3.41 & 4.88 & 0.00 & 0.00 & 5 & 3 \\
\hline DIST & 0.03 & 0.23 & 0.25 & 1.63 & 0.03 & 0.05 & 2.74 & 3.23 & 0.01 & 0.00 & 6 & 5 \\
\hline WNS & 0.14 & 0.20 & 0.15 & 0.22 & 0.02 & 0.03 & 2.00 & 3.00 & 0.05 & 0.00 & 7 & 7 \\
\hline LVI, & & -0.05 & & -0.03 & & 0.29 & & -0.32 & & 0.75 & & 1 \\
\hline DIST 2 & & -0.01 & & -1.21 & & 0.03 & & -2.51 & & 0.01 & & 8 \\
\hline $\begin{array}{l}\mathrm{a}_{2} \\
\mathrm{R}\end{array}$ & $\begin{array}{l}- \\
0.65 \\
19.3 *\end{array}$ & $\begin{array}{c}\overline{0} \\
21.72 \\
21 * \star\end{array}$ & & & & & & & & & & \\
\hline $\begin{array}{l}\text { U refers } \\
\text { sequent re } \\
\star \text { signific } \\
\star * \text { signifi }\end{array}$ & $\begin{array}{l}\text { o the } \\
\text { gressic } \\
\text { :ant at } \\
\text { cant at }\end{array}$ & $\begin{array}{l}\text { lousing } \\
\text { ou model } \\
0.05 \text { le } \\
0.051\end{array}$ & arts & model & A, & eco & sion & model, & this & and & & sub- \\
\hline
\end{tabular}


the rural countryside. If the tapering is gentle after a relatively low peak, the distance coefficient is likely to be negative. If the tapering is rapid with a high peak, even the squared function of distance might not capture this declination in terms of the sign of the coefficient. In the conversion model, however, the squared function of distance showed a low negative coefficient as expected. The values of -0.01 for the square of distance and 0.23 for distance translate to the relationship that the limit of the Portland fringe (as approximated from the conversion model) is a little over 20 miles from the CBD. Further, the peak of fringe area residential development is estimated to be at approximately 11.5 miles from the CBD.

The Residential Growth Model

Five variables are significant within 99 percent confidence limits in explaining housing starts (Table XVI). Of these, the percentage change in the levels of infrastructure between 1970 and 1980 account for over one-quarter (27 percent) of the variability in the pattern of housing development in the region as a whole, with an elasticity effect of 0.16. The interpretation of this is that half of the coefficient represents unit effect on residential development.

Change in network density and the available suitable land account for another 26 percent, while yet another 6 percent is contributed by family income and distance. Areas 
with water and septic tanks or cesspools (i.e., with no sewer) show a t-ratio significant at 0.05 level with a 2 percent contribution to the $R^{2}$. The final and least important variable in the starts model is the planned network with a t-ratio significant at the 0.09 level.

Variables measuring the effects of infrastructure (PCIN and WNS) have similar behaviors with respect to their elasticities $(0.16$ and 0.14 , respectively). Their magnitudes reflect a reasonable amcunt of sensitivity in influencing residential development. Their low levels reflect the way they were operationalized, but slight increments in their levels directly influence much larger respective increases in housing starts.

Network changes positively associate with development with a slightly more than proportional rate of change. Family income has similar positive association, and both these regressors have elasticities greater than one, with the latter being 1.95. These high elasticities give the indication that 1 percent increase in either of those variables effects more than $I$ percent corresponding increase in residential construction.

The significance levels of the t-ratios for network change, infrastructure change, and family income are high (0.001 or better) enough to establish a causal link with development. However, a rigid conclusion cannot be made from this model in support of the suggested direction of 
causality because (with reference to CNET. for instance), it is entirely possible that leapfrog development of some areas (such as around Beaverton) in the early 1970's may have resulted in congestion leading to a posteriori road improvements. On the other hand, the mushroom growth of other areas, such as Tigard, Tualatin, Wilsonville, and parts of northern Clackamas County around Harmony and Sunnyside Roads, is probably the result (rather than the cause) of a priori road improvements. The exact nature of this relationship could be better argued from the results of the recursive models.

The Residential Land Conversion Model

The land conversion model for all suburbs for the entire decade approximates the housing starts patterns with the exception of two additional variables, viz: land value and distance squared. A total of nine variables describe this model, of which seven have significant effects at the 0.01 level or better. The most important of these are change in network, family income, change in infrastructure, and distance, with a combined $R^{2}$ change of 0.30 out of a total of 0.72 . Land value alone explains nearly as much variance (0.29), had a negative elasticity, but exhibited a statistically insignificant t-ratio. Entered at the first step, land value had an initially significant t-ratio (0.0000), which fell after the entry of the land and distance variables, both of which have similar locational 
bearing. This implies that land value is also very impor- . tant. In addition, it varies inversely with the other two regressors and shares with them a common explanatory base. The square of distance also enhances this condition, except that it has a negative coefficient, implying a decline in the rate of development with distance.

The coefficients of both distance and FINC are significantly higher in the land conversion model than their corresponding values in the starts model. This shows that as distance increases more conversion activity occurs (probably because of the interaction between cheaper land and increasing parcel size at increasing distances outwards from the core-area). The intensity of this relationship depends on the rate of decline in land value outwards. The PCrN and CNET elasticities are lower in the conversion than in the starts case, meaning that increase in the size of land converted is less dependent on those variables (especially network change) than increase in housing starts is on them.

Submodels for Housing Starts and Land Conversion for the Subperiod 1971-1973

The general outcomes of the variables in the submodels for the subperiod 1971-1973 is similar to the pattern for the decade as a whole with the following differences: Available land suitable for residential development and the speculative influence of planned network improvements are not major considerations during this subperiod; (2) Accessi- 
bility ratio positively correlates with residential development, implying that there is a considerable clustering closer to major subcenters; and (3) The subareal differences in land value are more prominently related, especially with residential development.

Besides the above differences, considering the amount of total variance explained in each set of models/submodels, the infrastructure variables are even more dominant during this subperiod than they are in the decade models (Table XVII).

Recursive Submodels for Housing Starts and Land Conversion for the Subperiod 1974-1976

The variables defining the recursive submodels for the subperiod 1974-1976 are somewhat different except that land value is a common predictor in both submodels, accounting for 0.05 and $0.01 \mathrm{R}^{2}$ changes, respectively, in the starts and conversion submodels. As a matter of fact, land value influences show the most significant t-statistics in this period (Table XVIII).

In both submodels, construction activity and the equivalent land converted in the preceding subperiod account for much more of the variance than the rest of the variables in each submodel; approximately 58 percent (starts) and 78 percent (conversion), respectively. Changes in the infrastructure and network account for the remainder of the $R^{2}$ in starts, while suitable land and change in the unsewered but 


\section{TABLE XVII}

REGRESSION EQUATIONS FOR HOUSING STARTS AND LAND CONVERSION IN ALL SUBURBS FOR THE PERJ.OD 1971-1973

\begin{tabular}{|c|c|c|c|c|c|c|c|c|c|c|c|c|}
\hline \multirow[b]{2}{*}{ Variables } & \multicolumn{2}{|c|}{$\mathrm{B}$} & \multicolumn{2}{|c|}{ Beta } & \multicolumn{2}{|c|}{$\mathrm{R}^{2}$ Change } & \multicolumn{2}{|c|}{ T-Value } & \multicolumn{2}{|c|}{ Sig. Level } & \multicolumn{2}{|c|}{ step } \\
\hline & $\overline{\mathrm{U}}$ & $\mathrm{A}$ & $\mathbf{U}$ & $\mathrm{A}$ & $\mathbf{U}$ & $\mathrm{A}$ & $\mathrm{U}$ & $\mathrm{A}$ & $\mathrm{U}$ & $\mathrm{A}$ & $\mathrm{U}$ & A \\
\hline PCIN & 0.15 & 0.11 & 0.29 & 0.23 & 0.21 & 0.10 & 3.27 & 3.04 & 0.00 & 0.00 & 1 & 3 \\
\hline CNET & 0.97 & 0.34 & 0.34 & 0.13 & 0.11 & 0.01 & 3.17 & 1.74 & 0.00 & 0.08 & 2 & 8 \\
\hline LVL & -0.07 & -0.03 & -0.05 & -0.02 & 0.07 & 0.24 & -0.39 & -0.21 & 0.69 & 0.84 & 3 & 1 \\
\hline FINC & 2.31 & 2.33 & 0.31 & 0.35 & 0.05 & 0.08 & 3.35 & 4.48 & 0.00 & 0.00 & 4 & 5 \\
\hline FNET & -0.48 & & -0.20 & & 0.05 & & -1.82 & & 0.07 & & 5 & \\
\hline LAAND & 0.11 & 0.09 & 0.14 & 0.14 & 0.03 & 0.02 & 1.50 & 1.75 & 0.14 & 0.08 & 6 & 7 \\
\hline DIST & 0.05 & 0.21 & 0.36 & 1.66 & 0.02 & 0.05 & 2.60 & 2.72 & 0.01 & 0.01 & 7 & 4 \\
\hline WNS & 0.17 & 0.22 & 0.19 & 0.27 & 0.02 & 0.06 & 2.10 & 3.55 & 0.04 & 0.00 & 8 & 6 \\
\hline NET & 0.50 & 0.56 & 0.15 & 0.19 & 0.02 & 0.12 & 1.58 & 2.06 & 0.12 & 0.04 & 9 & 2 \\
\hline ACSR & & 0.52 & & 0.19 & & 0.01 & & 2.21 & & 0.03 & & 9 \\
\hline DIST 2 & & -0.01 & & -1.01 & & 0.01 & & -1.70 & & 0.09 & & 10 \\
\hline $\begin{array}{l}\mathrm{a}_{2} \\
\mathrm{R} \\
\mathrm{F}\end{array}$ & $\begin{array}{c}- \\
0.56 \\
10.2^{\star \star}\end{array}$ & $\begin{array}{l}- \\
0.70 \\
16.5^{* *}\end{array}$ & & & & & & & & & & \\
\hline
\end{tabular}




\section{TABLE XVIII}

RECURSIVE MODELS OF HOUSING STARTS AND LAND CONVERSION IN ALL SUBURBS FOR THE TIME PERIOD 1974-1976

\begin{tabular}{|c|c|c|c|c|c|c|c|c|c|c|c|c|}
\hline \multirow[b]{2}{*}{ Variables } & \multicolumn{2}{|r|}{ B } & \multicolumn{2}{|c|}{ Beta } & \multirow{2}{*}{$\frac{\mathrm{R}^{2} \mathrm{C}}{\mathrm{U}}$} & Change & \multicolumn{2}{|c|}{ T-Value } & \multirow{2}{*}{$\frac{\mathrm{sig} .}{\mathrm{U}}$} & \multirow{2}{*}{$\frac{\text { Level }}{\mathrm{A}}$} & \multicolumn{2}{|c|}{ Step } \\
\hline & $\mathrm{U}$ & $\mathrm{A}$ & $\bar{U}$ & $A$ & & $\bar{A}$ & $\mathbf{U}$ & $\mathrm{A}$ & & & $\mathrm{U}$ & $\mathrm{A}$ \\
\hline $\mathrm{u}_{71-73}$ & 0.58 & & 0.54 & & 0.58 & & 6.48 & & 0.00 & & 1 & \\
\hline LVL & -0.31 & -0.13 & -0.21 & -0.10 & 0.05 & 0.01 & -2.78 & -1.67 & 0.01 & 0.10 & 2 & 4 \\
\hline PCIN & 0.08 & & 0.18 & & 0.02 & & 2.30 & & 0.02 & & 3 & \\
\hline CNET & 0.37 & & 0.12 & & 0.01 & & 1.67 & & 0.10 & & 4 & \\
\hline$A_{71-73}$ & & 0.79 & & 0.77 & & 0.78 & & 12.83 & & 0.00 & & 1 \\
\hline LAND & & 0.08 & & 0.12 & & 0.02 & & 2.14 & & 0.04 & & 2 \\
\hline CWNS & & 0.07 & & 0.09 & & 0.01 & & 1.83 & & 0.07 & & 3 \\
\hline $\begin{array}{l}\mathrm{a}_{2} \\
\mathrm{~F}\end{array}$ & $\begin{array}{c}0.79 \\
0.66 \\
38.6^{*}\end{array}$ & $\begin{array}{c}0.26 \\
0.82 \\
83.0^{*} *\end{array}$ & & & & & & & & & & \\
\hline
\end{tabular}


watered area are the corresponding useful regressors with respect to land conversion.

The results in these submodels lend partial support to the causality hypothesis vis-a-vis change in infrastructure and land value on the one hand and residential development on the other.

Recursive Submodels for Housing Starts and Land Conversion for the Subperiod 1977-1979

The pattern of development during 1977-1979 is in some way similar to that of the period 1974-1976 (Table XIX). Residential development and land conversion activity during the earlier part of the decade (Table XVII) show barely marginal influences on the 1977-1979 pattern. However, those of the immediate anteceding subperiod, 1974-1976, are of prime importance in explaining the development of this subperiod. In addition to the impacts of developments in prior years, infrastructure variables (PCIN2, CWNS2, and PINF2) and network change are the only other explanatory variables in both submodels. The impact of these variables is relatively diminished due to the recursive nature of the submodels.

With the above results, two arguments could be made in support of the causality postulations made earlier. Eirst, residential growth and land conversion in the suburbs between 1970 and 1980 depend mainly on the levels of the available infrastructure and the changes therein. second, 
TABLE XIX

RECURSIVE MODELS OF HOUSING STARTS AND LAND CONVERSION IN ALL SUBURBS FOR THE TIME PERIOD 1977-1979

\begin{tabular}{|c|c|c|c|c|c|c|c|c|c|c|c|c|}
\hline \multirow[b]{2}{*}{ Variables } & \multicolumn{2}{|c|}{ B } & \multicolumn{2}{|c|}{ Beta } & \multirow{2}{*}{$\frac{\mathrm{R}^{2}}{\mathrm{U}}$} & \multirow{2}{*}{ Change } & \multicolumn{2}{|c|}{ T-Value } & \multirow{2}{*}{$\frac{\mathrm{sig} .}{\mathrm{U}}$} & \multirow{2}{*}{$\frac{\text { Level }}{\text { A }}$} & \multicolumn{2}{|c|}{ Step } \\
\hline & $\mathrm{U}$ & A & $\mathbf{U}$ & A & & & $\mathrm{U}$ & A & & & $\mathrm{U}$ & A \\
\hline $\mathrm{U}_{74-76}$ & 0.44 & & 0.53 & & 0.76 & & 8.19 & & 0.00 & & 1 & \\
\hline PCIN2 & 0.08 & & 0.20 & & 0.06 & & 3.88 & & 0.00 & & 2 & \\
\hline $\mathrm{U}_{71-73}$ & 0.25 & & 0.28 & & 0.03 & & 4.55 & & 0.00 & & 3 & \\
\hline FNET2 & 0.36 & 0.34 & 0.17 & 0.16 & 0.03 & 0.04 & 4.02 & 3.74 & 0.00 & 0.00 & 4 & 3 \\
\hline CWNS 2 & 0.11 & 0.11 & 0.08 & 0.08 & 0.01 & 0.01 & 1.92 & 1.90 & 0.06 & 0.06 & 5 & 5 \\
\hline$A_{74-76}$ & & 0.46 & & 0.49 & & 0.78 & & 6.20 & & 0.00 & & 1 \\
\hline$A_{71-73}$ & & 0.35 & & 0.36 & & 0.03 & & 4.73 & & 0.00 & & 2 \\
\hline PINF 2 & & 0.05 & & 0.13 & & 0.01 & & 2.67 & & 0.01 & & 4 \\
\hline $\begin{array}{l}\mathrm{a}_{2} \\
\mathrm{R}^{2} \\
\mathrm{~F}\end{array}$ & $\begin{array}{c}0.02 \\
0.89 \\
112.7 * \star\end{array}$ & $\begin{array}{c}-0.25 \\
0.87 \\
106.8^{\star} \star\end{array}$ & & & & & & & & & & \\
\hline
\end{tabular}


income of families, accessibility (network and distance variables), and land characteristics are influential in the early part of the decade, while during the second part of the decade, only the accessibility variables show causal influence in addition to infrastructure.

\section{MULTNOMAH COUNTY SUBMODELS}

As discussed in the previous chapter, Multnomah County as a whole had negligible growth during the decade in terms of increases in households and families. However, the proportion of county households and families residing in the study area increased from 20 and 25 percent, respectively, in 1970 to 27.7 and 32.6 percent in 1980. Assuming that there was little or no change in the composition of these social units during the intercensal period with regard to size, it follows that most of the intracounty movers as well as the few newcomers into the county preferred suburban locations, hence accounting for their growth.

The argument was also made that the suburbs of Multnomah County not only had the least increase in population, but also the largest increase in road network density (Table $x)$. The expectation is that the effect of network changes on residential growth would be more notable than those of other variables.

The significant variables explaining this pattern of growth are shown on Table $x x$. The striking difference be- 
TABLE XX

MULTNOMAH COUNTY SUBMODELS OF SUBURBAN RESIDENTIAL DEVELOPMENT AND LAND CONVERSION FOR THE DECADE 1970-1980

\begin{tabular}{|c|c|c|c|c|c|c|c|c|c|c|c|c|}
\hline \multirow[b]{2}{*}{ Variables } & \multicolumn{2}{|c|}{ B } & \multicolumn{2}{|c|}{ Beta } & \multirow{2}{*}{$\frac{\mathrm{R}^{2} \mathrm{C}}{\mathrm{U}}$} & \multirow{2}{*}{ A hange } & \multicolumn{2}{|c|}{ T-Value } & \multirow{2}{*}{$\frac{\text { Sig. }}{U}$} & \multirow{2}{*}{ Leve 1} & \multirow{2}{*}{\multicolumn{2}{|c|}{$\frac{\text { Step }}{\mathrm{UA}}$}} \\
\hline & $\mathrm{u}$ & $A$ & $\mathrm{U}$ & A & & & $U$ & A & & & & \\
\hline CNET & 2.07 & 1.07 & 0.72 & 0.38 & 0.46 & 0.05 & 6.3 & 3.3 & 0.00 & 0.00 & 1 & 6 \\
\hline LAND & 0.33 & 0.48 & 0.32 & 0.49 & 0.15 & 0.06 & 3.1 & 4.3 & 0.00 & 0.00 & 2 & 3 \\
\hline FNET & -0.64 & -1.10 & -0.22 & -0.39 & 0.04 & 0.05 & -2.0 & -4.1 & 0.06 & 0.00 & 3 & 5 \\
\hline FINC & 2.63 & 2.63 & 0.22 & 0.22 & 0.03 & 0.03 & 2.1 & 2.6 & 0.05 & 0.02 & 4 & 7 \\
\hline HHS & -3.36 & & -0.18 & & 0.02 & & -1.7 & & 0.11 & & 5 & \\
\hline DIST & & 0.38 & & 1.56 & & 0.50 & & 2.3 & & 0.03 & & 1 \\
\hline DIST2 & & -0.01 & & -1.13 & & 0.13 & & -1.7 & & 0.10 & & 2 \\
\hline LVL & & 0.89 & & 0.33 & & 0.03 & & 2.9 & & 0.01 & & 4 \\
\hline NET & & -0.87 & & -0.16 & & 0.01 & & -1.4 & & 0.19 & 8 & \\
\hline $\begin{array}{l}\mathrm{a}_{2} \\
\mathrm{R}^{2} \\
\mathrm{~F}\end{array}$ & $\begin{array}{c}\overline{0} .70 \\
13.6^{* *}\end{array}$ & $\begin{array}{l}-8.86 \\
19.3\end{array}$ & & & & & & & & & & \\
\hline
\end{tabular}


tween these models and those of the SMSA for the decade is that infrastructure plays no significant part in influencing either housing starts or land conversion in Multnomah County. On the contrary, the accessibility variables (CNET, FNET, NET, and DIST), land supply, and family income are the most important growth enhancing factors. Household size is a partial contributor to the $\mathrm{R}^{2}$ of the residential development model, with a negative coefficient and a low level of significance. Whereas the original network has a positive effect on the overall development of the region (Table XVII), in the Multnomah county case, it is negatively correlated with development, implying a reasonable amount of initial congestion. The future network change also has much higher negative significance while the network changes that occured during the decade show positive association. This means that the optimum level of network development for Multnomah County is not likely to be exceeded without having repellant effects on future suburban residential growth.

Developments occurring in the first subperiod reflect basically the same patterns of the county submodels for the decade (Table XXI). Accessibility variables are important especially in association with increasing parcel size, and the value of the land weakly relates to both types of development. Infrastructure has no influence, and family income elasticity (in the residential growth submodel) is much higher than the regional model's or the corresponding re- 
TABLE XXI

MULTNOMAH COUNTY SUBMODELS OF SURURBAN RESIDENTIAL GROWTH AND LAND CONVERSION FOR THE SUBPERIOD 1971-1973

\begin{tabular}{|c|c|c|c|c|c|c|c|c|c|c|c|c|}
\hline \multirow[b]{2}{*}{ Variables } & \multicolumn{2}{|c|}{$\mathrm{B}$} & \multicolumn{2}{|c|}{ Beta } & \multirow{2}{*}{$\frac{\mathrm{R}^{2} \mathrm{C}}{\mathrm{U}}$} & \multirow{2}{*}{ Change } & \multicolumn{2}{|c|}{ T-Value } & \multicolumn{2}{|c|}{ Sig. Level } & \multicolumn{2}{|c|}{ Step } \\
\hline & $\mathbf{U}$ & A & $\mathrm{U}$ & A & & & $\mathbf{U}$ & A & $\mathbf{U}$ & A & $\mathbf{U}$ & A \\
\hline CNET & 1.76 & 0.57 & 0.57 & 0.25 & 0.27 & 0.04 & 4.06 & 1.84 & 0.00 & 0.08 & 1 & 7 \\
\hline FNET & -1.27 & -0.81 & -0.41 & -0.35 & 0.14 & 0.05 & -2.78 & -2.79 & 0.01 & 0.01 & 2 & 6 \\
\hline FINC & 3.04 & 1.82 & 0.23 & 0.18 & 0.07 & 0.03 & 1.81 & 1.74 & 0.08 & 0.10 & 3 & 4 \\
\hline LAND & 0.40 & 0.33 & 0.37 & 0.40 & 0.05 & 0.05 & 2.26 & 2.78 & 0.03 & 0.01 & 4 & 3 \\
\hline LVL & 0.69 & 0.65 & 0.23 & 0.29 & 0.03 & 0.02 & 1.35 & 1.95 & 0.19 & 0.06 & 5 & 5 \\
\hline DIST & & 0.39 & & 1.92 & & 0.38 & & 2.09 & & 0.05 & & 1 \\
\hline DIST2 & & -0.01 & & -1.56 & & 0.16 & & -1.74 & & 0.09 & & 2 \\
\hline $\begin{array}{l}\mathrm{a}_{2} \\
\mathrm{R}\end{array}$ & $\begin{array}{l}0.56 \\
7.3^{* *}\end{array}$ & $\begin{array}{l}0.73 \\
10.4 * *\end{array}$ & & & & & & & & & & \\
\hline
\end{tabular}


gional subperiodic model, albeit with a weak t-ratio.

The pattern of the second period (Table XXII) shows that the smaller the original area with septic tanks was at the start of the period, the more development took place. However, as this area increases in size during the subperiod, more growth also occurs; as much as 8 percent of each

TABLE XXII

RECURSIVE SUBMODELS FOR MULTNOMAH COUNTY SUBURBS FOR THE SUBPERIOD 1974-1976

\begin{tabular}{|c|c|c|c|c|c|c|c|}
\hline \multirow[b]{2}{*}{ Parameter } & \multirow[b]{2}{*}{ Mode1 } & \multicolumn{6}{|c|}{$V A R I A B L E S$} \\
\hline & & $\mathrm{U}_{71-73}$ & DIST & CWNS & DIST2 & WNS & $A_{71-73}$ \\
\hline B & $\begin{array}{l}\text { U } \\
\mathrm{A}\end{array}$ & 0.17 & $\begin{array}{l}0.61 \\
0.11\end{array}$ & $\begin{array}{l}1.10 \\
0.71\end{array}$ & -0.02 & $\begin{array}{l}-0.55 \\
-0.33\end{array}$ & 0.35 \\
\hline Beta & $\begin{array}{l}\text { U } \\
\mathrm{A}\end{array}$ & 0.18 & $\begin{array}{l}2.35 \\
0.56\end{array}$ & $\begin{array}{l}0.60 \\
0.54\end{array}$ & -1.77 & $\begin{array}{l}-0.33 \\
-0.27\end{array}$ & 0.38 \\
\hline $\mathrm{R}^{2}$ Change & $\begin{array}{l}\text { U } \\
\mathrm{A}\end{array}$ & 0.42 & $\begin{array}{l}0.14 \\
0.09\end{array}$ & $\begin{array}{l}0.08 \\
0.08\end{array}$ & 0.04 & $\begin{array}{l}0.03 \\
0.02\end{array}$ & 0.64 \\
\hline T-Value & $\begin{array}{l}\text { U } \\
\text { A }\end{array}$ & 1.31 & $\begin{array}{l}2.61 \\
5.14\end{array}$ & $\begin{array}{l}2.90 \\
3.37\end{array}$ & -2.02 & $\begin{array}{l}-1.60 \\
-1.74\end{array}$ & 3.50 \\
\hline Sig. Level & $\begin{array}{l}\mathrm{U} \\
\mathrm{A}\end{array}$ & 0.20 & $\begin{array}{l}0.01 \\
0.00\end{array}$ & $\begin{array}{l}0.01 \\
0.00\end{array}$ & 0.05 & $\begin{array}{l}0.12 \\
0.05\end{array}$ & 0.00 \\
\hline Step & $\begin{array}{l}\mathrm{U} \\
\mathrm{A}\end{array}$ & 1 & $\begin{array}{l}2 \\
2\end{array}$ & $\begin{array}{l}3 \\
3\end{array}$ & 4 & $\begin{array}{l}5 \\
4\end{array}$ & 1 \\
\hline a & U & - & & & & & \\
\hline $\begin{array}{l}\mathrm{R}^{2} \\
\mathrm{E}\end{array}$ & $\begin{array}{l}\mathrm{a} \\
\mathrm{U} \\
\mathrm{A} \\
\mathrm{U} \\
\mathrm{A}\end{array}$ & $\begin{array}{c}\overline{0} \\
0.71 \\
0.82 \\
14.0^{\star \star} \\
34.4^{\star *}\end{array}$ & & & & & \\
\hline
\end{tabular}


of residential growth and land conversion activity can be attributed to this condition. With respect to their actual elasticities, the change condition shows slightly more than proportional coefficient to residential growth (1.10), while that of the original condition was much lower and negative.

Like the regional model, residential development in the succeeding subperiod (1977-1979) is very much dependent upon the nature and intensity of those in the second subperiod (Table XXIII), while that of 1971-1973 has little effect. Of notable difference is the fact that toward the end of the decade, infrastructure and planned network (FNET2) were major influencers of growth, especially the latter which has a positive coefficient. It is conceivable that the I-205 freeway (as well as other road improvements) may have played a vital role in this relationship.

In general, the pattern of suburban residential growth and land conversion in Multnomah county is somewhat different from that of the regional trend. The infrastructure variables which so prominently define the regional models are very ineffective in the Multnomah County case probably because in many instances it is a matter of their availability rather than effectiveness. However, PINF 2 managed to emerge as the second best variable in both recursive submodels for 1977-1979, and areas with septic tanks (i.e., areas with water and no sewer) show much higher relationship with growth in the middle part of the decade. Although 
TABLE XXIII

RECURSIVE SUBMODELS FOR MULTNOMAH COUNTY SUBURBS FOR THE SUBPERIOD 1977-1979

\begin{tabular}{|c|c|c|c|c|c|c|c|}
\hline \multirow[b]{2}{*}{ Parameter } & \multirow[b]{2}{*}{ Model } & \multicolumn{6}{|c|}{$V A R I A B I E S$} \\
\hline & & $U_{74-76}$ & PINF 2 & $\mathrm{U} 71-73$ & ENET2 & $A_{74-76}$ & CNET2 \\
\hline B & $\begin{array}{l}\mathrm{U} \\
\mathrm{A}\end{array}$ & 0.44 & $\begin{array}{l}0.10 \\
0.09\end{array}$ & 0.24 & 0.30 & 0.62 & 0.36 \\
\hline Beta & $\begin{array}{l}\mathrm{U} \\
\mathrm{A}\end{array}$ & 0.59 & $\begin{array}{l}0.17 \\
0.27\end{array}$ & 0.38 & 0.74 & 0.67 & 0.18 \\
\hline $\mathrm{R}^{2}$ Change & $\begin{array}{l}\mathrm{U} \\
\mathrm{A}\end{array}$ & 0.69 & $\begin{array}{l}0.08 \\
0.06\end{array}$ & 0.05 & 0.03 & 0.73 & 0.03 \\
\hline T-Value & $\begin{array}{l}\mathrm{U} \\
\mathrm{A}\end{array}$ & 5.93 & $\begin{array}{l}3.22 \\
3.22\end{array}$ & 3.37 & 2.30 & 7.27 & 2.10 \\
\hline Sig. Level & $\begin{array}{l}\mathrm{U} \\
\mathrm{A}\end{array}$ & 0.00 & $\begin{array}{l}0.00 \\
0.00\end{array}$ & 0.00 & 0.03 & 0.00 & 0.04 \\
\hline Step & $\begin{array}{l}\mathrm{U} \\
\mathrm{A}\end{array}$ & & $\begin{array}{l}2 \\
2\end{array}$ & 3 & 4 & 1 & 3 \\
\hline $\mathrm{R}^{2}$ & $\begin{array}{l}- \\
U \\
A \\
U \\
A \\
U \\
A\end{array}$ & $\begin{array}{r}-0.09 \\
-0.46 \\
0.85 \\
0.82 \\
41.4^{*} \\
45.0 * \star\end{array}$ & & & & & \\
\hline
\end{tabular}

these variables may be regarded to some extent as indirect measures of the effects of sewers on development, their negative influences in the second subperiod and the positive influence of PINF2 in the final subperiod strongly suggest that it was apparent (even as far back as the mid-1970's), that any substantial future growth in east Multnomah county 
would not satisfactorily depend on septic tanks and cesspools.

\section{WASHINGTON COUNTY SUBMODELS}

The equations for washington county constitute the best set of submodels with respect to spatial entities. All submodels have $R^{2}$ values ranging from 0.88 to 0.95 , with no more than five independent variables defining each submodel. The submodels for the decade and for the entire county are comprised of four independent variables (land conversion) and five variables (housing starts), respectively, (Table XXIV), with slightly different $R^{2}$ 's of 0.92 and 0.95 , of which 60 and 75 percent, respectively, are entirely due to the contribution of infrastructure. The corresponding elasticities are 0.27 and 0.29 , and these are among the lowest for all the descriptive variables.

Family income, the next important variable, is much less sensitive in growth prediction in washington county than in Multnomah County. Being the second best variable in each model, it makes significant contributions of 0.12 (starts) and 0.28 (conversion) to the $R^{2}$. The outcomes of two other variables, household size and distance, are also unlike those in Multnomah County. Household size has a positive coefficient, thus giving the impression of little or no effect due to population pressure in terms of density per dwelling unit. The distance coefficient is, however, 
TABLE XXIV

WASHINGTON COUNTY SUBMODELS OF SUBURBAN RESIDENTIAL DEVELOPMENT AND LAND CONVERSION

FOR THE DECADE 1970-1980

\begin{tabular}{|c|c|c|c|c|c|c|}
\hline \multirow[b]{2}{*}{ Parameter } & \multirow[b]{2}{*}{ Mode 1} & \multicolumn{5}{|c|}{$V A R I A B L E S$} \\
\hline & & PCIN & FINC & CWNS & HHS & DIST \\
\hline $\mathrm{B}$ & $\begin{array}{l}\mathrm{U} \\
\mathrm{A}\end{array}$ & $\begin{array}{l}0.29 \\
0.27\end{array}$ & $\begin{array}{l}0.98 \\
1.90\end{array}$ & $\begin{array}{l}0.14 \\
0.12\end{array}$ & $\begin{array}{l}2.04 \\
2.29\end{array}$ & -0.02 \\
\hline Beta & $\begin{array}{l}\mathrm{U} \\
\mathrm{A}\end{array}$ & $\begin{array}{l}0.88 \\
0.85\end{array}$ & $\begin{array}{l}0.30 \\
0.58\end{array}$ & $\begin{array}{l}0.19 \\
0.17\end{array}$ & $\begin{array}{l}0.19 \\
0.22\end{array}$ & -0.16 \\
\hline $\mathrm{R}^{2}$ Change & $\begin{array}{l}\mathrm{U} \\
\mathrm{A}\end{array}$ & $\begin{array}{l}0.78 \\
0.61\end{array}$ & $\begin{array}{l}0.12 \\
0.28\end{array}$ & $\begin{array}{l}0.02 \\
0.01\end{array}$ & $\begin{array}{l}0.02 \\
0.02\end{array}$ & 0.01 \\
\hline T-Value & $\begin{array}{l}\mathrm{U} \\
\mathrm{A}\end{array}$ & $\begin{array}{l}9.69 \\
8.56\end{array}$ & $\begin{array}{l}3.48 \\
7.60\end{array}$ & $\begin{array}{l}3.02 \\
2.17\end{array}$ & $\begin{array}{l}2.13 \\
2.01\end{array}$ & -1.72 \\
\hline Sig. Level & $\begin{array}{l}\mathrm{U} \\
\mathrm{A}\end{array}$ & $\begin{array}{l}0.00 \\
0.00\end{array}$ & $\begin{array}{l}0.00 \\
0.00\end{array}$ & $\begin{array}{l}0.01 \\
0.05\end{array}$ & $\begin{array}{l}0.05 \\
0.06\end{array}$ & 0.11 \\
\hline Step & $\begin{array}{l}\mathrm{U} \\
\mathrm{A}\end{array}$ & $\begin{array}{l}1 \\
1\end{array}$ & $\begin{array}{l}2 \\
2\end{array}$ & $\begin{array}{l}3 \\
3\end{array}$ & $\begin{array}{l}4 \\
4\end{array}$ & 5 \\
\hline $\begin{array}{l}a \\
R^{2} \\
F\end{array}$ & $\begin{array}{l}\mathrm{U} \\
\mathrm{A} \\
\mathrm{U} \\
\mathrm{A} \\
\mathrm{U} \\
\mathrm{A}\end{array}$ & $\begin{array}{l}- \\
- \\
0.95 \\
0.92 \\
53.5^{*} \\
44.8 * *\end{array}$ & & & & \\
\hline
\end{tabular}

negative--a sign relationship unique to only the Washington County models. Part of the reason for this is that although the Beaverton area is categorized as part of the urban nucleus of this study, in actual fact it is much further removed (travel time and distance-wise) from the Portland 
CBD.than even parts of the east Multnomah County suburbs and this situation may have been much worse in the early 1970's. In addition, an examination of the distribution of the dependent variables reveals a reasonable declining pattern outside the Beaverton city limits, even though in absolute terms the numbers for the Washington County outer fringe residential development were much higher than in other counties.

Similarities between the housing starts and land conversion models are best observed in Washington county. In the decade submodels (Table XXIV), the variables in each category are in identical sequence of entry with very similar performances. In this case either model could equally well obviate the performance of the other.

The pattern of growth during 1971-1973 (Table XXV) is slightly different from the overall decade pattern. Change in infrastructure and family income are by far the two most important variables with positive influences. An additional infrastructure variable (areas with those services at the start of the decade), posits a negative effect as well. The least effective variables are land value (in the conversion submodel) and original network density (starts), respective1y. Even though its t-ratio is somewhat insignificant, the coefficient of land value is positive assumingly because of the price differential between cheaper farmland and more expensive residential land especially in the band along the 
TABLE XXV

WASHINGTON COUNTY SUBMODELS OF SUBURBAN RESIDENTIAL GROWTH AND LAND CONVERSION FOR THE

SUBPERIOD 1971-1973

\begin{tabular}{|c|c|c|c|c|c|c|}
\hline \multirow[b]{2}{*}{ Parameter } & \multirow[b]{2}{*}{ Model } & \multicolumn{5}{|c|}{$V A R I A B L E S$} \\
\hline & & PCIN & FINC & NET & PINE & LVL \\
\hline B & $\begin{array}{l}\mathrm{U} \\
\mathrm{A}\end{array}$ & $\begin{array}{l}0.23 \\
0.45\end{array}$ & $\begin{array}{l}1.00 \\
1.34\end{array}$ & $\begin{array}{l}0.40 \\
0.46\end{array}$ & -0.24 & 0.38 \\
\hline Beta & $\begin{array}{l}\mathrm{U} \\
\mathrm{A}\end{array}$ & $\begin{array}{l}0.80 \\
1.60\end{array}$ & $\begin{array}{l}0.34 \\
0.47\end{array}$ & $\begin{array}{l}0.20 \\
0.23\end{array}$ & -0.91 & 0.18 \\
\hline $\mathrm{R}^{2}$ Change & $\begin{array}{l}\text { U } \\
\text { A }\end{array}$ & $\begin{array}{l}0.67 \\
0.49\end{array}$ & $\begin{array}{l}0.19 \\
0.35\end{array}$ & $\begin{array}{l}0.03 \\
0.02\end{array}$ & 0.04 & 0.02 \\
\hline T-Value & $\begin{array}{l}\mathrm{U} \\
\mathrm{A}\end{array}$ & $\begin{array}{l}9.36 \\
4.17\end{array}$ & $\begin{array}{l}3.54 \\
5.13\end{array}$ & $\begin{array}{l}2.08 \\
2.33\end{array}$ & -2.44 & 1.73 \\
\hline Sig. Level & $\begin{array}{l}\mathrm{U} \\
\mathrm{A}\end{array}$ & $\begin{array}{l}0.00 \\
0.00\end{array}$ & $\begin{array}{l}0.00 \\
0.00\end{array}$ & $\begin{array}{l}0.05 \\
0.04\end{array}$ & 0.03 & 0.11 \\
\hline Step & $\begin{array}{l}\text { U } \\
\mathrm{A}\end{array}$ & $\begin{array}{l}1 \\
1\end{array}$ & $\begin{array}{l}2 \\
2\end{array}$ & $\begin{array}{l}3 \\
4\end{array}$ & 3 & 5 \\
\hline A & $\mathrm{U}$ & - & & & & \\
\hline $\begin{array}{l}\mathrm{R}^{2} \\
\mathrm{~F}\end{array}$ & $\begin{array}{l}A \\
U \\
A \\
U \\
A\end{array}$ & $\begin{array}{c}\overline{0} .89 \\
0.92 \\
42.3^{* *} \\
30.9^{* *}\end{array}$ & & & & \\
\hline
\end{tabular}

Tanasbourne Mall-Aloha-Tigard-Tualatin axes, where most of the growth in the Washington County suburbs occurred.

The 1974-1976 recursive submodels (Table XXVI) Eurther confirmed the importance of the infrastructure variables in addition to the lag effects of the anteceding development. 
Eurther, the submodels emphasized the separation of residential areas from working and shopping areas, with accessibility ratio being negatively correlated with both starts and conversion. (As a matter of fact, in the conversion submodel, accessibility ratio was the only other useful variable besides the lag effects of previous development.)

TABLE XXVI

RECURSIVE SUBMODELS FOR WASHINGTON COUNTY SUBURBS

FOR THE SUBPERIOD 1974-1976

\begin{tabular}{|c|c|c|c|c|c|c|c|}
\hline \multirow[b]{2}{*}{ Parameter } & \multirow[b]{2}{*}{ Mode 1} & \multicolumn{6}{|c|}{$V A R I A B L E S$} \\
\hline & & $\mathrm{U}_{71-73}$ & PCIN & DIST2 & ACSR & PINF & $A_{71-73}$ \\
\hline B & $\begin{array}{l}\text { U } \\
\mathrm{A}\end{array}$ & 0.82 & 0.33 & -0.001 & $\begin{array}{l}-0.57 \\
-0.52\end{array}$ & -0.26 & 1.27 \\
\hline Beta & $\begin{array}{l}\text { U } \\
\mathrm{A}\end{array}$ & 0.69 & 1.16 & -0.16 & $\begin{array}{l}-0.28 \\
-0.24\end{array}$ & -0.96 & 1.02 \\
\hline $\mathrm{R}^{2}$ Change & $\begin{array}{l}\mathrm{U} \\
\mathrm{A}\end{array}$ & 0.87 & 0.04 & 0.01 & $\begin{array}{l}0.01 \\
0.05\end{array}$ & 0.02 & 0.83 \\
\hline T-Value & $\mathrm{U}$ & 4.78 & 2.45 & -1.93 & $\begin{array}{l}-2.66 \\
-2.47\end{array}$ & -2.08 & 10.30 \\
\hline Sig. Level & $\begin{array}{l}\mathrm{U} \\
\mathrm{A}\end{array}$ & 0.00 & 0.03 & 0.08 & $\begin{array}{l}0.02 \\
0.02\end{array}$ & 0.06 & 0.00 \\
\hline Step & $\begin{array}{l}\mathrm{U} \\
\mathrm{A}\end{array}$ & 1 & 2 & 3 & $\begin{array}{l}4 \\
2\end{array}$ & 5 & 1 \\
\hline $\mathrm{R}^{2}$ & $\begin{array}{l}\text { U } \\
A \\
U \\
A \\
U \\
A\end{array}$ & $\begin{array}{c}1.03 \\
0.28 \\
0.95 \\
0.88 \\
48.9 * * \\
55.9 * \star\end{array}$ & & & & & \\
\hline
\end{tabular}


This means that both categories of development are inversely related to nearness to a subcentral area (such as a regional shopping center or major employment area), which partially explains the reason for the separation of residential development from secondary or other higher order activities in Washington county. Since the availability of land for different zonal uses within the county did not pose a problem, there was, therefore, little need for competition among various land-use sectors (residential, commercial, and industrial). Thus, land value may not have been adversely affected by this condition, and this possibility forms part of the locational reasons for the rapid springing up of shopping malls in the Washington County area in the 1970's.

The recursive submodels for the final subperiod (Table XXVII) are both constituted entirely by different sets of variables. With previous immediate development being dominant, housing starts is influenced in addition by two infrastructure variables, while conversion by household size (with marginal significance), planned network, and one other utility variable. At higher confidence limits (95 percent), only two variables yield significant results in each submodel. The starts model would be defined by the preceding levels of infrastructure and the latent effects of previous development. The conversion model would be constituted by the effects of future network changes and the conversion activity of the antecedent period. In other respects, the 
TABLE XXVII

RECURSIVE SUBMODELS FOR WASHINGTON COUNTY SUBURBS FOR THE SUBPERIOD 1977-1979

V A R I A B L E S

\begin{tabular}{|c|c|c|c|c|c|c|c|c|}
\hline \multirow[b]{2}{*}{ Parameter } & \multirow[b]{2}{*}{ Model } & \\
\hline & & $\mathrm{U}_{71-73}$ & PINF 2 & CWNS 2 & $A_{74-76}$ & HHS 2 & FNET & WNS 2 \\
\hline B & $\begin{array}{l}\mathrm{U} \\
\mathrm{A}\end{array}$ & 0.73 & 0.10 & 0.10 & 0.69 & -1.83 & 0.48 & 0.08 \\
\hline Beta & $\begin{array}{l}\mathrm{U} \\
\mathrm{A}\end{array}$ & 0.66 & 0.33 & 0.11 & 0.66 & -0.15 & 0.20 & 0.14 \\
\hline $\mathrm{R}^{2}$ Change & $\begin{array}{l}\mathrm{U} \\
\mathrm{A}\end{array}$ & 0.89 & 0.04 & 0.02 & 0.86 & 0.07 & 0.01 & 0.01 \\
\hline T-Value & $\begin{array}{l}\mathrm{U} \\
\mathrm{A}\end{array}$ & 6.55 & 3.21 & 1.92 & 7.72 & -1.79 & 2.25 & 1.80 \\
\hline Sig. Level & U & 0.00 & 0.01 & 0.07 & 0.00 & 0.09 & 0.04 & 0.09 \\
\hline Step & $\begin{array}{l}\mathrm{U} \\
\mathrm{A}\end{array}$ & 1 & 2 & 3 & 1 & 2 & 3 & 4 \\
\hline $\begin{array}{l}\mathrm{a} \\
\mathrm{R}^{2} \\
\mathrm{~F}\end{array}$ & $\begin{array}{l}\mathrm{U} \\
\mathrm{A} \\
\mathrm{U} \\
\mathrm{A} \\
\mathrm{U} \\
\mathrm{A}\end{array}$ & $\begin{array}{c}0.38 \\
0.81 \\
0.95 \\
0.95 \\
93.2^{\star \star} \\
66.8 * \star\end{array}$ & & & & & & \\
\hline
\end{tabular}

submodels are equally good; they both have the same outstanding $R^{2}$ values $(0.95)$, positive $Y$-intercepts, and high F-ratios.

In essence, the Washington County residential development and land conversion models are very similar (although better statistically) to those of the region as a whole, but 
very different from those of Multnomah County. For instance, in washington County, infrastructure variables are highly influential throughout the decade and in the recursive models as well, whereas in Multnomah County, accessibility variables are more emphasized. Income influences are comparatively respectable in both counties, but while growth in Multnomah also depends on land supply, in Washington County residential growth and land conversion are completely indifferent to the supply of suitable residential land. Finally, in the regional and Multnomah County models, the lag effects of developments in the first subperiod (19711973) are manifested in the final period as well. In the washington County models, only developments in 1974-1976 show latent effects in the final period suggesting significant differencus between the counties. Also, reasonable changes in washington county in the nature of residential development and ancillary factors between the early and later parts of the decade are suggested.

\section{CLACKAMAS COUNTY SUBMODELS}

In Clackamas County, the results of the regression analyis (Table XXVIII) show that only land converted to residential use could be predicted to any appreciable degree at the decade level, although both models are derivable for shorter periods from the selected pool of variables. The decade conversion model in this case is constituted by four 
variables with an $R^{2}$ of 0.84 . The variables of water but no sewer and residual land are by far the best, contributing 0.71 to the $R^{2}$, with t-ratios significant at 0.01 level. The other two variables, prior network and network change, are weakly significant.

The only variable entering the stepwise regression for housing starts was residual land with 0.23 change in $R^{2}$ and 0.08 significance level. This curve has a positive intercept of 2.57 with an F-ratio of 3.6 significant at 0.08 level. The elasticity of the only independent variable is 0.16 and the corresponding standardized value is 0.48 .

The Eringe area in Clackamas County shows perhaps the most abrupt frontier condition with a sudden transition from

TABLE XXVIII

CLACKAMAS COUNTY SUBMODEL FOR RESIDENTIAL LAND CONVERSION DURING THE DECADE 1970-1980

\begin{tabular}{lccccc}
\hline Variables & $\mathrm{B}$ & Beta & $\mathrm{R}^{2}$ Change & T-Value & Sig. Level \\
\hline CWNS & -0.62 & -0.98 & 0.54 & -5.90 & 0.00 \\
LAND & 0.07 & 0.53 & 0.17 & 3.60 & 0.01 \\
CNET & -0.25 & -0.31 & 0.08 & -1.76 & 0.11 \\
NET & -0.22 & -0.21 & 0.04 & -1.49 & 0.17 \\
\hline $\begin{array}{l}\mathrm{R}^{2} \\
\mathrm{~F}\end{array}$ & 0.16 & & & & \\
$\mathrm{~F}$ & $11.0 * *$ & & & & \\
\hline
\end{tabular}


urban to rural agricultural land. As a result the ratio of residential unit to converted land size maintains an unpredictable variability (vis-a-vis the selected variables) which the research fails to capture, especially in the case of housing starts for the decade. In other words, in Clackamas County, growth in the volume of housing starts depends more on other explanatory factors.

The goodness of fit of the regression for the initial subperiod is weaker than that of the decade conversion submodel (Table XXIX). The starts submodel has an $R^{2}$ of 0.49 and the conversion submodel 0.57 , both of which are constituted by two change variables (CWNS and CNET) having negative elasticities. The respective intercepts are 3.31 and 2.67 , connoting that the growth pattern of the first three years of the 1970's is a continuation of a declining trend initiated sometime in the mid- to late-1960's.

During the next three years, however, the growth curves denote positive gradients (Table XXX) with accessibility and household size being most important. It is interesting to note that at the same period (1974-1976) accessibility was also a concern in Washington County (Table XXVI). The difference, however, is that in Clackamas county, residential development tends to agglomerate close to subcenters whereas it is the reverse in Washington county. The submodels for this period also show no relationship with the preceding development (demolitions). 
TABLE XXIX
CLACKAMAS COUNTY SUBMODELS OF RESIDENTIAL
GROWTH AND LAND CONVERSION FOR THE
SUBPERIOD $1971-1973$

\begin{tabular}{|c|c|c|c|c|c|c|}
\hline \multirow[b]{2}{*}{ Parameter } & \multirow[b]{2}{*}{ Model } & \multicolumn{2}{|c|}{ VARIABLES } & \multirow[b]{2}{*}{$a$} & \multirow[b]{2}{*}{$\mathrm{R}^{2}$} & \multirow[b]{2}{*}{ F } \\
\hline & & CWNS & CNET & & & \\
\hline B & $\begin{array}{l}\mathrm{U} \\
\mathrm{A}\end{array}$ & $\begin{array}{l}-0.57 \\
-0.64\end{array}$ & $\begin{array}{l}-0.42 \\
-0.46\end{array}$ & $\begin{array}{l}3.31 \\
2.67\end{array}$ & $\begin{array}{l}0.49 \\
0.57\end{array}$ & $\begin{array}{l}5.3^{*} \\
7.4^{* *}\end{array}$ \\
\hline Beta & $\begin{array}{l}\text { U } \\
\mathrm{A}\end{array}$ & $\begin{array}{l}-0.82 \\
-0.88\end{array}$ & $\begin{array}{l}-0.45 \\
-0.48\end{array}$ & & & \\
\hline $\mathrm{R}^{2}$ Change & $\begin{array}{l}\mathrm{U} \\
\mathrm{A}\end{array}$ & $\begin{array}{l}0.34 \\
0.40\end{array}$ & $\begin{array}{l}0.15 \\
0.17\end{array}$ & & & \\
\hline T-Value & $\begin{array}{l}\mathrm{U} \\
\mathrm{A}\end{array}$ & $\begin{array}{l}-3.25 \\
-3.85\end{array}$ & $\begin{array}{l}-1.80 \\
-2.10\end{array}$ & & & \\
\hline Sig. Level & $\begin{array}{l}\mathrm{U} \\
\mathrm{A}\end{array}$ & $\begin{array}{l}0.01 \\
0.00\end{array}$ & $\begin{array}{l}0.10 \\
0.06\end{array}$ & & & \\
\hline Step & $\begin{array}{l}\mathrm{U} \\
\mathrm{A}\end{array}$ & $\begin{array}{l}1 \\
1\end{array}$ & $\begin{array}{l}2 \\
2\end{array}$ & & & \\
\hline
\end{tabular}

In the final period (Table XXXI) change in infrastructure is more important in the housing starts model than the lag effect of previous development. Being the only two variables defining that model, these variables have elasticities of 0.16 and 0.32 and $R^{2}$ changes of 0.38 and 0.16 , respectively. The land conversion model is described by three variables, the most important of which is the lag effect of prior development with an $R^{2}$ change of 0.29 . The 
other two variables are network and suitable land. These added 0.23 and 0.13 , respectively to the $R^{2}$.

The decade model shows the negative effect of CWNS and the positive influence of LAND to be the most important predictors of the decade pattern. The high levels of performance of PCIN2 and LAND2 in the final subperiod merely support this contention. Further, it is implied that the performance of infrastructure variables throughout the decade was dictated by the rate of sewer coverage.

TABLE XXX

RECURSIVE SUBMODELS FOR CLACKAMAS COUNTY SUBURBS FOR THE SUBPERIOD 1974-1976

\begin{tabular}{|c|c|c|c|c|c|c|c|}
\hline \multirow[b]{2}{*}{ Parameter } & \multirow[b]{2}{*}{ Model } & \multicolumn{3}{|c|}{ VARIABLES } & \multirow[b]{2}{*}{$\mathbf{a}$} & \multirow[b]{2}{*}{$\mathrm{R}^{2}$} & \multirow[b]{2}{*}{$\mathrm{F}$} \\
\hline & & ACSR & HHS & PINF & & & \\
\hline B & $\begin{array}{l}\mathrm{U} \\
\mathrm{A}\end{array}$ & $\begin{array}{l}1.01 \\
0.87\end{array}$ & $\begin{array}{l}5.35 \\
5.51\end{array}$ & $\begin{array}{l}0.06 \\
0.05\end{array}$ & - & $\begin{array}{l}0.65 \\
0.64\end{array}$ & $\begin{array}{l}6.0^{* *} \\
6.0 * *\end{array}$ \\
\hline Beta & $\begin{array}{l}\text { U } \\
\text { A }\end{array}$ & $\begin{array}{l}0.58 \\
0.55\end{array}$ & $\begin{array}{l}0.52 \\
0.58\end{array}$ & $\begin{array}{l}0.36 \\
0.29\end{array}$ & & & \\
\hline $\mathrm{R}^{2}$ Change & $\mathrm{U}$ & $\begin{array}{l}0.35 \\
0.31\end{array}$ & $\begin{array}{l}0.18 \\
0.25\end{array}$ & $\begin{array}{l}0.12 \\
0.08\end{array}$ & & & \\
\hline T-Value & $\begin{array}{l}\text { U } \\
\mathrm{A}\end{array}$ & $\begin{array}{l}3.09 \\
2.92\end{array}$ & $\begin{array}{l}2.63 \\
2.94\end{array}$ & $\begin{array}{l}1.83 \\
1.46\end{array}$ & & & \\
\hline Sig. Level & $\begin{array}{l}\mathrm{U} \\
\mathrm{A}\end{array}$ & $\begin{array}{l}0.01 \\
0.02\end{array}$ & $\begin{array}{l}0.03 \\
0.02\end{array}$ & $\begin{array}{l}0.10 \\
0.17\end{array}$ & & & \\
\hline Step & $\begin{array}{l}\mathrm{U} \\
\mathrm{A}\end{array}$ & $\begin{array}{l}1 \\
1\end{array}$ & $\begin{array}{l}2 \\
2\end{array}$ & $\begin{array}{l}3 \\
3\end{array}$ & & & \\
\hline
\end{tabular}


TAQBLE XXXI

RECURSIVE SUBMODELS FOR CLACKAMAS COUNTY SUBURBS

FOR THE SUBPERIOD 1977-1979

\begin{tabular}{|c|c|c|c|c|c|c|}
\hline \multirow[b]{2}{*}{ Parameter } & \multirow[b]{2}{*}{ Model } & \multicolumn{5}{|c|}{$V A R I A B L E S$} \\
\hline & & PCIN2 & $\mathrm{U}_{74-76}$ & $A_{74-76}$ & NET2 & LAND2 \\
\hline B & U & 0.10 & 0.32 & 0.31 & -0.63 & 0.06 \\
\hline Beta & U & 0.49 & 0.42 & 0.39 & -0.52 & 0.38 \\
\hline $\mathrm{R}^{2}$ Change & A & 0.38 & 0.16 & 0.29 & 0.23 & 0.13 \\
\hline T-Value & $\begin{array}{l}\mathrm{U} \\
\mathrm{A}\end{array}$ & 2.26 & 1.96 & 1.97 & -2.74 & 1.90 \\
\hline Sig. Level & $\begin{array}{l}\mathrm{U} \\
\mathrm{A}\end{array}$ & 0.05 & 0.08 & 0.08 & 0.02 & 0.09 \\
\hline step & $\begin{array}{l}\text { U } \\
A\end{array}$ & 1 & 2 & 1 & 2 & 3 \\
\hline $\begin{array}{l}\mathrm{a} \\
\mathrm{R}^{2} \\
\mathrm{~F}\end{array}$ & $\begin{array}{l}\mathrm{U} \\
\mathrm{A} \\
\mathrm{U} \\
\mathrm{A} \\
\mathrm{U} \\
\mathrm{A}\end{array}$ & $\begin{array}{l}1.27 \\
2.52 \\
0.54 \\
0.65 \\
6.5 * * \\
6.0 * *\end{array}$ & & & & \\
\hline
\end{tabular}

CLARK COUNTY SUBMODELS

Land attributes are more important in Clark County than in any other county within the metropolitan region. In the decade submodels, suitable land is perfectly proportional $(b=1.00)$ to housing starts and slightly more than 
proportional to conversion activity. In both subnodels it contributes 0.76 to each $R^{2}$ with highly significant t-ratios (Table XXXII). A pair of different independent variables complete each submodel: family income and network for housing starts, and accessibility ratio and the square of distance for conversion. Family income and network together

\section{TABLE XXXII}

CLARK COUNTY SUBMODELS OF RESIDENTIAL GROWTH AND LAND CONVERSION FOR THE DECADE 1970-1980

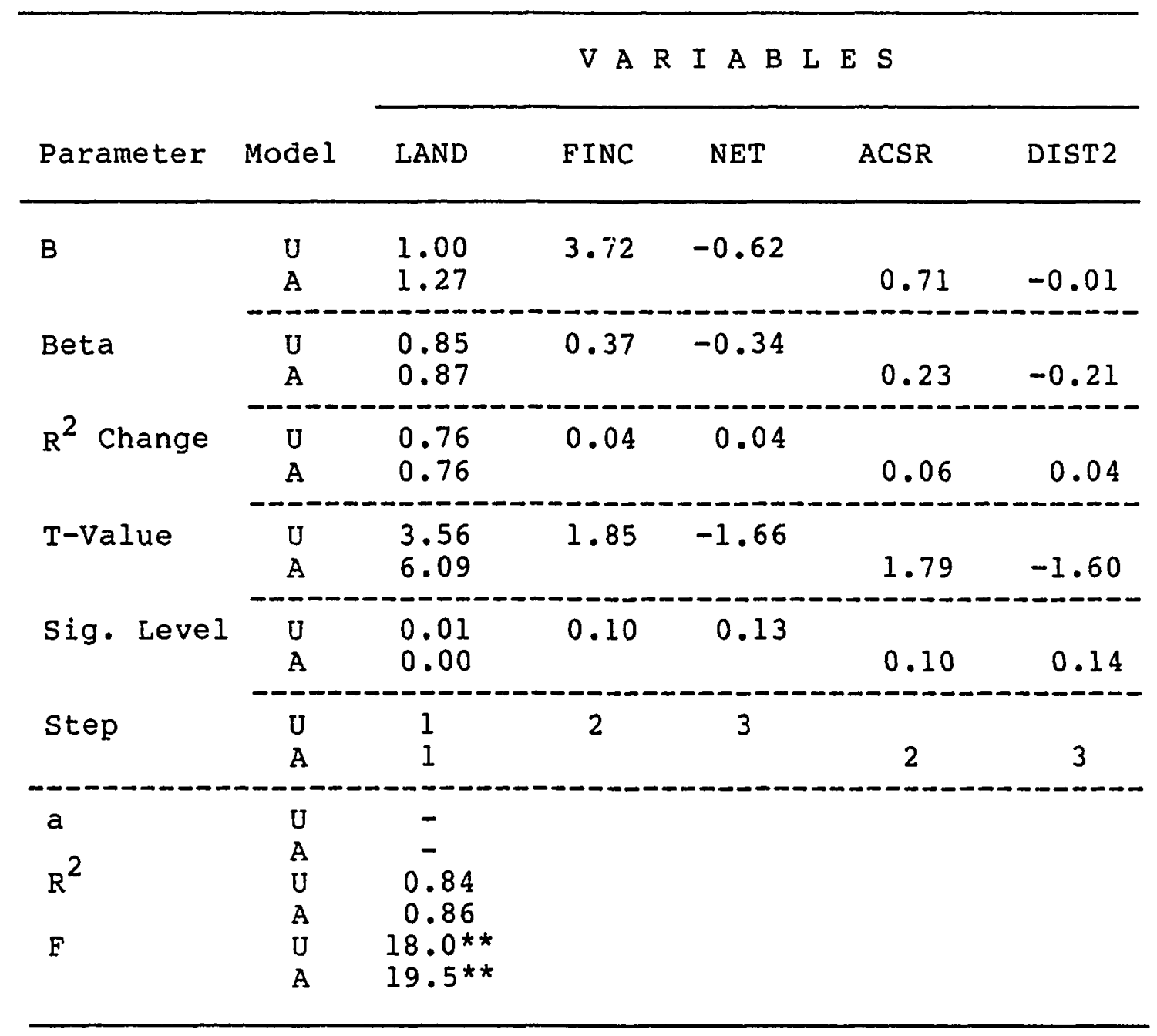


add 0.10 to the housing starts $R^{2}$, and the elasticity of the former (3.72) is its highest performance in all models/submodels, indicating that almost 4 percent increase in housing starts in clark county is accounted for by 1 percent increase in family income. Network, on the other hand, had a negative elasticity as in Clackamas and Multnomah Counties, but unlike washington county.

Accessibility ratio has positive elasticity in this model. Like Clackamas County, this implies a clustering of residential development near subcenters, unlike the case of Washington County where different types of development are segregated.

The submodels for the first subperiod (Table XXXIII) are similar to the decade pattern except that the effect of the original network density is either minimal or absent. Residual suitable land is clearly the most important explanatory variable, being the only significant one in both submodels at the 0.05 level.

In the second subperiod (Table XXXIV), household size shows some effect by maintaining a moderately high negative elasticity in the starts submodel, while previous development had perfect elasticities (1.01 and 1.00$)$ in the two submodels. Land value also had a weak positive influence on conversion.

In the final subperiod, the development condition of the 1974-1976 subperiod has no effect whatsoever. However, 
TABLE XXXIII

CLARK COUNTY SUBMODELS OF RESIDENTAIL DEVELOPMENT AND LAND CONVERSION

FOR THE SUBPERIOD 1971-1973

\begin{tabular}{|c|c|c|c|c|c|c|c|c|}
\hline \multirow[b]{2}{*}{ Parameter } & \multirow[b]{2}{*}{ Model } & \multicolumn{4}{|c|}{ VARIABLES } & \multirow[b]{2}{*}{$a$} & \multirow[b]{2}{*}{$\mathrm{R}^{2}$} & \multirow[b]{2}{*}{ E } \\
\hline & & LAND & FINC & $\operatorname{ACSR}$ & DIST2 & & & \\
\hline B & $\begin{array}{l}\mathrm{U} \\
\mathrm{A}\end{array}$ & $\begin{array}{l}0.68 \\
1.27\end{array}$ & 3.95 & 0.80 & -0.01 & - & $\begin{array}{l}0.74 \\
0.82\end{array}$ & $\begin{array}{l}16.0^{* *} \\
14.7 * *\end{array}$ \\
\hline Beta & $\begin{array}{l}U \\
A\end{array}$ & $\begin{array}{l}0.54 \\
0.84\end{array}$ & 0.37 & 0.25 & 0.25 & & & \\
\hline $\mathrm{R}^{2}$ Change & $\begin{array}{l}\mathrm{U} \\
\mathrm{A}\end{array}$ & $\begin{array}{l}0.68 \\
0.69\end{array}$ & 0.06 & 0.07 & 0.06 & & & \\
\hline T-Value & $\begin{array}{l}\text { U } \\
\mathrm{A}\end{array}$ & $\begin{array}{l}2.23 \\
5.23\end{array}$ & 1.54 & 1.72 & 1.70 & & & \\
\hline Sig. Level & $\begin{array}{l}\mathrm{U} \\
\mathrm{A}\end{array}$ & $\begin{array}{l}0.05 \\
0.00\end{array}$ & 0.15 & 0.12 & 0.12 & & & \\
\hline Step & $\begin{array}{l}\mathrm{U} \\
\mathrm{A}\end{array}$ & $\begin{array}{l}1 \\
1\end{array}$ & 2 & 2 & 3 & & & \\
\hline
\end{tabular}

that of 1971-1973 shows high significant contribution, increasing the $R^{2}$ values by 0.84 and 0.90 , respectively. Land is the only other contributor with 0.06 and $0.04 \mathrm{R}^{2}$ changes, respectively, and t-ratios significant at the 0.03 level (Table XXXV).

Most of the clark County submodels would effectively reduce to simple linear forms at the 95 percent confidence limit. The decade and first subperiodic submodels would all be entirely a function of land with $R^{2}$ 's as good as 0.76 and 
TABLE XXXIV

RECURSIVE SUBMODELS FOR CLARK COUNTY SUBURBS

FOR THE SUBPERIOD 1974-1976

\begin{tabular}{|c|c|c|c|c|c|c|c|c|}
\hline \multirow[b]{2}{*}{ Parameter } & \multirow[b]{2}{*}{ Mode1 } & \multicolumn{4}{|c|}{ VARIABLES } & \multirow[b]{2}{*}{ a } & \multirow[b]{2}{*}{$\mathrm{R}^{2}$} & \multirow[b]{2}{*}{$\mathrm{F}$} \\
\hline & & $U_{71-73}$ & 3 HHS & $A_{71-73}$ & LVL & & & \\
\hline B & $\begin{array}{l}\mathrm{U} \\
\mathrm{A}\end{array}$ & 1.01 & -2.87 & 1.00 & 0.34 & $\begin{array}{r}1.18 \\
-1.10\end{array}$ & $\begin{array}{l}0.92 \\
0.94\end{array}$ & $\begin{array}{l}62.1^{* *} \\
79.1^{*}\end{array}$ \\
\hline Beta & $\begin{array}{l}\mathrm{U} \\
\mathrm{A}\end{array}$ & 1.02 & -0.18 & 1.00 & 0.12 & & & \\
\hline $\mathrm{R}^{2}$ Change & U & 0.89 & 0.03 & 0.92 & 0.02 & & & \\
\hline T-Value & $\begin{array}{l}\mathrm{U} \\
\mathrm{A}\end{array}$ & 10.80 & -1.91 & 12.24 & 1.42 & & & \\
\hline Sig. Level & $\begin{array}{ll}\mathrm{U} \\
\mathrm{A}\end{array}$ & 0.00 & 0.08 & 0.00 & 0.18 & & & \\
\hline Step & $\begin{array}{l}\text { U } \\
\text { A }\end{array}$ & 1 & 2 & 1 & 2 & & & \\
\hline
\end{tabular}

0.68 , respectively. Submodels of the next subperiods are heavily influenced by the developments in the 1971-1973 subperiod with $R^{2}$ 's of 0.89 and 0.92 . It is only in the final subperiod that suitable land adds to the effects of the 1971-1973 development at a statistically significant $\left(P_{0.03}\right)$ level. Since initial development is a function of suitable land, it may be argued that all residential development in Clark County during the decade may have been a function of the land availability attribute. 
TABLE XXXV

\begin{abstract}
RECURSIVE SUBMODELS FOR CLARK COUNTY SUBURBS
FOR THE SUBPERIOD 1977-1979
\end{abstract}

\begin{tabular}{|c|c|c|c|c|c|c|c|}
\hline \multirow[b]{2}{*}{ Parameter } & \multirow[b]{2}{*}{ Model } & \multicolumn{3}{|c|}{ VARIABLES } & \multirow[b]{2}{*}{ a } & \multirow[b]{2}{*}{$\mathrm{R}^{2}$} & \multirow[b]{2}{*}{$\mathbf{F}$} \\
\hline & & $U_{71-73}$ & LAND $2^{+}$ & $A_{71-73}$ & & & \\
\hline B & $\begin{array}{l}\mathrm{U} \\
\mathrm{A}\end{array}$ & 0.69 & $\begin{array}{l}0.47 \\
0.40\end{array}$ & 0.76 & $\begin{array}{l}-0.55 \\
-0.73\end{array}$ & $\begin{array}{l}0.90 \\
0.94\end{array}$ & $\begin{array}{l}48.6 * * \\
86.5 * *\end{array}$ \\
\hline Beta & $\begin{array}{l}\mathrm{U} \\
\mathrm{A}\end{array}$ & 0.65 & $\begin{array}{l}0.36 \\
0.27\end{array}$ & 0.77 & & & \\
\hline $\mathrm{R}^{2}$ Change & $\begin{array}{l}\text { U } \\
\mathrm{A}\end{array}$ & 0.84 & $\begin{array}{l}0.06 \\
0.04\end{array}$ & 0.90 & & & \\
\hline T-Value & $\begin{array}{l}\text { U } \\
\text { A }\end{array}$ & 4.47 & $\begin{array}{l}2.51 \\
2.67\end{array}$ & 7.79 & & & \\
\hline Sig. Level & $\begin{array}{l}\text { U } \\
\mathrm{A}\end{array}$ & 0.00 & $\begin{array}{l}0.03 \\
0.02\end{array}$ & 0.00 & & & \\
\hline
\end{tabular}

+ Entered second in each case.

RELATIVE STRENGTHS OF THE MODELS

The relative strengths and weaknesses of the models may be approximated from two important statistics slown in the preceding tables. The first, and perhaps more important one, is the $\mathrm{R}^{2}$ which is also called the coefficient of determination. This shows how well the regression equation accounts for variations in the dependent variable. Mathematically, it is the ratio of the variance explained by the regression to the total variance (Lewis-Beck, 1980). The 
second, the F-value, is similarly the ratio of the regression variance to the error variance at the respective degrees of freedom. Nie, et al., (1975) explain that these statistics may either be applied to sample data for generalization to a population or utilized in hypothesis testing about the population as a whole. A significant F-ratio denotes that at least one of the regression coefficients of the population has an absolute value greater than zero. In addition to this overall test of goodness to fit of the regression equation, the contribution of each independent variable or a set of independent variables may be assessed by using the respective changes in $\mathrm{R}^{2}$ associated with them as the numerator of the formula for the computation of the E-ratio.

In the analysis, the residential starts models have somewhat lower $\mathrm{R}^{2}$ 's than the land conversion models except for the final recursive submodels of the region and Multnomah County, as well as all of the washington county submodels. In the latter case, the proportion of variance in each model explained by the predictors is over 90 percent with the starts models being slightly better. In general spatial terms, Washington county models and the regional final submodels produced the best results.

The relative proportions of the mean variances of the regression curves to those of the residuals are shown by the F-ratios. With the exception of Clackamas county, all 
equations are highly significant at better than 99 percent confidence limits. In Clackamas County, the starts submodels for the decade and first subperiod have levels of significance at 0.08 and 0.03 , respectively. The rest of the six submodels for that county, however, are significant at 0.01 level or better.

\section{SPATIAL AND TEMPORAL DIFFERENCES IN SUBURBAN RESIDENTIAL HOUSING AND LAND-CONVERSION TRENDS}

The relative strengths and weaknesses of the models have been discussed, and the extent to which some of the errors between time periods correlate has also been highlighted. With reference to the null hypothesis, it is necessary to assess if and to what degree differences occur between spatial units and between time periods. In other words, at what level can the null hypothesis of no difference between the regression equations or coefficients be rejected for the time series or for the spatial units? To satisfy these concerns, the equations are subjected to appropriate forms of the Chow test (Chow, 1960; Maddala, 1977).

The Chow Test

There are, in all, five areas (four counties and the SMSA) and four equations (the decade and three subperiods) for each type of development for each area. The units of observation for all the counties sum up to the SMSA total $(n=83)$. The number of variables in the models of the decade 
and the first subperiod are the same, but due to the recursive nature of the analysis, the other two successive subperiods each has one more variable than the previous period. For each time period, however, the number of variables is the same across all counties and the SMSA. These restrictions limit the number of tests to five comparisons as follows :

Test 1. The unrestricted county models for the decade against the restricted SMSA model for the decade.

Test 2. The unrestricted county submodels for the first subperiod against the restricted SMSA model for the decade.

Test 3. The unrestricted county submodels against the restricted SMSA model for the first subperiod in both cases.

Test 4. The unrestricted county submodels against the restricted SMSA model for the second subperiod.

Test 5 . The unrestricted county submodels against the restricted SMSA model for the final recursive subperiod.

Thus, the general form of the chow test applicable to these situations would be:

$$
F=\frac{(\text { RRSS }- \text { URSS }) / K}{U R S S /(n-2 R)}
$$


where RRSS is the residual sums of squares for the respective restricted equation at $\mathrm{K}$ degrees of freedom.

URSS is the summed residual sums of squares for the respective unrestricted equations at $K$ and $n-2 K$ degrees of freedom.

From the results on Table XXXVI, the following conclusions can be made in respect of the postulations (null. hypothesis) made earlier:

1. There is a highly significant difference between the SMSA models for the pattern of residential housing development and land conversion and those of the respective constituent counties for the decade as a whole. Thus, the null hypothesis is rejected.

2. There is no difference between the decade residential housing model for the SMSA and those of the constituent counties for the first subperiod. However, the respective land conversion equations were significantly different for the two time periods.

3. Differences between the SMSA and the county models for all subperiods are highly significant for land converson, and marginally significant (at 0.01 level) for housing starts in the first two subperiods, but highly so in the final recursive models. 
TABLE XXXVI

RESULTS OF CHOW TESTS FOR SPATIAL AND TEMPORAL DIFFERENCES IN STABILITY OF COEFFICIENTS

\begin{tabular}{|c|c|c|c|c|c|c|}
\hline \multirow[b]{2}{*}{ Test Step } & \multirow[b]{2}{*}{ MODEL } & \multicolumn{3}{|c|}{$T E S T$} & \multicolumn{2}{|c|}{$\#$} \\
\hline & & 1 & 2 & 3 & 4 & 5 \\
\hline $\mathrm{K}$ & $\mathrm{U}, \mathrm{A}$ & 14 & 14 & 14 & 15 & 16 \\
\hline RRSS & $\begin{array}{l}\mathrm{U} \\
\mathrm{A}\end{array}$ & $\begin{array}{l}13.398 \\
12.044\end{array}$ & $\begin{array}{l}13.398 \\
12.044\end{array}$ & $\begin{array}{r}16.863 \\
9.432\end{array}$ & $\begin{array}{r}13.387 \\
6.150\end{array}$ & $\begin{array}{l}3.559 \\
3.619\end{array}$ \\
\hline URSS & $\begin{array}{l}\mathrm{U} \\
\mathrm{A}\end{array}$ & $\begin{array}{l}6.287 \\
3.490\end{array}$ & $\begin{array}{r}10.273 \\
4.360\end{array}$ & $\begin{array}{r}10.273 \\
4.360\end{array}$ & $\begin{array}{l}7.963 \\
2.302\end{array}$ & $\begin{array}{l}1.64 \\
1.802\end{array}$ \\
\hline (RRSS-URSS) /K & $\begin{array}{l}\mathrm{U} \\
\mathrm{A}\end{array}$ & $\begin{array}{l}0.508 \\
0.611\end{array}$ & $\begin{array}{l}0.223 \\
0.549\end{array}$ & $\begin{array}{l}0.471 \\
0.362\end{array}$ & $\begin{array}{l}0.362 \\
0.257\end{array}$ & $\begin{array}{l}0.122 \\
0.114\end{array}$ \\
\hline URSS $/(n-2 K)$ & $\begin{array}{l}\mathrm{U} \\
\mathrm{A}\end{array}$ & $\begin{array}{l}0.114 \\
0.064\end{array}$ & $\begin{array}{l}0.187 \\
0.079\end{array}$ & $\begin{array}{l}0.187 \\
0.079\end{array}$ & $\begin{array}{l}0.150 \\
0.043\end{array}$ & $\begin{array}{l}0.032 \\
0.035\end{array}$ \\
\hline F-Value & $\begin{array}{l}\mathrm{U} \\
\mathrm{A}\end{array}$ & $\begin{array}{l}4.46^{*} \\
9.55^{*}\end{array}$ & $\begin{array}{l}1.19 \mathrm{~ns} \\
6.95^{\star *}\end{array}$ & $\begin{array}{l}2.52 * \star \\
4.58 * *\end{array}$ & $\begin{array}{l}2.41 * * \\
5.98 * *\end{array}$ & $\begin{array}{l}3.81 * * \\
3.26 * *\end{array}$ \\
\hline $\mathrm{n}=83$ & & & & & & \\
\hline
\end{tabular}

$\mathrm{ns}=$ not significant.

* = significant at 0.05 level.

** = significant at 0.01 level.

Since the number of variables varies among the subperiods and since the number of cases for all subperiods does not sum up to the county total (in fact, the cases were the same for all periods), there is no basis for application of the Chow test for differences between subperiods within the same county. Nevertheless, it may be inferred from test 2 that although there is no difference between the starts 
models, the level of difference in the conversion model in test 2 and differences in both types of models in the subsequent periods present a good case for inference of differences between time periods, especially as models of later periods are essentially improvements on earlier time periods.

\section{BEHAVIOR OF ELASTICITIES OVER SPACE AND TIME}

The results of the chow tests imply a reasonable amount of differential occurrences in the separate counties. For example, the elasticities of some variables may be positive in some counties and negative in others. Or, if the signs are the same, the magnitudes of the elasticities may be very different over space sad time, suggesting different structural conditions. In order to capture some of these structural differences, the significant variables in each model are grouped into major categories and the performances of their elasticities evaluated over space and time.

\section{Land Attributes}

Table XXXVII displays the elasticities of residentially zoned vacant land and land value in both categories of models over the five areas and four time periods. The distribution of the elasticities shows that availability of residential land did not feature as an important determinant of residential development at any time in Washington county. 
TABLE XXXVII

BEHAVIOR OF ELASTICITIES OF VARIABLES

MEASURING LAND ATTRIBUTES

\begin{tabular}{|c|c|c|c|c|c|c|c|c|c|c|c|}
\hline & & \multicolumn{2}{|c|}{ Clack. } & \multicolumn{2}{|c|}{ Mult. } & \multicolumn{2}{|c|}{ Wash. } & \multicolumn{2}{|c|}{ Clark } & \multicolumn{2}{|c|}{ SMSA } \\
\hline & & $\mathrm{U}$ & A & $\mathrm{U}$ & A & $\mathrm{U}$ & $A$ & $\mathrm{U}$ & A & $\mathrm{U}$ & A \\
\hline \multirow[t]{2}{*}{$\mathrm{T}_{1}$} & LAND & & & 0.40 & 0.33 & & & 0.68 & 1.27 & 0.11 & 0.09 \\
\hline & LVL & & & 0.69 & 0.65 & & 0.38 & & & -0.07 & -0.03 \\
\hline \multirow[t]{2}{*}{$\mathrm{T}_{2}$} & LAND & & & & & & & & 0.34 & & 0.08 \\
\hline & LVL & & & & & & & & - & -0.31 & -0.13 \\
\hline \multirow[t]{2}{*}{$\mathrm{T}_{3}$} & LAND & & 0.06 & & & & & 0.47 & 0.40 & & \\
\hline & LVI & & & & & & & & & & \\
\hline \multirow[t]{2}{*}{$\mathrm{D}$} & LAND & 0.16 & 0.07 & 0.33 & 0.48 & & & 1.00 & 1.27 & 0.24 & 0.20 \\
\hline & LVL & & & & 0.89 & & & & & & -0.05 \\
\hline
\end{tabular}

In Clackamas County, importance of land is slightly suggested in the third period and in the decade as a whole. In Multnomah County, availability of land is a major concern in the models of the first subperiod and the decade. In Clark County, land is shown to have a major influence in all time periods.

The importance of land value is less than that of unconstrained land in all models except in Multnomah County where the elasticities of land value in the models for the decade and Eirst subperiod are higher than the regional 
case. Eurther, they are positive in Multnomah and Washington Counties but consistently negative in the regional models with the strongest effect showing in the second subperiod. This means that there is competition for land, especially in Multnomah County, and residential development increases with increasing land value. At the SMSA level, however, the reverse is true, supporting the contention that higher land values inhibit residential development in areas with approximately equal inventory of suitable residential land.

\section{Infrastructure Conditions}

Change in infrastructure (combined effects of water and sewer) is a major positive factor in the regional models for all time periods with about equal elasticities in the models of the decade and first subperiod (Table XXXVIII). In the latter subperiods, it shows lower elasticities. In the decade models, areas without sewers (but with septic tanks and cesspools) show some regional importance in addition to change in infrastructure. In the counties, change conditions are negative in clackamas county but reasonably positive in Washington County. No infrastructure variable is of any significance in all models of Clark County and in many of the models of Multnomah and Clackamas Counties.

In Washington County, the original level of infrastructure is highly negative during the first and second subperiods but declines in the final period. On the other 
TABLE XXXVIII

BEHAVIOR OF ELASTICITIES OF

INFRASTRUCTURE VARIABLES

\begin{tabular}{|c|c|c|c|c|c|c|c|c|c|c|c|}
\hline & & \multicolumn{2}{|c|}{ clack. } & \multicolumn{2}{|c|}{ Mult. } & \multicolumn{2}{|c|}{ Wash. } & \multicolumn{2}{|c|}{ Clark } & \multicolumn{2}{|c|}{ SMSA } \\
\hline & & $\mathrm{U}$ & A & $\mathrm{U}$ & A & $\mathrm{U}$ & A & $\mathrm{U}$ & A & $\mathrm{U}$ & A \\
\hline $\mathrm{T}_{1}$ & $\begin{array}{l}\text { PINF } \\
\text { PCIN } \\
\text { WNS } \\
\text { CWNS }\end{array}$ & -0.57 & -0.64 & & & 0.23 & $\begin{array}{r}-0.24 \\
0.45\end{array}$ & & & $\begin{array}{l}0.15 \\
0.17\end{array}$ & $\begin{array}{l}0.11 \\
0.22\end{array}$ \\
\hline $\mathrm{T}_{2}$ & $\begin{array}{l}\text { PINF } \\
\text { PCIN } \\
\text { WNS } \\
\text { CWNS }\end{array}$ & 0.06 & 0.05 & $\begin{array}{r}-0.55 \\
1.10\end{array}$ & $\begin{array}{r}-0.33 \\
0.71\end{array}$ & 0.33 & -0.26 & & & 0.08 & 0.07 \\
\hline $\mathrm{T}_{3}$ & $\begin{array}{l}\text { PINF } \\
\text { PCIN } \\
\text { WNS } \\
\text { CWNS }\end{array}$ & 0.10 & & 0.10 & 0.09 & $\begin{array}{l}0.10 \\
0.10\end{array}$ & 0.08 & & & $\begin{array}{l}0.08 \\
0.11\end{array}$ & $\begin{array}{l}0.05 \\
0.11\end{array}$ \\
\hline D & $\begin{array}{l}\text { PINF } \\
\text { PCIN } \\
\text { WNS } \\
\text { CWNS }\end{array}$ & & -0.62 & & & $\begin{array}{l}0.29 \\
0.14\end{array}$ & $\begin{array}{l}0.27 \\
0.12\end{array}$ & & & $\begin{array}{l}0.16 \\
0.14\end{array}$ & $\begin{array}{l}0.10 \\
0.20\end{array}$ \\
\hline
\end{tabular}


hand, change condition has highly positive elasticities in the first two subperiods. Tn Multnomah County, aside from the low positive influence of PINF in the final recursive period, variables measuring the effects of septic tanks and cesspools (WNS and CWNS) show very high elasticities. WNS is negative while CWNS shows more or less perfectly proportional and positive elasticities. In clackamas county, however, CWNS elasticities are highly negative in the first subperiod, but in subsequent periods PINF and PCIN show moderate positive influences.

Change in infrastructure is the best single variable in the regional models. This contribution is mostly due to its performance in Washington County where the elasticities are shown to be much higher than the regional case. The general response of areas with water and no sewer is that the larger that area is at the start of the period, the more the development. This probably relates to the condition, especially in Washington County, where such areas were gradually sewered during the decade.

\section{Socio-Economic Conditions}

of the socio-economic factors considered, family income is more important than household size in the regional and all other submodels except those of Clackamas county. In other counties, the family income elasticity appears only in the first subperiod and decade models. In both cases the coefficients are close to 4.0 in clark county, between 2.0 
and 3.0 in Multnomah, and between 1.0 and 2.0 in Washington County (Table XXXIX). The regional models have elasticities ranging from 1.95 to 2.71 for family income.

With respect to household size, the decade models for the region, and Washington and Clackamas submodels for the second recursive period have positive elasticities. The Clackamas County elasticities measure over 5.0. Although negative elasticities are recorded in a few cases, the highly positive values for household size lend partial support to the initial postulates regarding its influence on devel-

TABLE XXXIX

BEHAVIOR OF ELASTICITIES OF SOCIAL FACTORS

\begin{tabular}{|c|c|c|c|c|c|c|c|c|c|c|c|}
\hline & & \multicolumn{2}{|c|}{ clack. } & \multicolumn{2}{|c|}{ Mult. } & \multicolumn{2}{|c|}{ Wash. } & \multicolumn{2}{|c|}{ Clark } & \multicolumn{2}{|c|}{ SMSA } \\
\hline & & $\mathrm{U}$ & A & $\mathrm{U}$ & A & $\mathrm{U}$ & $A$ & $\mathrm{U}$ & $\mathrm{A}$ & $\mathrm{U}$ & A \\
\hline \multirow[t]{2}{*}{$\mathrm{T}_{1}$} & FINC & & & 3.04 & 1.82 & 1.00 & 1.34 & 3.95 & & 2.31 & 2.33 \\
\hline & HHS & & & & & & & & & & \\
\hline \multirow[t]{2}{*}{$\mathrm{T}_{2}$} & FINC & & & & & & & & & & \\
\hline & HHS & 5.35 & 5.51 & & & & & -2.87 & & & \\
\hline \multirow[t]{2}{*}{$\mathrm{T}_{3}$} & FINC & & & & & & & & & & \\
\hline & HHS & & & & & & -1.83 & & & & \\
\hline \multirow[t]{2}{*}{$D$} & FINC & & & 2.63 & 2.63 & 0.98 & 1.90 & 3.72 & & 1.95 & 2.71 \\
\hline & HHS & & & -3.36 & & 2.04 & 2.29 & & & 2.71 & \\
\hline
\end{tabular}


opment regardless of the fact that its level of significance and contributions to the variance are relatively weak.

Accessibility

The estimates of the coefficients of the access variables (Table XL) portray a good approximation of the outer fringe of the portland suburbs. This is estimated in the

TABLE XL

BEHAVIOR OF COEFFICIENTS OF ACCESSIBILITY VARIABLES

\begin{tabular}{|c|c|c|c|c|c|c|c|c|c|c|}
\hline & \multicolumn{2}{|c|}{ Clack. } & \multicolumn{2}{|c|}{ Mult. } & \multicolumn{2}{|c|}{ Wash. } & \multicolumn{2}{|c|}{ Clark } & \multicolumn{2}{|c|}{ SMSA } \\
\hline & $\mathrm{U}$ & A & $\mathrm{U}$ & A & $\mathrm{U}$ & $A$ & $\mathrm{U}$ & A & $\mathrm{U}$ & A \\
\hline \multirow[t]{3}{*}{$\mathrm{T}_{1}$} & DIST & & & 0.39 & & & & & 0.05 & 0.21 \\
\hline & DIST2 & & & -0.01 & & & & -0.01 & & -0.01 \\
\hline & ACSR & & & & & & & 0.80 & & 0.52 \\
\hline \multirow[t]{3}{*}{$\mathrm{T}_{2}$} & DIST & 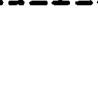 & 0.61 & 0.11 & & & & & & \\
\hline & DIST2 & & -0.02 & & -0.01 & & & & & \\
\hline & $\operatorname{ACSR} 1.01$ & 0.87 & 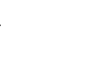 & 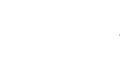 & -0.57 & -0.52 & & & & \\
\hline \multirow[t]{3}{*}{$\mathrm{T}_{3}$} & DIST & & & & & & & & & \\
\hline & DIST2 & & & & & & & & & \\
\hline & ACSR & & & & & & & & & \\
\hline \multirow[t]{3}{*}{$\mathrm{D}$} & DIST & & & 0.38 & -0.02 & & & & 0.03 & 0.23 \\
\hline & DIST2 & & & -0.01 & & & & -0.01 & & -0.01 \\
\hline & ACSR & & & & & & & 0.71 & & \\
\hline
\end{tabular}


combined effects of DIST and DIST2 to be approximately between 21 and 23 miles from the CBD peaking at approximately 11.5 miles. In Multnomah County, the theoretical estimate is over 30 miles but practically limited by the Sandy River to approximately 20 miles. Accessibility ratio (which depicts the influence of subcenters) has positive elasticities in the regional conversion model of the first subperiod, and in two conversion models for Clark County. In Clackamas County, the ratio shows unitary elasticity $(b=1.01)$ in the starts model of the second period. In the corresponding submodel for the conversion, the respective elasticity is 0.87. In washington County, both submodels of the same period show negative elasticities, suggesting the opposite condition of moderate development away from subcenters.

with respect to these elasticities, it is difficult to make a generalization on the impact of subcentral access on residential development at the regional level. The moderate positive elasticity $(0.52)$ in the regional conversion submodel of the first subperiod suggests that the general trend in the early part of the decade is that residential development tends to cluster near subcenters. In the latter part of the decade, however, this is true only for clackamas and Clark Counties, suggesting the effects of new subcenters constructed in the latter part of the decade.

\section{Network Density}

The effects of network density heavily load the Mult- 
nomah County models more than any other subregional models. With high road improvements, change in network density has positive elasticities ranging from 0.57 in the first subperiod to over 2.0 in the decade model (Table XLI). The effect of future network changes vary from -1.27 in the first period to -0.64 in the decade equations. Similar performances of these variables are noted in the regional case.

In Clackamas county only the original density and the change condition show negative effects in all but the second recursive subperiod. In Washington County, on the other hand, the effect of the original density is observed only in the first subperiod with positive elasticities. In Clark County network effects show no limitation to development in any recursive submodel, albeit a low negative elasticity in the residential model of the decade. In all counties, future network changes have negative elasticities in all periods except the final recursive subperiod.

Network change is the second most important variable in the regional decade model. Like accessibility, the performance of this category of variables in Multnomah County is higher than the regional pattern, hence the influence of the Multnomah County conditions.

\section{Lag Effect of Previous Development}

The influence of previous residential development on current construction is least important in Clackamas County 
TABLE XLI

BEHAVIOR OF ELASTICITIES OF VARIABLES

MEASURING NETWORK DENSITY

\begin{tabular}{|c|c|c|c|c|c|c|c|c|c|c|c|}
\hline & & \multicolumn{2}{|c|}{ clack. } & \multicolumn{2}{|c|}{ Mult. } & \multicolumn{2}{|c|}{ Wash. } & \multicolumn{2}{|c|}{ clark } & \multicolumn{2}{|c|}{ SMSA } \\
\hline & & $\mathrm{U}$ & A & $\mathrm{U}$ & A & $\mathrm{U}$ & A & $\mathrm{U}$ & A & $\mathrm{U}$ & A \\
\hline $\mathrm{T}_{1}$ & $\begin{array}{l}\text { NET } \\
\text { CNET } \\
\text { ENET }\end{array}$ & -0.42 & -0.46 & $\begin{array}{r}1.76 \\
-1.27\end{array}$ & $\begin{array}{r}0.57 \\
-0.81\end{array}$ & 0.40 & 0.46 & & 0.97 & $\begin{array}{l}0.50 \\
0.34 \\
0.48\end{array}$ & 0.56 \\
\hline $\mathrm{T}_{2}$ & $\begin{array}{l}\text { NET } \\
\text { CNET } \\
\text { FNET }\end{array}$ & & & & & & & & & 0.37 & \\
\hline $\mathrm{T}_{3}$ & $\begin{array}{l}\text { NET } \\
\text { CNET } \\
\text { FNET }\end{array}$ & & -0.63 & 0.39 & 0.36 & & 0.48 & & & 0.36 & 0.34 \\
\hline$D$ & $\begin{array}{l}\text { NET } \\
\text { CNET } \\
\text { FNET }\end{array}$ & -0.25 & $\begin{array}{r}-0.22 \\
2.07\end{array}$ & $\begin{array}{r}1.07 \\
-0.64\end{array}$ & $\begin{array}{l}-0.87 \\
-1.10\end{array}$ & & & -0.62 & & $\begin{array}{r}1.23 \\
-0.39\end{array}$ & $\begin{array}{r}0.78 \\
-0.42\end{array}$ \\
\hline
\end{tabular}


and increasingly important in Washington and Multnomah Counties (Table XLII). In Multnomah the elasticities increase over time showing that the effect of recent prior construction activity is more important than the lag effects of much earlier periods, especially in the case of housing starts. In Washington County only recent prior development

is important, with a diminishing effect over time. In clark, only development in the early part of the decade shows influence in the subsequent periods. In the SMSA as a whole, the trend is that the effect of the construction activity of the recent past is greater than that of earlier periods.

TABLE XLII

BEHAVIOR OF ELASTICITIES OF VARIABLES MEASURING

EFEECTS OF PREVIOUS RESIDENTIAL DEVELOPMENT

IN RECURSIVE MODELS

\begin{tabular}{|c|c|c|c|c|c|c|c|c|c|c|c|}
\hline & & \multicolumn{2}{|c|}{ Clack. } & \multicolumn{2}{|c|}{ Mult. } & \multicolumn{2}{|c|}{ Wash. } & \multicolumn{2}{|c|}{ Clark } & \multicolumn{2}{|c|}{ SMSA } \\
\hline & & $\mathrm{U}$ & $A$ & $\mathrm{U}$ & $A$ & U & A & $\mathrm{U}$ & $A$ & $\mathrm{U}$ & A \\
\hline $\mathrm{T}_{2}$ & PD1 & & & 0.17 & 0.35 & 0.83 & 1.27 & 1.01 & 0.34 & 0.58 & 0.79 \\
\hline \multirow[t]{2}{*}{$\mathrm{T}_{3}$} & PDI & & & 0.24 & & & & 0.69 & 0.76 & 0.25 & 0.35 \\
\hline & PD2 & 0.32 & 0.31 & 0.44 & 0.62 & 0.73 & 0.69 & & & 0.44 & 0.46 \\
\hline
\end{tabular}

PDI represents developments in the first subperiod. PD2 represents developments in the second subperiod. 
Summary of Spatial and Temporal Differences in Performance of Models

From the assessment of the behavior of the elasticities, it may be summarized that:

1. Infrastructure is the most important variable positively influencing fringe area residential development. This outcome is primarily due to change conditions in sewer service in Washington County during the decade. Septic tanks and cesspools have little positive effect on residential development, but in some areas, a decline in the size of areas covered by these services over time correlates with increased residential development.

2. Land attributes are of moderate importance to development, with land constraints being of diminishing importance over the decade, and land value showing increasing negative influence. The behavior of the land coefficients in clark county exerted a heavy influence on the regional pattern. 3. Accessibility and network changes are the second major influencers of fringe area development in the region. With respect to subcentral access, Clackamas and Clark Counties show a tendency toward increased development near subcenters while in Washington County, development is favored away from subcenters. 
4. Socio-economic factors (income conditions especially) are the third most important positive determinants of fringe area residential development.

5. The lag effects of previous development are generally positive but more so in Washington and Multnomah Counties than other subareas. 
CHAPTER VI

CONCLUSION

SUMMARY

The research problem of this study was conceptualized within the framework of the national trend of suburbanization within SMSA's in the last two decades. With specific focus on the Portland SMSA, fringe area residential growth and land conversion were examined using data for the decade 1970-1980. In Chapter I, intrametropolitan and nonmetropolitan population shifts were examined at national and local levels. The scope of the research problem and the delimitation of the Portland fringe were derived from census demarcations and adjusted to suit the local conditions of the study area.

Detailed research into the physical and socio-economic literature (Chapter II) guided the operationalization of the problem, the selection of allegedly useful variables, postulation of expected relationships, and assessment of the quantitative as well as qualitative techniques used in the study. In Chapter III, null-type postulations were specified based on the physical facilities and services available to the counties constituting the SMSA. The major variables considered were grouped into land attributes, infrastructure 
levels, accessibility conditions, network density, and socio-economic factors. The general hypothesis was made that fringe area residential growth and land conversion were the same in all counties, and suburban movers were indifferent to county distinctions and subperiods of the decade.

In Chapter IV, the qualitative analysis revealed important differences in the structure of physical facilities and services, as well as the socio-economic opportunities available to fringe areas of the different counties. The quantitative analysis (Chapter V) utilized regression techniques to isolate the key explanatory factors of fringe area growth in each region and time. The analyzed relationships were statistically tested using the chow technique. The tests showed significant differences in the performance of the elasticities of the variables across time periods in the constituent counties. Also, there were significant differences among the counties.

The technical summary in Chapter $v$ gives an indication of which variables are of regional importance and which ones are important only to some counties. On a regionwide basis, infrastructure, accessibility and network density, and income characteritics were, respectively, the most important factors accounting for fringe area residential growth. In the counties, the most important variables were infrastructure in washington county, network and accessibility in Multnomah, and land attributes in Clark and Clackamas Coun- 
ties. Family income was more or less equally important to all counties across all time periods.

\section{CONCLUSION}

The metropolitan-wide models show the importance of the variables of infrastructure, network changes, family income, and land availability, respectively. Examination of subperiodic models shows the additional importance of subcentral access in the first subperiod and land value in the second subperiod. Areas with water and septic tanks but without sewer service showed slight importance in all subperiods.

The major conclusion that may be drawn from the research is that the derived models and tests indicate the existence of different parameter estimates for most of the major variables in the different counties. Secondly, the tested variables are confirmed as showing high differential responses in the constituent counties, resulting in a different set of major variables explaining the residential development trend in the fringe of each county.

In Washington County, the tremendous positive influence of the county-wide sewer service district is reflected by the high positive effect of infrastructure both locally and regionally. As Blalock (1964) suggests, it is tempting to overdraw inferences from data, especially when the responses of some variables are overwhelming. However, it may 
be inferred that, at least at the county level, a single service district has more significant influence on fringe area growth than a number of smaller ones, probably suggesting that within a county, the larger the area covered by one service district the more economical the service to the consumer (Bruggink, 1979). It must be emphasized, however, that regardless of how logical this assumption might seem, the same cannot be inferred for the region as a whole.

In east Multnomah County, arterial road developments positively influenced suburban residential growth. However, the results suggest that the continued increase of road construction is becoming a constraint on residential development. In the middle of the decade, the bulk of residential development occured away from areas with water but without sewer service.

In clark County, land is perceived to be cheaper than in other suburban areas. Further, both clark and Clackamas counties have large land holdings proximate to the CBD. As a result, fringe area residential development in both locations have depended primarily on the supply of land suitable for development.

The importance of land and land value decrease with time both locally and regionally. Infrastructure also decreases in importance at the regional level, but increases considerably with time in washington County. Accessibility constraints show more importance early in the decade, while 
income variations maintain a constant influence over time. Methodologically, the technique and results of this study provide a framework that could be applied to other SMSAs with slight adjustments. Parameter differences allow for attributes to be adjusted by county in order to derive more accurate estimations of the functional effects of variables.

\section{DISCUSSION}

To establish their validity and applicability elsewhere, the findings (especially the regionwide results) and the outcomes of major variables need to be discussed and evaluated against the results of studies conducted earlier elsewhere and highlighted in the theoretical review section.

Hawley (1950) and Berry and Kasarda (1977) explained and emphasized the theoretical importance of physical facilities and infrastructure to residential development. Corsi's (1974) finding in his Ohio Turnpike study was consistent with that theory, noting that public facilities were useful in predicting residential development. On the other hand, Habig's (1972) results from Franklin county, Ohio, contended that in simultaneous development, sewer service was useful in predicting commercial development but insignificant in influencing residential development. While the results of the current study concur with corsi's findings, they do not necessarily refute Habig's contentions as the 
issue of simultaneous development was not addressed by this study. In fact, the results in Multnomah county may be partially indicative of this condition.

The combined effects of public facilities and access were also consistent with results of studies on the seattle fringe (Morrill, 1965), Urbandale (Lee, 1977), Toronto (Bourne, 1974), and the Twin Cities in Minnesota (GLeeson, $1979)$.

The importance of family income conforms with Schnore's (1973) finding that median family income is one of the most important socio-economic variables accounting for the city-suburb population differentiation, and also with Scheenman and Muller's (1974) results that conversion is a function of fiscal influences in addition to other variables.

Although the effects of subcenters were not important at the regional level, the observations made at the county level support the contentions of Hushak (1975), Bourne (1974), and Corsi (1974) on the influence of subcenters on fringe area development. But even more important is the fact that the effect of CBD access is more dominant than subcentral access in this study, supporting the contention of Stanback and knight (1976) that suburbs will continue to depend on the central city.

The importance of the availability of unconstrained land to fringe area residential growth was a basic premise 
made in this study. The results showed that in at least two counties (Clark and Clackamas), this postulation is primarily upheld (Malarkey, 1978). In the regional models, the effect of suitable land on residential development was less outstanding, but statistically significant.

Land value was expected to show a much better negative influence than the analysis portrayed. It had regional significance with an improved performance later in the decade. This suggests that its effects are probably latent, and perhaps require longer than 3-year subperiods to capture significant time differences in its performance. Nonetheless, there were differences among the counties, and this gives the indication that observations made elsewhere (Hushak, 1975; Gleeson, 1979) may be supported by other similar studies that may be conducted in this region in the future with different operationalization techniques.

In general, the differential importance of the major independent variables in the counties and time-recursive models establish a causal link with regionwide fringe area residential development. With respect to the counties, a similar argument can be made in many cases. In Multnomah County, however, it is difficult to establish a causal link in either direction between development and the nonexistent variable of sewer facility. However, the reverse may be discerned to a convincing level that the lack of growth relates to the conditions of high network density and con- 
gestion, and septic tanks and cesspools more than anything else. Since these variables were applied to other counties as well, then a comparative assessment of the results provides the rational means of inference of the potential effect of the variable (sewers) that is largely absent in east Multnomah County. Since sewers enhanced fringe area growth in Washington County, can the argument then be made that the lack of sewers caused low growth in east Multnomah County? As much as the answer depends on other factors as well, it can be rationalized from the results that septic tanks and cesspools have hampered growth in east Multnomah County, and since they failed to do so in other counties and rather the effect of sewers prevailed, it may be reasonably surmised that growth in east Multnomah County could be enhanced mainly by the provision of sewer service.

Finally, mid- to high-income earners in the metropolitan area are increasing in proportion at the fringe area, even in areas where there is increased out-migration. Sternlieb's (1971) "sandbox" concept continues to be true as the proportion of the poor increase in the urban nucleus. This implies that the attention of planners within the region should be drawn to the fact that the demand for physical and environmental services by fringe area residents will continue to increase in the near future. As a result, the necessary planning steps need to be adopted in order to avoid the mismatch of facilities and population densities. 


\section{LIMITATIONS OF THE RESEARCH}

The analysis of the data was a multivariate approach to the assessment of spatial variations in fringe area residential growth and land conversion. Like most statistical techniques, the validity and reliability of the results are limited by the many assumptions that the techniques inhere. For example, the assumption can only be made that if all factors and attractions were the same in the suburban areas of the counties, then suburban migrants will be indifferent to county distinctions.

Although the study has shown this not to be the case and that the determining factors are distinctly different among counties, an inventory of all the accounting factors (endogenous and exogenous) which might influence the results cannot be claimed. For example, the study utilized aggregate data at the census tract level which could lead to slightly different results from other units of analysis. Also, although some variables on amenities were included, other unique ties and preferences (physical or social) may influence the results. Some people (nevertheless small) might never move to the fringe area regardless of how distressed their current location might become, even if their economic opportunities are comparable to those of suburban movers. This locational fixity may be partially explained by the intercepts of the models, but otherwise difficult to quancify as a predictor. The quantifiable attributes none- 
theless produced useful results and the study provides a yardstick for evaluating why and what proportions of suburban movers go to which part of the Portland fringe.

\section{UTILITY AND IMPLICATIONS OF THE RESEARCH}

A good deal of planning studies preceding this research have focused on different aspects of growth constraints in the Portland SMSA. Many of these studies were sponsored by municipal corporations or the separate counties usually with the intent of isolating a planning constraint, and rarely transcending jurisdictional lines. Some of the studies conducted by the regional planning agencies (CRAG, MSD, METRO) have aptly addressed part of the interjurisdictional questions, albeit with one concern (rarely more) at a time. To date no study has looked at the four counties in as much a totality of focus with respect to the number and types of variables as the current one has done, although the focus here is on the fringe areas. In this regard, for the area studied, the study provides the means whereby the effects of a large number of variables have been tested simultaneously across all counties for the same time periods. It would be a useful reference document for researchers and planners for evaluating the impacts of similar or different variables in the counties of the region. In particular, the possibility of stimulating growth in east Multnomah County through the establishment of sewer service 
in addition to other variables is suggested by the results of the research. Second, the largest service districts for infrastructure have shown the greatest influence on growth, implying significant savings on the cost of those services to the suburban consumer.

\section{SUGGESTIONS FOR FUTURE RESEARCH}

This study has a physical impetus and it is conceivable that a complementary study on fringe area development could concentrate on more social factors than herein considered. In particular, rent differentials (Wingo, 1961; Alonso, 1967), ethnicity and segregation (Shevky and williams, 1949; Van Arsdol, et al., 1958; Udry, 1964; Murdie, 1969; and Schnore, 1973) could be considered. In addition, fiscal influences and land value could also be examined in more detail (Tiebout, 1956; Scheenman and Muller, 1974). The location of this SMSA in two states having different tax structures provides an advantageous basis for this kind of analysis.

A good deal of literature (Breckenfeld, 1972; James and Hughes, 1973; Wheaton, 1979, etc.) discusses the suburbanization of both commercial and industrial activites, in addition to that of the population. Some of the literature has also cited the possibility that some forms of industrial activities are gradually being replaced by other activities near the CBD. This sets the stage for different forms of 
studies on the factors accounting for the flight of either of these activities to the suburbs. Also, the degree at which one replaces the other near the CBD may be determined, and how differences occur in subareas.

With respect to Multnomah County, the possible dangers of underground leakages from septic tank and cesspool leach fields (Keyes, 1976) could be assessed by looking at soil and ground water samples, and comparing toxicity levels of dissolved substances.

Methodologically, with this and other studies as background knowledge, the selection and screening of variables for related studies in the Portland Metropolitan Area should be attained with minimum difficulty. With a contracted list of pretested variables, the need to employ exploratory techniques such as the stepwise option would have been eliminated, and the use of ordinary regression would become more appropriate.

With respect to the units of analysis, census tracts have the advantages of convenient aggregation, and easy access and retrieval of data from Census Bureau records and computer tapes. Tract level data are, therefore, immensely useful where the study area is constituted by optimum-sized tracts with minimal variation in size. Extreme size differences, however, may pose problems because as tracts get larger, they tend to approximate the general characteristics 
of the study area. In such a case, subdivisions of the tract would likely produce better results.

In place of census tracts, traffic zones may be equally useful, especially where there is a lot of variation in the sizes of the tracts but much less variation in the sizes of traffic zones, i.e., the traffic zones are delimited such that in areas with smaller-sized census tracts, a traffic zone is constituted by one or more census tracts. And where there are large tracts, a subdivision of a tract would constitute a zone. However, whether tracts or zones are utilized, the assignment of attributes should take into consideration differences that may abound in the constituent counties or other political subunits.

When most or all of the metropolitan region is utilized in a study, since tract size is a function of population density, the study area may be stratified into chiefly residential and nonresidential (CBD) areas. Depending on the nature of decline of residential activity towards the rural component of the SMSA, the residential stratum may either be analyzed using the tracts, or, if the fringe area tracts are unusually large, the outer tracts may be redivided to suit the size categories of the inner residential area tracts. Since census blocks at the fringe area usually approximate the size of inner city tracts, their use as units of analysis may be considered.

With regards to the representation of the study area, 
the problem of sampling may be important where there are far too many tracts, zones, blocks, or other units of analysis. Where the study area comprises few tracts, if block level data can be obtained without much emphasis and concern placed on size differences, then a pool of the blocks would provide a reasonably large population from which the desired sample may be selected. This approach may be useful in an actively growing fringe where there is no reason or desire to regroup units into subareas of the study area. But if the useable units are few, to avoid statistical problems emanating from few degrees of freedom, the whole population may be utilized. 


\section{REFERENCES}

Alonso, W. 1960. "Economic Change and Rural-Urban Land Conversion," Econometrica, 29, pp. 1-23.

Alonso, W. 1964. Location and Land Use: Towards a General Theory of Land Rent, Cambridge, Massachusetts: Harvard University press.

Alonso, w. 1968. "The Quality of Data and the Choice and Design of Predictive Models," Highway Research Board Special Report, No. 97, Washington, D.C.: Highway Research Board, pp. 178-192.

Anderson, T.R. and L.L.Bean. 1961. "The Shevky-Bell social Areas: Confirmation of Results and Reinterpretation," Social Forces, Vol. 40, No. 4, pp. 119-124.

Beimfohr, O.W. 1953. "Some Factors in the Industrial Potential of Southern Illinois," Transactions of the Illinois state Academy of Science, Vol. 46, pp. 97-103.

Be11, W. 1955. "Economic, Family, and Ethnic Status: An Empirical Test." American Sociological Review, Vol. 20, pp. 465-52.

Bell, W. and M. Force. 1956. "Urban Neighborhood Types and Participation in Formal Associations," American Sociological Review, Vol. 21, p. 25-34.

Berry, B.J.I. 1965. "The Retail Component of the Urban Model," Journal of the American Institute of Planners, Vol. 31, No. 2, pp. 150-155.

Berry, B.J.L. and J.D. Kasarda. 1977. Contemporary Urban Ecology, New York: MacMillan Publishing Company.

Blalock, H.M., Jr. 1961. Causal Inferences in Nonexperimental Research, Chapel Hill: University of North Carolina Press.

Blalock, H.M., Jr. 1982. Conceptualization and Measurement in the social Sciences, Beverly Hills, Cal.: Sage Publications.

Blan, P. 1980. "Implication of Growth in Services for Social Structure," Social Science Quarterly, No. 1, pp. 3-22. 
Bogue, D.J. 1953. Population Growth in Standard Metropolitan Areas, 1900-1950. Washington, D.C.: U.S. Government Printing Office.

Bourne, L.S. 1974. "A Descriptive Typology of Urban Land Use Structure and Change," Land Economics, Vol. 50, No. 3; pp. $271-280$.

Boyce, D.E. and R.W. Cote. 1966. "Verification of Land Use Forecasting Models: Procedures and Data Requirements," Highway Research Record, No. 26, pp. 60-65.

Brand, D., B. Barber and M. Jacobs. 1967. "Technique for Relating Transportation Improvements and Urban Development Patterns," Highway Research Record, No. 207, pp. 53-56.

Breckenfeld, G. 1972. "'Downtown' has Fled to the Suburbs," Fortune, 80-87, pp. 156-162.

Brown, H.J. and H. Kirby. 1971. Empirical Models of Urban Land Use, New York: Columbia University Press.

Bruggink, T.H. 1979. "The Economic Performance of the Municipal Water Industry: Public Enterprise Versus Private Enterprise," Ph.D. Dissertation, Univerity of Illinois at Urbana-Champaign.

Burgess, E.W. (ed.) 1925. Urban Community, (University of Chicago Studies in Urban Sociology), Chicago: University of Chicago Press.

Burrows, L.B. 1978. Growth Management: Issues, Techniques and Policy Implications, New Brunswick, N.J.: RutgersThe State University of New Jersey.

Burton, I. 1959. "Retail Trade in a Dispersed City," Transactions of the Illinois State Academy of Science, Vol. 25, pp. $145-150$.

Burton, I. 1968. "A Restatement of the Dispersed City Hypothesis," Anals of the Association of American Geographers, Voi. 53, No. 3, pp. 285-289.

Chalmers, J.A. and M.A. Greenwood. 1980. "The Economics of the Rural to Urban Migration Turnaround," Social Science Quarterly, Nos. 3 and 4 .

Chapin, F.S. and E.J. Kaiser. 1979. Urban Land Use Planning, Chicago: University of Illinois Press. 
Chow, G.C. 1960. "Tests of Equality Between sets of Coefficients in Two Linear Regressions," Econometrica, Vol. 28 , No. 3, pp. 591-605.

Clark, C. 1951. "Urban Population Densities," Journal of the Royal Statistical Society, Series A, 114, 490-496.

Clark, C. 1967. Population Growth and Land Use, New York: st. Martin's Press.

Colby, C.C. 1933. "Centrifugal and Centripetal Forces in Urban Geography," Anals of the Association of American Geographers, Vol. $\overline{23}, \mathrm{pp} \cdot 1-20$.

Columbia Region Association of Governments. 1969. Land-Use Allocations to the Year 2000 for the Portland-Vancouver SMSA, Portland, Or.: CRAG.

Columbia Region Association of Governments. 1972. CRAG Overview: Data for the Planning Process, Portland, Or.: CRAG \& ODOT.

Corsi, T.M. 1974. "A Multivariate Analysis of Land Use Change: Ohio Turnpike Interchanges," Land Economics, Vol. 50 , No. 3, pp. 271-280.

Czamanski, S. 1963. "A Model of Urban Growth," Ph.D. Dissertation, University of Pennsylvania.

Diamond, D.B. 1980. "The Relationship Between Amenities and Urban Land Frices," Land Economics, Vol. 56, No. 1, pp. $21-32$.

Dolce, P.C. 1976. Suburbia, Garden City, N.Y.: Doubleday, Anchor Press.

Donnell, R.P. 1980. "Fire in the City: Spatial Perspectives on Urban Structural Fire Problems," Dh.D. Dissertation, Syracuse University.

Downing, P.B. 1977. "Suburban Nongrowth Policies," Journal of Economic Issues, Vol. XI, No. 2, pp. 387-400.

Downs, A. 1970. Urban Problems and Prospects, Chicago: Markham Pubishing Company.

Downs, A. 1973. Opening up the suburbs: An Urban strategy for America, New Haven: Yale University Press. 
Dueker, K.J., J.G. Strathman, I.P. Levin, and A.G. Phipps. 1983. "Rural Residential Development Within Metropolitan Areas," Computers, Environment, and Urban systems, Vol. 8, No. 2, pp. 12i-i29.

Durbin, J, and G.S. Watson. 1950. "Testing for serial correlation in Least Squares Regression. I," Biometrika, vol. 37, pp. 409-428.

Durbin, J. and G.S. Watson. 1951. "Testing for Serial Correlation in Least Squares Regression. II, "Biometrika, Vol. 38, pp. 159-178.

Dworkin, J.M. 1978. "Wastewater Management and Decision Making: The Role of the Community Acceptance in the Adoption of Land Treatment," Ph.D. Dissertation, Clark University.

Erber, E. 1970. Urban Planning in Transition, New York: Grossman Publishers.

Fagerlund, E.A. 1979. "The Urban settlement Pattern and the Cost of Providing Wastewater Disposal Service." Ph.D. Dissertation, University of Minnesota.

Famisa, 2.S. 1977. "The Conversion of Agricultural Land to Non-Agricultural Uses in the Phoenix-Tucson Corridor, 1940-1975," Ph.D. Dissertation, Arizona State University.

Fishman, B. 1977. "A Simple Robust Test of the Empirical Relevance of Local Public Services and Neighborhood Characteristics in the choice of Residential Location," Ph.D. Dissertation, University of California, Los Angeles.

Fujita, M. 1976. "Toward a Dynamic Theory of Urban Land Use," The Regional Science Association Papers, Vol. 37. $\mathrm{pp}$. 133-166.

Gleeson, M.E. 1979. "Effect of an Urban Growth Management System on Land Values," Land Economics, Vol. 55, No. 3, pp. 350-365.

Goldner, W. 1968. "Projective Land Use Model (PLUM): A Model for the Spatial Allocation of Activities and Land Uses in a Metropolitan Region," BATSC Technical Report 219, Berkeley, California: Bay Area Transportation Study Commission. 
Granger, C.W.J. 1969. "Spatial Data and Time-Series Analysis," in scott, A.J. (ed.), studies in Regional.Science, London: Pion, pp. 1-24.

Greenberg, M.R. 1969. "The Implications of Urbanization for Public Water Supply Systems in the New York Metropolitan Region," Ph.D. Dissertation, Columbia University.

Habig, W.C. 1972. "Application of a Land Use Allocation Model for Franklin County, Ohio," in Sweet, D.C. (ed.), Models of Urban Structure, Lexington, Massachusetts: D.C. Heath and Company.

Haggett, P. and R.J. Chorley. 1969. Network Analysis in Geography, London: Edward Arnold Publishers.

Haig, R.M. 1926. "Towards an Understanding of the Metropolis," Quarterly Journal of Economics, 40, pp. 197-208.

Hansman, J.M. 1976. "Urban Water Services Pricing: Public vs. Private Firms," Ph.D. Dissertation, George Washington University.

Harris, B. 1968. "Quantitative Models of Urban Development: Their Role in Metropolitan Policy Making," in Perloff, H.S. and L. Wingo (eds.), Issues in Urban Economics, Baltimore: The Johns Hopkins Press.

Harris, C. 1943. "Suburbs," American Journal of Sociology, Vol. 49 , pp. 1-3.

Harris, C.D. and E.L. Ullman. 1945. "The Nature of Cities," Anals of the American Academy of Politcal and Social Science, Vol. 242, pp. 7-17.

Hawley, A.H. 1950. Human Ecology, New York: The Ronald Press Company.

Hawley, A.H. 1956. The Changing Face of Metropolitan America, Glencoe, Ill.: The Free Press.

Hawley, 1971. Urban Society: An Ecological Approach, New York: Ronald Press.

Hawley, A.H. 1975. Man and Environment, New York: The New York Times Company.

Hawley A.H. and O.D. Duncan. 1957. "Social Area Analysis: A Critical Appraisal," Land Economics, 33, pp. 337-345.

Henkel, R.E. 1976. Tests of Significance, Beverly Hills, California: Sage Publications. 
Herbert, D.T. 1967. "Social Area Analysis: A British Study," Urban Studies, IV, I, pp. 41-60.

Herbert, D.T. and R. Johnston. (eds.) 1978. Social Areas in Cities: Process, Patterns, and Problems, New York: Wiley Press.

Hill, D.M. 1965. "A Growth Allocation Model for the Boston Region," Journal of the American Institute of Planners, 31, (2): 111-120.

Hoyt, H. 1939a. One Hundred years of Land Values in Chicago, New York: Arno Press.

Hoyt, H. 1939b. The Structure and Growth of Residential Neighborhoods in American Cities, Washington, D.C.: U.L.I. Press.

Hoyt, H. 1968. The Changing Principles of Land Economics, From Horse and Buggy to the Nuclear Age; Fifteen 20th Century Revolutions that have Changed Land Economics. Washington, D.C.: U.L.I. Press.

Hoyt, W.F. 1980. "Spatial Patterns of Development and the Land Conversion Process in the Urban Fringe," Ph.D. Dissertation, Ohio State University.

Hull, C.H. and N.H. Nie (eds.) 1981. SPSS Update 7-9: New Procedures and Facilities for Releases 7-9, New York: McGraw-Hill Book Company.

Hushak, L.J. 1975. "The Urban Demand for Urban-Rural Fringe Land," Land Economics, Vol. 51, No. 2, pp. 112-123.

Isard, W. 1956. Location and Space Economy, Cambridge, Massachusetts: M.I.T. Press.

Isard, W. and $Y$. Kanemoto. 1976. "Stages in Space-Time Development," The Regional Science Association Papers, Vol. 37 , pp. $99-132$.

James F.J., Jr. and J.W. Hughes. 1973. "The Process of Employment Location Change: An Empirical Analysis," Land Economics, Vol. 49, pp. 404-413.

Johnson, J.H. 1967. Urban Geography, Oxford, England: Pergamon Press.

Johnson, J.H. (ed.) 1974. Suburban Growth, London: John Wiley \& Sons. 
Johnson, M.S. and J.M. Lea. 1982. "Differential Capitalization of Local Public Service Characteristics," Land Economics, Vol. 58, No. 2, pp. 189-203.

Jud, G.D. 1980. "The Effects of zoning on Single-Family Residential Property Values: Charlotte, N.C.," Land Economics, Vol. 56, No. 2, pp. 143-154.

Kamara, S.G. 1980. "Public Transit and Student Choice: A Study with Portland State University Students," M.S. Thesis, Portland State University.

Kauffman, W.C. and S. Greer. 1960. "Voting in a Metropolitan Community," Social Forces, 38, pp. 196-204.

Keyes, D.L. 1976. Land Development and the Natural Environment: Estimating Impacts, Washington, D.C.: The Urban Institute.

Lamb, D.B. 1967. "Research of Existing Land Use Models," Report No. 1045, Pittsburgh: Southwest Pennsylvania Regional Planning Commission.

Land Conservation and Development Commission, Oregon, 1974. Statewide Planning Goals and Guidelines, Salem, OR.: LCDC.

Lathrop, G.T. and J.R. Hamburg. 1965. "An OpportunityAccessibilicy Model for Allocating Regional Growth," Journal of the American Institute of Planners, Vol. 31 , No. 2 .

Lee, L.K. 1977. "The Conversion of Agricultural Land to Urban Use: An Examination of the Land Use Process in Urbandale, Iowa, 1950-1974," Ph.D. Dissertation, Iowa State Univrsity.

Leven, C. 1968. "Towards a Theory of the City," Highway Research Board Special Report, No. 97, washington, D.C.: Highway Research Board, 102-115.

Leven, C.L. 1978. "Growth and Nongrowth in Metropolitan Areas and the Emergence of Polycentric Metropolitan Form" The Regional Science Association Papers, Vol. 41. pp. 75-100.

Lewis-Beck, M.S. 1980. Apclied Regression: An Introduction, Beverly Hills California: Sage Publications.

Long, L. and D. DeAre. 1983. "The Slowing of Urbanization in the U.S.," Scientific American, Vol. 249, No. 1, pp. 33-41. 
Lowry, I.S. 1964. Model of Metropolis, Santa Monica, California: Rand Corporation.

Lowry, I.S. 1965. "A Short Course in Model Design," Journal of the American Institute of Planners, Vol. 31 , No. 2 , pp. 158-166.

Lowry, I.S. 1968. "Seven Models of Urban Development: A Structural Comparison," in Hemmens, G.C. (ed.) Urban Development Models, Washington, D.C.: Highway Research Board.

Lycan, R. and J. Weiss. 1979. "Age Cohort Projections of Populations for Metropolitan Area Census Tracts," in Golant, S.M. (ed.) Location and Environment of Elderly Population, New York: John Wiley and Sons.

Lycan, R., P. Pendleton and J. Weiss. 1978. Residential Mobility study for Portland, oregon, Portland, OR: Portland state University.

Lynch, K. 1961. "The Pattern of the Metropolis," in Rodwin, L. (ed.), The Future Metropolis, New York: George Braziller, Inc.

Lynch, K. 1964. A Theory of Good Form, Cambridge, Massachusetts: The M.I.T. Press

Malarkey, D.P.D. 1978. "Process of Land Conversion: An Example of Wilsonville, Oregon," Ph.D. Dissertation, University of Oregon.

Mayer, H.M. 1969. The Spatial Expression of Urban Growth, Washington, D.C.: AAG Commision on College Georgraphy, Resource Paper No. 7.

Metropolitan Service District. 1971-1980. Building Permit Statistics by Census Tract, 1970-1980 Series, Portland, OR.: METRO.

Metropolitan Service District. 1979. Urban Growth Boundary Findings, Portland, OR.: METRO.

Milgram, G. 1967. The City Expands, A Study of: The Conversion of Land From Rural to Urban Use, Philadelphia, 1945-1962, Philadelphia: University of Pennsylvania Press.

Mills, E.S. 1967. "An Aggregative Model of Resource Allocation in a Metropolitan Area," American Economic Review Papers, 57, pp. 197-210. 
Miron, J.R. 1974. "Economic Bases in the Theory of City Growth," Ph.D. Dissertation, Univrsity of Toronto.

Mohan, R. 1979. Urban Economic and Planning Models, Baltimore, MD.: John Hopkins University.

Morrill, R.L. 1965. "Expansion of the Urban Fringe: A Simulation Experiment," Papers of the Regional Science Association, Vol. 15, pp. 185-199.

Morris, J.H. 1969. "'Meet Me at the Mall' - Big Shopping Centers are Becoming the Focus of Life in the Suburbs," Wall Street Journal, Feb. 20, Vol. 1, No. 9.

Moses, L. and H. Williamson, Jr. 1967. "The Location of Economic Activity in Cities," American Economic Review, 57, $\mathrm{pp} .211-222$.

Muller, P. 1976. The Outer City, Washington, D.C.: AAG Commission on College Geography.

Muller, T. 1975. Fiscal Impacts of Land Development: A Critique of Methods and Review of Issues, Washington, D.C.: The Urban Institute.

Muller, T. and G. Dawson. 1972. The Fiscal Impact of Residential and Commercial Development: A Case Study, Washington, D.C.: The Urban Institute.

Muller, T., K. Neels, J. Tilney and G. Dawson. 1978. The Impact of Beltways on Central Business Districts: A Case Study of Richmond, washington, D.C.: The Urban Institute.

Murdie, R.A. 1969. Factorial Ecology of Metroplitan Toronto, 1951-1961, Chicago, Ill.: The University of Chicago Press.

Muth, R.F. 1961a. "Economic Change and Rural-Urban Land Conversion," Econometrica, Vol. 29, pp. 1-23.

Muth, R.F. 1961b. "The Spatial Structure of the Housing Market," Papers and Proceedings of the Regional Science Association, 7, pp. 207-220.

Muth, R.F. 1969. Cities and Housing: The Spatial Pattern of Urban Residential Housing, Chicago, Il.: The University of Chicago Press.

Neiman, M. 1980. "Zoning Policy, Income Clustering, and Suburban Change," Social Science Quarterly, Nos. 3 \& 4, pp. 666-675. 
Nelson, K.P. 1980. "Recent Suburbanization of Blacks," American Planning Association Journal, Vol. $46, p$. 287-300.

Neutze, M. 1969. The Suburban Apartment Boom, Baltimore, MD. : Johns Hopkins University.

Nie, N.H., C.H. Hull, J.G. Jenkins, K. Steinbrenner, and D.H. Bent. 1975. Statistical Package for the Social Sciences, New York: McGraw-Hill Book Company.

Oates, W.E. 1969. "The Effects of Property Taxes and Local Public Spending on Property Values: An Empirical Study of Tax Capitalization and the Tiebout Hypothesis," Journal of Political Economy, Vol. 77, No. 6, pp. 957-971.

Oi, W.Y. and P.W. Shuldiner. 1962. An Analysis of Urban Travel Demands, Evaston: Northwestern University Press.

Orleans, P. 1966. "Robert Park and Social Area Analysis: A Convergence of Traditions in Urban Sociology," Urban Affairs Quarterly, I, No. 4, pp. 5-19.

Ottensman, J.R. 1974. "The Changing Spatial Structure of an American City: Milwaukie, 1920-1970," Ph.D. Dissertation, University of North Carolina.

Ottensman, J.R. 1977. "Urban Sprawl, Land Values, and the Density of Development," Land Economics, V1. 53, No. 4, pp. 389-400.

Papageorgiou, G.J. 1976. Mathematical Land Use Models, Lexington, MA: Heath and Company

Park, R., E.W. Burgess and R.D. Mckenzie. (eds.) 1925. The City, Chicago, Il.: The University Press.

Philbrick, A.K. 1961. "Analysis of the Geographical Patterns of Gross Land Uses and Changes in Number of Structures in Relation to Major Highways in the Lower Half of the Lower Peninsular of Michigan," Ph.D. Dissertation, Michigan State University.

Pindyck, R.S. and D.L. Rubinfeld. 1981. Econometric Models and Economic Forecasts, New York: McGraw-Hill Book Company.

Polk, K. 1957. "Juvenile Delinquency and Social Areas," Social Problems, Vol. 5, pp. 214-217. 
Polk, K. 1967. "Urban Social Areas and Delinquency," Social Problems, Vol. 8, pp. 320-325.

Reed, E.A.F. 1982. "Exclusionary Zoning and the Urban Ecology in Springfield, Massachusetts," Ph.D. Dissertation, University of Massachusetts.

Richardson, H.W. 1977. The New Urban Economics, London: Pion Ltd.

Robertson, K.A. 1981. "The Redevelopment of the American Central Business District: An Examination of the State of Knowledge, Policy Dilemmas, and Recent Retail Trends," Ph.D. Dissetration, University of Delaware.

Said, G.M. and B.G. Hutchinson. 1981. "Policy-oriented Urban-Systems Model: Structure and Application," Transportation Research Record, No. 848 , pp. 1-7.

Schaenman, P.S. 1976. Using an Impact Measurement System to Evaluate Land Development, Washington, D.C.: The Urban Institute.

Schaenman, P.S. and T. Muller. 1974. Measuring Impacts of Land Development: An Initial Approach, Washington, D.C.: The Urban Institute.

Schmenner, R. 1975. City Taxes and Industry Location, New Haven: Yale University Press (Mimeograph).

Schneider, M. 1968. "Access and Land Development," Highway Research Board Special Report, No. 97, Washington, D.C.: Highway Research Board, 164-177.

Schneider, M. 1969. Transportation and Lane Development, Washington, D.C.: Creighton, Hamburg, Inc.

Schnore, L.F. 1973. "Social Classes in Cities and Suburbs," in Hawley, A.H. and Rock, V.P. (eds.) 1973. Segregation in Residential Areas, Washington, D.C.: National Academy of Sciences.

Schnore, L.F. and V.Z. Klaff. 1972. "Suburbanization in the Sixties: A Preliminary Analysis," Land Economics, Vol. 48, No. 1, pp. 23-33.

Shaw, C.R., F. Zorbaugh, H.D. McKay, and L.S. Cottrell. 1929. Delinquency Areas, Chicago: University of Chicago press. 
Shevky, E. and M. Williams. 1949. The Social Areas of Los Angeles: Analysis and Typology, Berkeley: University of California Press.

Shevky, E. and W. Bell. 1955. Social Area Analysis: Theory, Illustrative Application and Computational Procedures, tanford: Stanford University Press.

Sly, D.F. and J. Tayman. 1980. "Changing Metropolitan Morphology and Municipal Service Expenditures in Cities and Rings," Social Science Quarterly, Nos. 3 \& 4 , pp. 595-611.

Stafford, H.A., Jr. 1962. "The Dispersed City," The Professional Geographer, Vol. XIV, No. 4, pp. 8-10.

Stanback, T.M., Jr. and R. Knight. 1976. Suburbanization and the City, New York: Allanheld, Osmun \& Co. Publishers.

Sternlieb, G. 1971. "The City as a Sandbox," Public Interest, Vol. 25, pp. 14-21.

Sternlieb, G. and J.W. Rughes. 1975. Post-Industrial AmeriCa: Metropolitan Decline and Interregional Job Shifts, New Brunswick, N.J.: Rutgers-The State University of New Jersey.

Sternlieb, G., R. Burchell and L. Sagalyn. 1971. The Affluent Suburb: Housing Needs and Attitudes, New Brunswick, N.J.: Transaction Books.

Sweet, D. 1972. Models of Urban Structure, Lexington, Massachusetts: D.C. Heath and Company.

Tiebout, C.M. 1956. "A Pure Theory of Local Expenditures," Journal of Political Economy, 64, 416-424.

Tiebout, C.M. 1958. "Hawley and Duncan on Social Area Analysis: A Comment," Land Economics, 34, pp. 182-184.

Toulan, N.A. 1965. "Public and Private Costs of Open Space Preservation," Ph.D. Dissertation, University of Pennsylvania.

Toyoda, T. 1974. "Use of the Chow Test Under Heteroskedasticity," Econometrica, Vol. 42, 3, pp. 601-608.

U.S. Bureau of the Census. 1971. U.S. Census of Population: 1970, Number of Inhabitants, Final Report, [PC (1) Al, United States Summary], Washington, D.C.: USGPO. 
U.S. Bureau of the Census. 1981. U.S. Census of Population: Supplementary Report, [PC $(\overline{80})-$ SI - 5], Washington, D.C.: USGPO.

U.S. Department of Transportation. 1980. The Land Use and Urban Development Impacts of Beltways, Washington, D.C.: USGPO.

U.S. Government. 1969. "Population Trends: Hearings Before the Ad Hoc Subcommittee on Banking and Currency, House of Representatives, Ninety-First Congress, Part 1," Washington, D.C.: USGPO.

U.S. Soil Conservation Service. 1972. Soil Survey of Clark County, Washington, Washington, D.C.: U.S. Department of Agriculture.

U.S. Soil Conservation Service. 1982. Soil Survey of Washington County, Oregon, Washington, D.C.: U.S. Department of Agriculture.

U.S. Soil Conservation Service In Print. Soil survey of Clackamas County, Oregon, Washington, D.C.: U.S. Department of Agriculture.

U.S. Soil Conservation Service In Print. Soil Survey of Multnomah County, Oregon, Washington, D.C.: U.S. Department of Agriculture.

Udry, J.R. 1964. "Increasing scale and Social Differentiation: New Tests of Two Theories from Shevky and Bell," Social Forces, 42 , pp. 403-417.

Van Arsdol, M.D., Jr., S.F. Camilleri and C.F. Schmid, G.F. 1958. "The Generality of Urban Social Area Indexes," American Sociological Review, Vol. 23, No. 3

Varadhan, S.R.S. and N. Rubin. 1973. Mathematical Statistics, New York University: Courant Institute of Mathematical sciences.

von Boventer, E. 1976. "Transportation Costs, Accessibility and Agglomeration Economies: Centers, Subcenters, and Metropolitan Structures," Regional Science Association Papers, Vol. 41, pp. 75-100.

von Thunen, J.H. 1966. Der Isolierte staat in Beziehung auf Nationalokonomie und Landwirtschaft, stuttgart: Gustav Fisher Publication (Reprint of 1826 ). 
Voorhees, A.M. and Associates, Inc. 1974. "Simulation City Approach for Freparation of Urban Area Data Bases," Final Report, EPA/600/5-74-001, McLean, Virginia: Andrew C. Lemer.

Weyland, J.H. 1977. "Travel Behaviior and Transportation Association with Planned Unit Development: A Study of Recent Suburban Development in New Jersey," Ph.D. Dissertation, Rutgers-The State University of New Jersey.

Wheaton, W.C. (ed.) 1979. Interregional Movernents and Regional Growth, (Coupe Papers on Public Economics), Washington, D.C.: The Urban Institute.

Wingo, L. 1961. "An Economic Model of the Utilization of Land for Residential Purposes," Papers and Proceedings of the Regional Science Association, 7, pp. 191-205. 
APPENDIX

CENSUS TRACTS IN STUDY AREA

\begin{tabular}{|c|c|c|c|c|c|c|}
\hline County & 1970 & 1980 & 1970 & 1980 & 1970 & 1980 \\
\hline \multirow[t]{13}{*}{ Mult. } & 43.00 & 43.00 & 84.00 & 84.00 & 97.02 & 97.02 \\
\hline & 70.00 & 70.00 & 85.00 & 85.00 & 98.01 & 98.01 \\
\hline & 71.00 & 71.00 & 89.00 & 89.00 & 98.02 & 98.02 \\
\hline & 77.00 & 77.00 & 90.00 & 90.00 & 99.00 & 99.00 \\
\hline & 78.00 & 78.00 & 91.00 & 91.00 & 100.00 & 100.00 \\
\hline & 79.00 & 79.00 & 92.01 & 92.01 & 101.00 & 101.00 \\
\hline & 80.01 & 80.01 & 92.02 & 92.02 & 102.00 & 102.00 \\
\hline & 80.02 & 80.02 & 93.00 & 93.00 & 103.00 & 103.00 \\
\hline & 81.00 & 81.00 & 94.00 & 94.00 & 104.01 & 104.03 \\
\hline & 82.01 & 82.01 & 95.00 & 95.00 & & 104.04 \\
\hline & 82.02 & 82.02 & 96.01 & 96.01 & 104.02 & 104.02 \\
\hline & 83.00 & 83.01 & 96.02 & 96.02 & & \\
\hline & & 83.02 & 97.01 & 97.01 & & \\
\hline
\end{tabular}


APPENDIX (CONTINUED)

\begin{tabular}{|c|c|c|c|c|c|c|}
\hline county & 1970 & 1980 & 1970 & 1980 & 1970 & 1980 \\
\hline \multirow[t]{7}{*}{ Clack. } & 204.00 & 204.01 & 222.00 & 221.01 & 229.00 & 29.00 \\
\hline & & 204.02 & & 222.02 & 230.00 & 230.00 \\
\hline & 205.00 & 205.01 & 223.00 & 223.00 & 231.00 & 231.00 \\
\hline & & 205.02 & 226.00 & 226.00 & 232.00 & 232.00 \\
\hline & 207.00 & 207.00 & 227.00 & 227.01 & 233.00 & 233.00 \\
\hline & 221.00 & 221.01 & & 227.02 & & \\
\hline & & 221.02 & 228.00 & 228.00 & & \\
\hline \multirow[t]{9}{*}{ Wash. } & 308.00 & 308.00 & 319.00 & 319.01 & 325.00 & 325.00 \\
\hline & 315.00 & 315.01 & & 319.02 & 326.00 & 326.00 \\
\hline & & 315.02 & 320.00 & 320.00 & 327.00 & 327.00 \\
\hline & & 315.03 & 321.00 & 321.01 & 328.00 & 328.00 \\
\hline & 316.00 & 316.01 & & 321.02 & 329.00 & 329.00 \\
\hline & & 316.02 & 322.00 & 322.00 & 330.00 & 330.00 \\
\hline & 317.00 & 317.01 & 323.00 & 323.00 & 331.00 & 331.00 \\
\hline & & 317.02 & 324.00 & 324.01 & 332.00 & 332.00 \\
\hline & 318.00 & 318.00 & & 324.02 & 333.00 & 333.00 \\
\hline
\end{tabular}


APPENDIX (CONTINUED)

\begin{tabular}{lcccccc}
\hline County & 1970 & 1980 & 1970 & 1980 & 1970 & 1980 \\
\hline \multirow{2}{*}{ Clark } & 405.02 & 405.02 & 410.01 & 410.03 & 413.00 & 413.01 \\
& 405.03 & 405.03 & & 410.04 & & 413.02 \\
& 406.00 & 406.00 & & 410.05 & & 413.03 \\
407.00 & 407.01 & 410.02 & 410.02 & 414.00 & 414.00 \\
& & 407.02 & 411.01 & 411.01 & 415.00 & 415.00 \\
& 408.00 & 408.01 & 411.02 & 411.03 & & \\
& 408.02 & & 411.04 & & \\
409.00 & 409.01 & 412.00 & 412.01 & & \\
& 409.02 & & 412.02 & &
\end{tabular}

